\title{
CORE-TEMPERATURE EXCURSIONS FOLLOWING A PIPING FAILURE IN THE PLUTONIUM RECYCLE TEST REACTOR
}

by

Alexis W. Lemmon, Jr. Car1 A. Alexander

Lewis E. Hulbert

Robert B. Filbert, $J$ r.

July 6,1959

Columbus 1, Ohio 


\section{DISCLAIMER}

This report was prepared as an account of work sponsored by an agency of the United States Government. Neither the United States Government nor any agency Thereof, nor any of their employees, makes any warranty, express or implied, or assumes any legal liability or responsibility for the accuracy, completeness, or usefulness of any information, apparatus, product, or process disclosed, or represents that its use would not infringe privately owned rights. Reference herein to any specific commercial product, process, or service by trade name, trademark, manufacturer, or otherwise does not necessarily constitute or imply its endorsement, recommendation, or favoring by the United States Government or any agency thereof. The views and opinions of authors expressed herein do not necessarily state or reflect those of the United States Government or any agency thereof. 


\section{DISCLAIMER}

Portions of this document may be illegible in electronic image products. Images are produced from the best available original document. 
ABSTRACT ........................... 1

INTRODUCTION ........................... 1

Reactor Configuration....................... 1

Fuel Elements ......................... 3

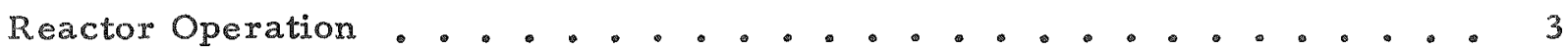

Postulated Incidents .......................... 4

METHOD OF CALCULATION .....................4 4

INPUT DATA .......................... 5

Decay Heat . . . . . . . . . . . . . . . . . 5

Flow Rates ...................... 6

Heat Transfer Coefficients . . . . . . . . . . . . . . . 8

Initial Temperatures ....................... 9

Chemical Reaction ....................... 12

CASES COMPUTED .......................... 12

Cases Studied ........................ 13

Case I............................... 13

Case II . . . . . . . . . . . . . . . . . . . 27

Case III . . . . . . . . . . . . . . . . . . . 28

Case IV .............................. 34

CONCLUSIONS AND RECOMMENDATIONS ................ 37

REFERENCES . . . . . . . . . . . . . . . . . . 38

APPENDIX A

PHYSICAL AND THERMODYNAMIC PROPERTIES OF REACTOR MATERIAIS . A-1

APPENDIX B

MATHEMATICAL MODEL AND METHODS OF MACHINE COMPUTATION . . . B-1

APPENDIX C

THE FORTRAN PROGRAM ........................ C-1

APPENDIX D

RADIATION HEAT TRANSFER EFFECTS. ................. D-I 


\title{
CORE-TEMPERATURE EXCURSIONS FOLLOWING A PIPING FAILURE IN THE PLUTONIUM RECYCLE TEST REACTOR.
}

\author{
A. W. Lemmon, Jr., C. A. Alexander, L. E. Hulbert, \\ and $R$. B. Filbert, $J x$.
}

An evaluation of the temperature excursion and its possible consequences arising from loss of coolant from the Plutonium Recycle Test Reactor (PRTR) has been made for four different postulated ruptures in the primary heavy water coolant system. As a basis for the evaluation, a series of computations was made. These were based on incremental heat and mass balances for sections of Zircaloy-clad $\mathrm{UO}_{2}$ and plutonium-aluminum fuel elements. Solutions to each problem defined by the postulated break size and its location were obtained by finite-difference approximations performed by an IBMI 653 machine digital computer.

The four postulated rupiures were: (1) a complete parting of the 14-in.diameter outlet pipe near the upper ring header so that coolant would be lost from both broken ends; (2) a rupture equivalent to a 14-in.-diameter hole in the primaryloop piping adjacent to the upper ring header; (3) a complete parting of a 1-3/4-in. upper jumper; and ( 4 ) a complete parting of a 1-3/4-in. bottom jumper. The plutonium-aluminum elements represent the most critical component; melting of these elements would begin about 219 seconds after the rupture occurred if emergency backup light water coolant were not available to the system. It was found that the injection of $750 \mathrm{gallons}$ per minute (gpm) of emergency coolant ( $375 \mathrm{gpm}$ to each ring header) would be adequate to prevent melting or failure of any reactor component for all cases studied even if injection did not begin until 2 or 3 min after the rupture occurred An earlier injection time would, of course, be beneficial.

\section{INTRODUCTION}

During the design and construction and prior to the operation of a nuclear reactor, questions are always raised regarding the safety of the planned operation and the possibility of the release of radioactive materials to the surroundings. In the present case of the Plutonium Recycle Test Reactor (PRTR), a pressurized water reactor, the usual question concerning the dangers possible if a rupture occurs in the primary coolant system has been asked. This study was undertaken in an attempt to evaluate the possible consequences of such an occurrence.

\section{Reactor Configuration}

The PRTR is a heavy water-moderated and -cooled heterogeneous test reactor with a thermal power rating of 70 megawatts. A pictorial representation of the reactor is shown in Figure 1 .

The reactor core consists of 85 Zircaloy -2 process tubes which contain the fuel elements and through which the pressurized primary heavy water coolant passes. These 


\section{DRT REACTOR GORE F SHELOING}

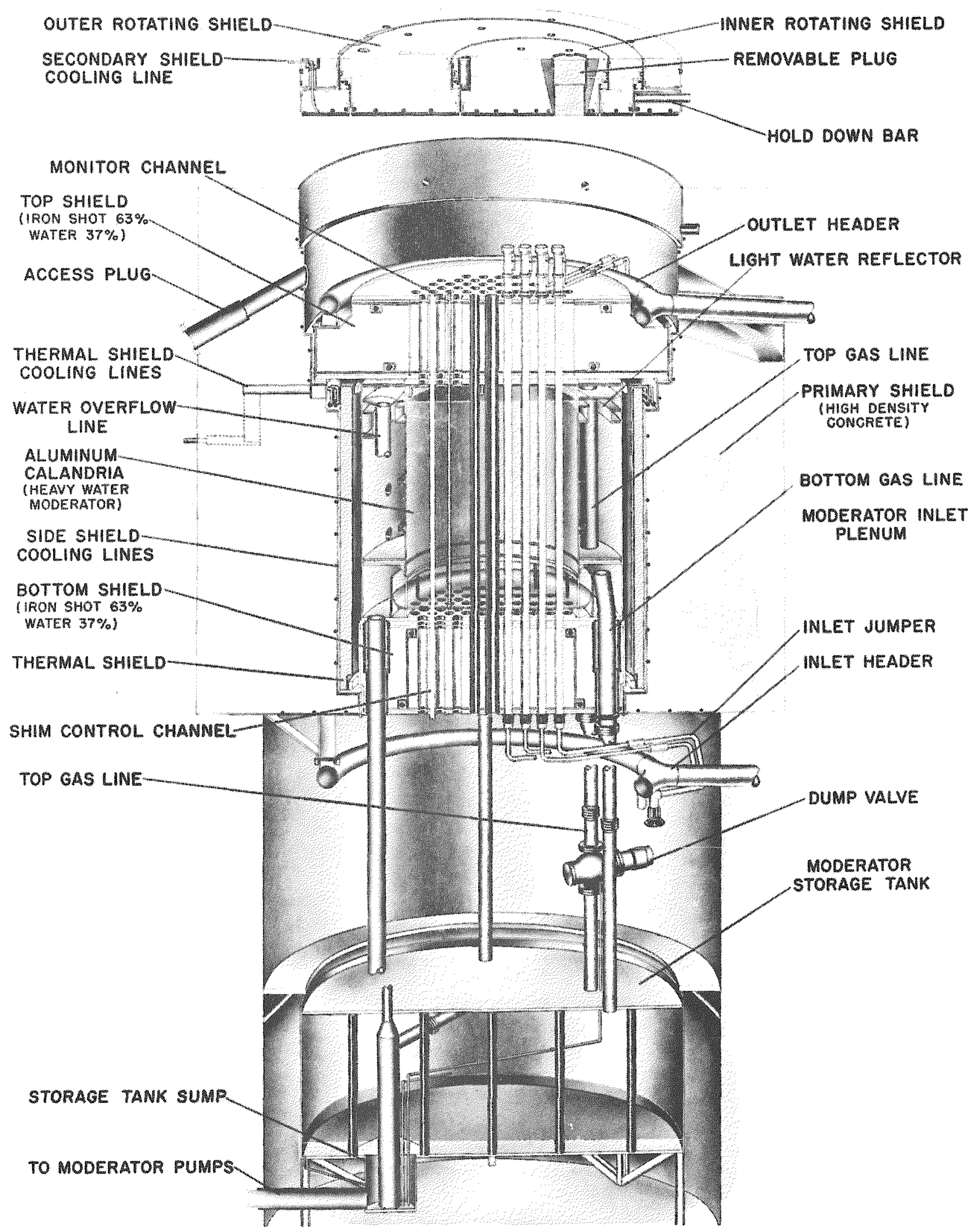

FIGURE 1. REACTOR CONEIGURATION 
85 process tubes are individually connected to ring headers both at the top and bottom of the reactors. Surrounding each process tube is an aluminum shroud tube. The annular space between the shroud tube and the process tube is filled with helium.

The shroud tubes are an integral part of the calandria which is a large aluminum vessel enclosing the 85 tubes. The calandria contains the heavy water moderator. The reactor is controlled by adjusting the level of the heavy water in the calandria. By dumping the heavy water moderator in the calandria into a dump chamber below the reactor, scram is effected. A complete description of the reactor and the containment building, plus engineering data has been provided by Wittenbrock(1).

\section{Fuel Elements}

Fuel elements for the initial loading in the PRTR are to be composed of plutoniumaluminum alloy $(\mathrm{Pu}-\mathrm{Al})$ in some of the process tubes and sintered uranium dioxide in the majority of the process tubes. All the fuel elements will be clad with Zircaloy-2. Two different configurations are planned for the $\mathrm{UO}_{2}$ elements. The Mark I element consists of 19 rods of about 0.56 -in. clad diameter in a cluster. Around a center rod a re 6 rods which form the 6-rod ring, and to the outside of the 6-rod ring are 12 rods which form the 12 -rod ring.

The Mark II fuel element consists of a center clad rod about which a concentric ring of clad $\mathrm{UO}_{2}$ is placed. An additional clad concentric ring is placed around the outside of the first concentric ring. The annular spaces between the rod and the first ring, between the two rings, and between the outex ring and the process tube form the void space for the primary coolant flow. All the Pu-Al elements will be of the Mark I configuration.

\section{Reactor Operation}

During normal operation the pressurized heavy water primary coolant will be pumped into the bottom ring header, flow up through the 85 fuel-containing process tubes, and into the top ring header. From the top ring header the coolant will flow to a heat exchanger where the heat is removed by vaporizing light water at 425 psi. From the heat exchanger the coolant will enter the pressurizer and subsequently return to the pumps.

The maximum thermal power rating of any of the process tubes is 1.2 megawatts, and each process tube is orificed so that the amount of coolant entering is proportional to the power being generated in the tube.

(1) References at end of text. 
Postulated Incidents

For the purpose of this analysis it was postulated that a rupture had occurred somewhere in the primary coolant system. By use of an IBM 653 Digital Computer, conditions within the core were simulated from the calculated flow rates, power generation rates, and physical and thermal properties of the core components.

The ruptures postulated in this analysis were selected on the basis of presenting the most severe test of the reactor concept possible to determine if the reactor system, including the emergency back-up coolant system, would be adequate in even such cases. No consideration of "most probable" leaks was intended in this analysis.

\section{METHOD OF CALCULATION}

The method of approach in using the digital computer to simulate conditions within the reactor after a postulated rupture had occurred was to select a single fuel element within a process tube and determine its temperatures at all times after the incident was presumed to happen. Other information computed beside the element temperatures was coolant temperature, coolant mass flow rate, mole fraction hydrogen in the flow stream, and cumulative hydrogen generation. (The hydrogen might be produced from the reaction of coolant with the Zircaloy-2 cladding used throughout the reactor to clad the fuel elements.)

Specifically, for purposes of calculation, a single fuel element was divided longitudinally into 29 segments and a material balance and heat balance performed on each segment of the element as well as the coolant associated with that segment at a fixed time. After the calculation was completed stepwise, from one end of the element to the other, the computation was repeated at a new time increment. Details of the mathematical relationships and their derivations and simplifications are given in Appendix $B$. The IBM 653 FORTRAN program is described in Appendix C.

The data needed for the computation of the heat balance of the element can be determined by the way in which the temperature of a segment might change. The temperature of the segment can change by the rmal conduction along the element, hence the temperature of the adjoining segments at the last computed time increment must be known, as well as the thermal conductivity of the element as a function of temperature.

Heat can be transferred between the element and the coolant by convective heat transfer. The factors affecting heat transfer to the coolant are coolant velocity and temperature and the thermal properties of the coolant such as viscosity, thermal conductivity, density and specific heat. Of course, the state (liquid or vapor) of the coolant is a factor in determining the rate of convective heat transfer.

Heat transferred by radiation from the elements of a process tube to each other or to the Zircaloy -2 process tube wall may also be important at higher temperatures. This contribution has been considered in Appendix $D$. 
Since the temperature would increase through the decay heat generation within the segment, the generation rate as well as the specific heat of the element material are necessary to complete this information.

The element temperature may also rise through the reaction of the coolant with the cladding material. This reaction,

$$
2 \mathrm{H}_{2} \mathrm{O}+\mathrm{Zr} \rightarrow \mathrm{ZrO}_{2}+2 \mathrm{H}_{2}
$$

results in the formation of 2 moles of hydrogen from 2 moles of water and liberates considerable heat.

\section{INPUT DATA}

In order to perform the machine computation it was necessary to prepare input information in a form that could be used by the machine. This required relating the physical properties of the reactor materials, such as specific heat, thermal conductivity, density, reaction rate, and decay heat generation, to the reactor geometry. In addition to the properties above, other derived quantities and initial conditions were required. These were heat transfer coefficients, inlet water temperatures, initial fuel element temperatures, and flow rates of coolant associated with a particular fuel element.

The physical properties of the reactor materials are given in Appendix A.

\section{Decay Heat}

The decay heat generation rate at any point would be a function of time alone and was an initial condition for each incremental machine computation. Within the reactor the decay heat generation would be a function of position since the flux varies both. axially and radially. All of the computations made in this investigation were for a $1200-\mathrm{kw}$ process tube, which represents the maximum power generation tube within the reactor. The longitudinal power generation within the core was represented by a chopped cosine distribution(2),

$$
P(h)=P_{0} \cos 0.0111 \mathrm{~h},
$$

where $h$ is the distance from the center to the end of the fuel element in centimeters, and $P_{0}$ is the power at the center of the tube. For a 6-rod element in a 1.2-megawatt cluster, $P_{0}=339.8 \mathrm{w}$ per $\mathrm{cm}$. A 12 -rod element has a $P_{0}$ that is 1.1559 times that of a 6-rod element.

During the course of this investigation a more complete analysis of the longitudinal power distribution was performed at Hanford(3) with a resulting curve that was slightly skewed from the cosine distribution. This skewed curve gave a peak power to average power ratio of about 1.2 as compared with 1.3 for the cosine distribution. Thus the skewed curve resulted in a more uniform power distribution than the earlier 
cosine function, although the difference would be rather small. However, the cosine distribution was used throughout this investigation for purposes of consistency and since it gave slightly higher peak temperatures. This would also tend to offset the possibility of being nonconservative as a result of the uncertainties in the decay heat generation rate after scram.

To determine the decay heat generation of a fuel element at a particular point along the element and at a specified time after scram required first determining the power generation of a particular fuel element. This was done, whether for a 6-rod or 12-rod or a concentric ring element, by normalizing with respect to the distribution so that the total power generation of the element corresponds to its true contribution to the total $1200-\mathrm{kw}$ tube. This gave the vertical distribution at normal operating power, from which a value of a particular increment of length could be selected. This value multi plied by the relative power, $\mathrm{P} / \mathrm{P}_{\mathrm{O}}$, given in Figure 2 , gave the decay heat generation at any specified time. The Untermyer and Weills total-power-generated curve for infinite previous operation was used.

Elow Rates

The derived input data for flow rates through the reactor were determined from the reactor geometry, normal operating conditions, blowdown flow predictions made by Ambrose(4), and estimates of safety injection water flow rates. Flow rate through the reactor during normal operation will be about $1200 \mathrm{lb}$ per sec. During blowdown, rates might be as high as $5500 \mathrm{lb}$ per sec for a large hole at the time of the incident and as low as $50 \mathrm{lb}$ per sec for small breaks. After blowdown and before injection of safety water, there would be essentially no flow. After injection could be begun approximately $50 \mathrm{lb}$ per sec would flow through the 85 process tubes, the amount depending somewhat on location and size of break. Specific flow rates for each case considered are dis cussed with each case.

In the case of the concentric ring element, calculation of flow distribution past individual elements was straightforwaxd since the flow areas had been adjusted during the fuel element design procedure to give flow rates in each flow passage proportional to the heat release for that passage (and proportional to the flow areas).

For the 19-rod cluster element, determination of flow rates was not as clear cut. The 19-rod cluster element consists of a center rod which is surrounded by six rods which are individually wrapped with a Zircaloy wire. In the resultant cluster, each rod has six nearest neighbors and the spacing between centers of the rods is equal to the diameter of the rod plus the diameter of the wire. Considering the equilateral triangle formed by the lines joining the centers of three adjacent rods the void area between interior rods was calculated. This was the area available to coolant flow through the interior spaces of the tubes. From the over-all dimensions of the process tube, the void area available for flow between the wall of the process tube and exterior to the 12rod elements was determined. The relative mass flow through each area was determined by equating the pressure drops through an interior passage to that for an exterior passage. Pressure drops were calculated from a standaxd friction factor correlation and included consideration of entrance and exit losses.

Table 1 gives the results of this calculation. The flow distribution shown was assumed constant independent of variations in total flow rate through the reactor. 


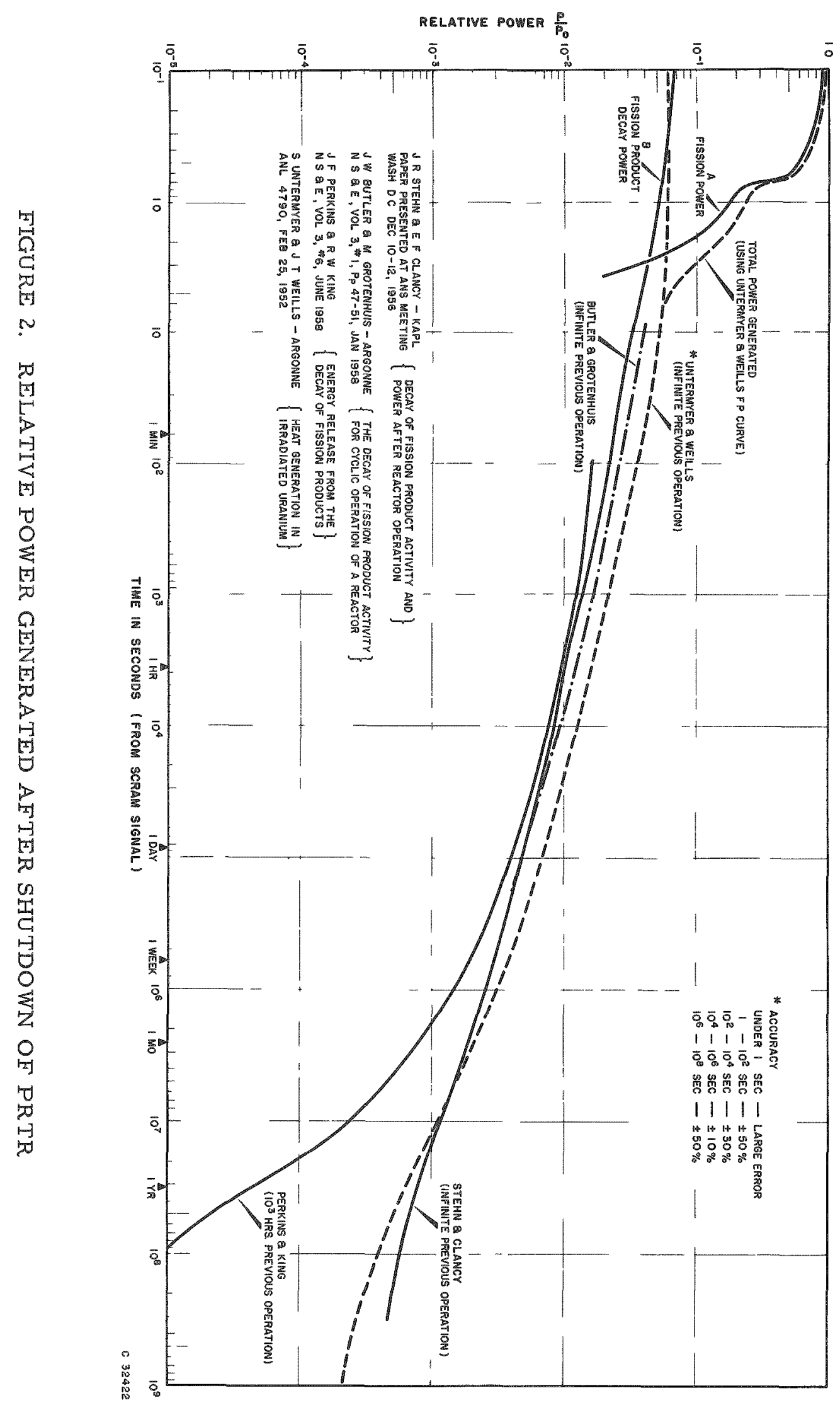


TABLE 1. FLOW DISTRIBUTION WITHIN REACTOR FOR A 19-ELEMENT CLUSTER

\begin{tabular}{lc}
\hline & $\begin{array}{c}\text { Per Cent of } \\
\text { Total Flow }\end{array}$ \\
\cline { 2 - 2 } Through a 1.2-Megawatt Process Tube & 1.515 \\
Through an Interior Channel & 0.0167 \\
Between Process Tube Wall and 12-Element Ring & $12 \times 0.0929$ \\
Associated With Interior Element & 0.0334 \\
Associated With 12-Rod Element & 0.1096 \\
\hline
\end{tabular}

Heat Transfer Coefficients

Knowing the flow rates past an element, obtained in the manner just described, forced-convection heat transfer coefficients could be evaluated for the periods when forced convection would be the heat transfer mode. The convective heat transfer coefficients were computed from Colburn's correlation(5). For a more pessimistic value, the heat transfer coefficients were reduced 30 per cent for uncertainty in correlation and spread of data. Since the flow channels were noncircular the channel equivalent diameter was increased arbitrarily by 20 per cent as suggested by McAdams(5) to compensate. This resulted in another factor of 0.7 so that the heat transfer coefficient was reduced to $0.5(0.7 \times 0.7)$ of that recommended to be conservative. Heat transfer coefficients calculated for circulating water either during blowdown or during pump operations were of the order of $1000 \mathrm{Btu} /(\mathrm{hr})\left(\mathrm{ft}^{2}\right)(\mathrm{F})$ after adjusting for these possible effects of noncircular channels and correlational deficiencies.

For steam flow, rather than liquid or mixed-phase flow, the computer had been programed to calculate the heat transfer coefficients. Equations representing the physical and thermal properties of the vapor were written in the program. Details of the equations and the operation by which the computer determines whether liquid or gaseous coolant is present are given in Appendix $B$.

During some periods after a postulated rupture, it was found that there would be es sentially no flow in the reactor but that liquid water would be covering all ox part of the axial length of the fuel element. This situation would exist primarily during the later stages of blowdown for the smaller ruptures and during some parts of the injection phase. Considering that these conditions corresponded to the mode of heat transfer classified as film boiling in a confined space, a value for the heat transfer coefficient was computed using the Bonilla correlation(6), as $22 \mathrm{Btu} /(\mathrm{hr})\left(\mathrm{ft}^{2}\right)(\mathrm{F})$. Although the available correlations indicated that this heat transfer coefficient is a function of the temperature difference, so much uncertainty exists as to the probable actual conditions within the reactor for these postulated situations that this conservative value was assumed constant for all cases where film boiling in a confined space was believed to exist. 
Initial Temperatures

Information available on the steady-state operating temperatures of the fuel ele ments indicated a large radial temperature gradient existed across $\mathrm{UO}_{2}$ elements during normal operation. Expected values for temperatures at various positions in the UO 2 fuel elements have been provided by Wittenbrock(2) and are plotted in Figures 3 and 4. The existence of this gradient presented a problem in calculating the early phases of the postulated incidents in that surface temperatures are required in the machine computation and radial temperature gradients can not be accommodated. If the predicted surface temperatures were employed this would mean that the large amount of sensible heat would be ignored. Conversely if an average temperature were chosen as representative of the element, then the sensible heat of the rod would be considered but the computed heat transfer from the rod to the coolant would be considerably greater than that which would occur.

After considering the various ramifications of this problem it was decided that the average element temperatures would be utilized in the machine calculation in order that the sensible heat of the element could be followed. The average temperatures used for input are listed in Table 2. However, it was also decided that an adjustment of the apparent temperature difference between the fuel element and the fluid would be adjusted so that the heat transfer computed would be the proper value. An analysis, reported fully as a part of Case I, was performed. The results indicated that if 12 per cent of the apparent temperature difference between the average rod temperature and the fluid were used both the heat transfer to the fluid and the sensible heat in the rod would be substantially correct.

TABLE 2. AVERAGE STEADY-STATE TEMPERATURES OF UO 2 MARK I FUEL ELEMENTS IN A 1.2MEGAWATT CLUSTER AS USED IN MACHINE COMPUTATION

\begin{tabular}{cc}
\hline & $\begin{array}{c}\text { Average } \\
\text { Interval Number }\end{array}$ \\
\hline $1-30$ & 480 \\
$2-29$ & 570 \\
$3-28$ & 698 \\
$4-27$ & 788 \\
$5-26$ & 860 \\
$6-25$ & 959 \\
$7-24$ & 1040 \\
$8-23$ & 1112 \\
$9-22$ & 1184 \\
$10-21$ & 1256 \\
$11-20$ & 1310 \\
$12-19$ & 1364 \\
$13-18$ & 1400 \\
$14-17$ & 1436 \\
$15-16$ & 1463 \\
\hline
\end{tabular}




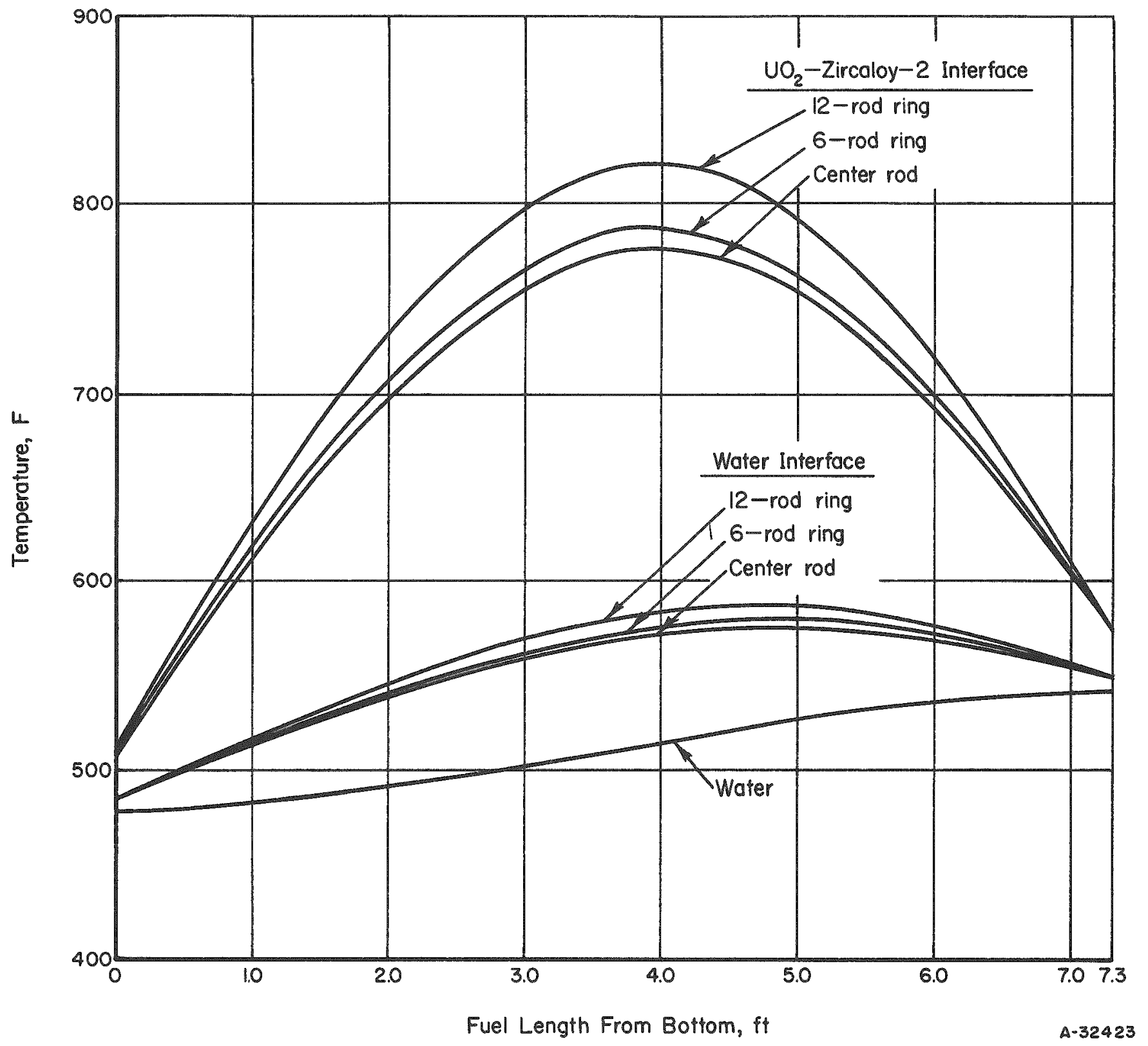

FIGURE 3. TEMPERATURES AT WATER INTERFACE AND UO 2 -ZIRCALOY-2 INTERFACE FOR 19-ROD UO 2 CLUSTER 


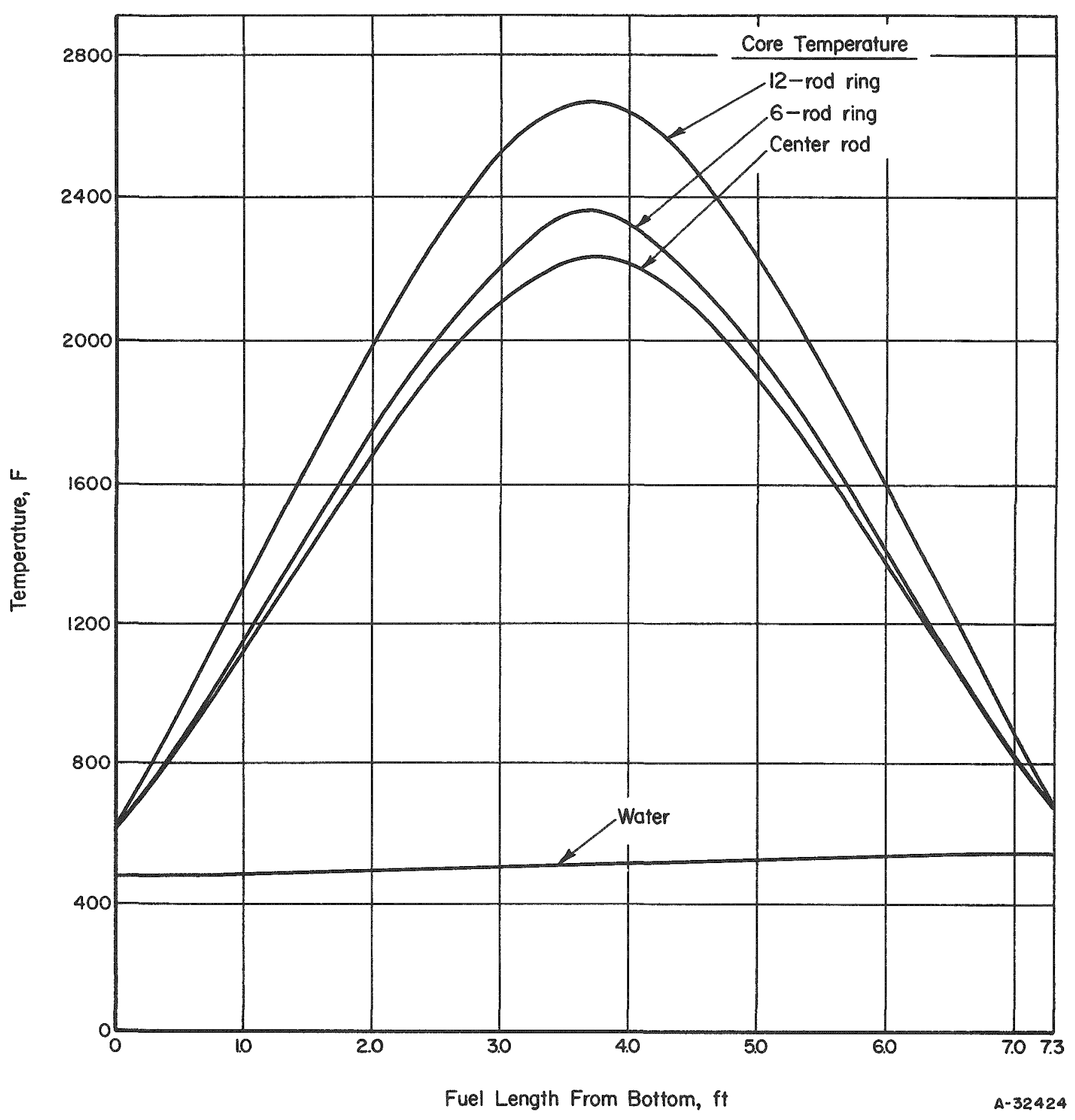

FIGURE 4. CORE TEMPERATURES FOR 19-ROD UO ${ }_{2}$ CLUSTER 
After the completion of the blowdown phase, or before completion in the case of long blowdown periods, the heat flux would become small and the temperature gradient, i. e., the difference between average temperature and surface temperature, would also become small and could be neglected.

\section{Chemical Reaction}

At sufficiently high temperatures a chemical reaction between the Zircaloy cladding and any water present in the system becomes a significant contributor to the heat effects. The reaction can be represented by the equation.

$$
\mathrm{Zr}(\mathrm{c})+2 \mathrm{H}_{2} \mathrm{O}(\mathrm{g}) \rightarrow \mathrm{ZrO}_{2}(\mathrm{c})+2 \mathrm{H}_{2}(\mathrm{~g}) \text {. }
$$

Reaction rates used in the calculations were those obtained in another study by Battelle(7). The solid-phase rate of reaction was represented by the equation

$$
v^{2}=\left(0.1132 \times 10^{6}\right) t \exp [(-34,000 \pm 1440) / R T],
$$

where

$$
\begin{aligned}
& \mathrm{v}=\text { ml hydrogen produced per } \mathrm{cm}^{2} \\
& T=\text { degrees Kelvin } \\
& t=\text { sec. }
\end{aligned}
$$

Since there is some uncertainty concerning the rate of this reaction, both the experimentally derived values based on the above equation and a rate 5 times that which the equation were used to perform a sensitivity analysis. This is reported fully as a part of Case I.

Heat effects for this reaction are given in Appendix A, Table A-4.

\section{CASES COMPUTED}

Once it has been assumed that a rupture has occurred in the primary coolant system of a specified size and at a specified location, the following sequence of events is considered to be representative of conditions within the reactor. Immediately after the postulated rupture occurs, a considerable mass of pressurized water flows through the rupture. This period would be characterized by high flow rates through the reactor and rapid pressure decay in the primary system. At a fraction of a second after the rupture would occur, scram would be initiated either by a flow sensor or a low pressure sensor. Scram in the PRTR is to be accomplished by dumping the heavy water moderator from the calandria in which are located the 85 process tubes, into a dump chamber below. Scram in this manner would result in a very rapid decrease in reactivity as shown in the decay heat generation curve, Figure 2. 
After scram would occur, the power generation rate would rapidly fall to a low value and then change rather slowly due to the logarithmic nature of the decay process. Depending upon the size and position of the postulated rupture, it is estimated that primary coolant would be available for cooling from several seconds to several minutes after the rupture.

\section{Cases Studied}

The cases studied were those in which it was postulated that:

(1) The 14-in. pipe running from the upper ring header to the heat exchanger parted and was displaced so that coolant from the header leg would is sue through one end and coolant from the heat exchanger leg is sue through the other end.

(2) A single rupture equivalent to a rupture in the 14-in. pipe would occur near the upper ring header. In this case coolant would flow from both the reactor leg and heat exchanger leg out the single rupture.

(3) A complete parting and displacement of one of the upper jumpers that connects each process tube to the upper ring header.

(4) A complete parting and displacement of a bottom jumper that connects each of the process tubes to the bottom ring header.

The computation of flow rates and pressure decay following these postulated ruptures, upon which a large part of this analysis is based, has been provided by Ambrose ${ }^{(4)}$.

\section{Case I}

Case I was postulated as that of a complete parting of the 14-in. outlet pipe which runs from the outlet header to the heat exchanger. The sequence of events postulated are: a rapid pressure decay in the reactor during which time most of the primary coolant would be lost from the system through the two ends of the rupture pipe (blowdown phase), a period of time following in which the fuel elements would be covered by stagnant steam and no heat would be lost from the elements (adiabatic phase), and finally the period subsequent to the time emergency back-up coolant would reach the fuel element (injection phase).

\section{Blowdown Phase}

Loss of Coolant. Blowdown conditions were predicted by Ambrose(4) and indicate that the initial discharge of primary coolant after the postulated incident would be 
$5500 \mathrm{lb}$ per sec. This value would drop to about $1600 \mathrm{lb}$ per sec at $0.2 \mathrm{sec}$ after the incident. After this time the discharge rate would remain between 1500 and 2000 lb per sec until about $16 \mathrm{sec}$ had elapsed. The discharge through the reactor leg during this later period would be between 500 and $700 \mathrm{lb}$ per sec which is somewhat less than normal coolant flow of about $1200 \mathrm{lb}$ per sec through the reactor.

At $16.4 \mathrm{sec}$ after the incident it was predicted that the pressure in the primary coolant system would have fallen to about 330 psia and the temperature of the remaining coolant in the system would be about $426 \mathrm{~F}$. An integration of the flow rate versus time curve up to $16.4 \mathrm{sec}$ showed that the water remaining in the system would be less than sufficient to fill the bottom ring header and the connecting inlet pipe back to the check valve. Consequently, the re is every indication that the steam being formed by flashing will no longer carry out liquid with it (because of the larger separation area afforded in the ring header), and only steam would now be passing through the core and out the rupture.

The blowdown predictions indicate that the steam flow would decrease from about $40 \mathrm{lb}$ per sec at $17 \mathrm{sec}$ after the incident to about $1 \mathrm{lb}$ per sec at $30 \mathrm{sec}$. At $30 \mathrm{sec}$ it was predicted that the pressure in the primary coolant system would have decayed to about $24 \mathrm{psia}(9 \mathrm{psig}$ ) and a temperature of $238 \mathrm{~F}$, at which point it would be equal to the pressure in the containment vessel. With equal pressures the flow would stop. The water level in the primary loop, if no injection had been begun, would be about at the center line of the bottom ring header. This condition was defined as the end of the blowdown period.

At approximately 22 to 24 sec after the postulated rupture, when the pressure in the primary coolant system would fall to 100 psig (115 psia) and the corresponding temperature would be $338 \mathrm{~F}$, auxiliary backup light water coolant could be injected for the first time. This of course will depend upon the final design of the sarety injection system, but no system less effective than this has been assumed in this analysis. If the safety injection system were automatic, injection would begin at 22 sec after this postulated incident. If the safety injection system were manual, or if there were a failure in the automatic feature, injection could start at any time after this postulated incident when the pressure were lower than 100 psig. These possibilities are covered in this analysis.

Fuel Element Temperatures. Since scram would occur approximately $0.1 \mathrm{sec}$ after the incident, the coolant flow through the reactor prior to scram would be greater than normal. So, it would not be expected that a temperature excursion should occur prior to scram. The period in the first second after scram is initiated presents the best possibility of a temperature excursion during the blowdown phase since, during this period, it may be possible that the decay heat generation decreases more slowly than the heat transfer falls due to a decrease in the discharge rate. After the first second, the decay heat generation would be less than 25 per cent of full power, while the heat transfer coefficient would be expected to be greater than 25 per cent of normal since the flow rate through the core at this time would be considerably greater than 25 per cent of normal.

Analytical Solution Versus Machine Calculation. In order to check the validity of the use of the machine program for the blowdown calculations, an analytical solution was 
made for the blowdown conditions of Case I. This solution was similar in nature to that performed previously at Battelle(8). It was based on the assumption of a constant heat transfer coefficient of $3600 \mathrm{Btu} /(\mathrm{hr})\left(\mathrm{ft}^{2}\right)(\mathrm{F})$ and a constant thermal conductivity of 2.6 $\mathrm{Btu} /(\mathrm{hr})\left(\mathrm{ft}^{2}\right)(\mathrm{F} / \mathrm{ft})$. The temperatures were determined at the midplane of the core at the end of the blowdown phase. Table 3 gives center line and surface temperatures of a UO2 19-rod cluster fuel element and water temperatures initially and at 16 sec after the incident. Results of the machine calculations are given for comparison in this table as well as in Figure 5 as a function of time.

\section{TABLE 3. FLUID AND ELEMENT TEMPERATURES AT CENTER OE UO 2 FUEL ELEMENT}

\begin{tabular}{lrr}
\hline & & \multicolumn{2}{c}{$\begin{array}{c}\text { Temperature, } F, \\
\text { at Indicated Time, } \\
\text { sec }\end{array}$} \\
\cline { 2 - 3 } Analytical Solution & 0 & 16 \\
\hline Center Line of Element & 2370 & 586 \\
Surface of Element & 570 & 445 \\
Water & 450 & 426 \\
Machine Calculation & & \\
Average Element Temperature for & & \\
Full $\Delta t$ & 1463 & 426 \\
12 per cent $\Delta t$ & 1463 & 498 \\
6 per cent $\Delta t$ & 1463 & 740 \\
\hline \hline
\end{tabular}

Temperatures of the element averaged over the radius of the element were used at the beginning and end of the defined blowdown period to compute a temperature difference. It was found that the temperature diffexence between the surface and the water coolant was very nearly 6 per cent of the difference between the average element temperatures and the water temperatures over the whole length of the rod at $t=0$. $A$ corresponding comparison at $t=16$, using the results of the analytical solution, showed a ratio of 18 per cent. This comparison led to the decision to perform the machine calculation during blowdown while using a temperature difference 12 per cent of that computed from the average element temperature and the coolant temperature at each point. The maximum fuel element temperature at $t=16 \mathrm{sec}$ as predicted by the machine calculation would be $498 \mathrm{~F}$ when the 12 per cent temperature difference was assumed. This compares with a value of approximately $507 \mathrm{~F}$ which can be predicted from the results of the analytical solution. After the completion of water flow portion of blowdown, in this case after $16 \mathrm{sec,} \mathrm{it} \mathrm{was} \mathrm{considered} \mathrm{that} \mathrm{the} \mathrm{radial} \mathrm{gradient} \mathrm{was}$ sufficiently flat that the assumption that the surface temperature is equal to the average temperature would introduce small exror, particularly when an adiabatic period follows. This treatment was necessary only for the UOZ elements. The Pu-Al elements have a very small radial temperature gradient because of the much greater thermal conductivity of the Pu-Al.

Maximum Temperatures. Using the above assumptions, the machine computation indicated that the average rod temperature rose only $2 \mathrm{~F}$ duxing the first second for a 


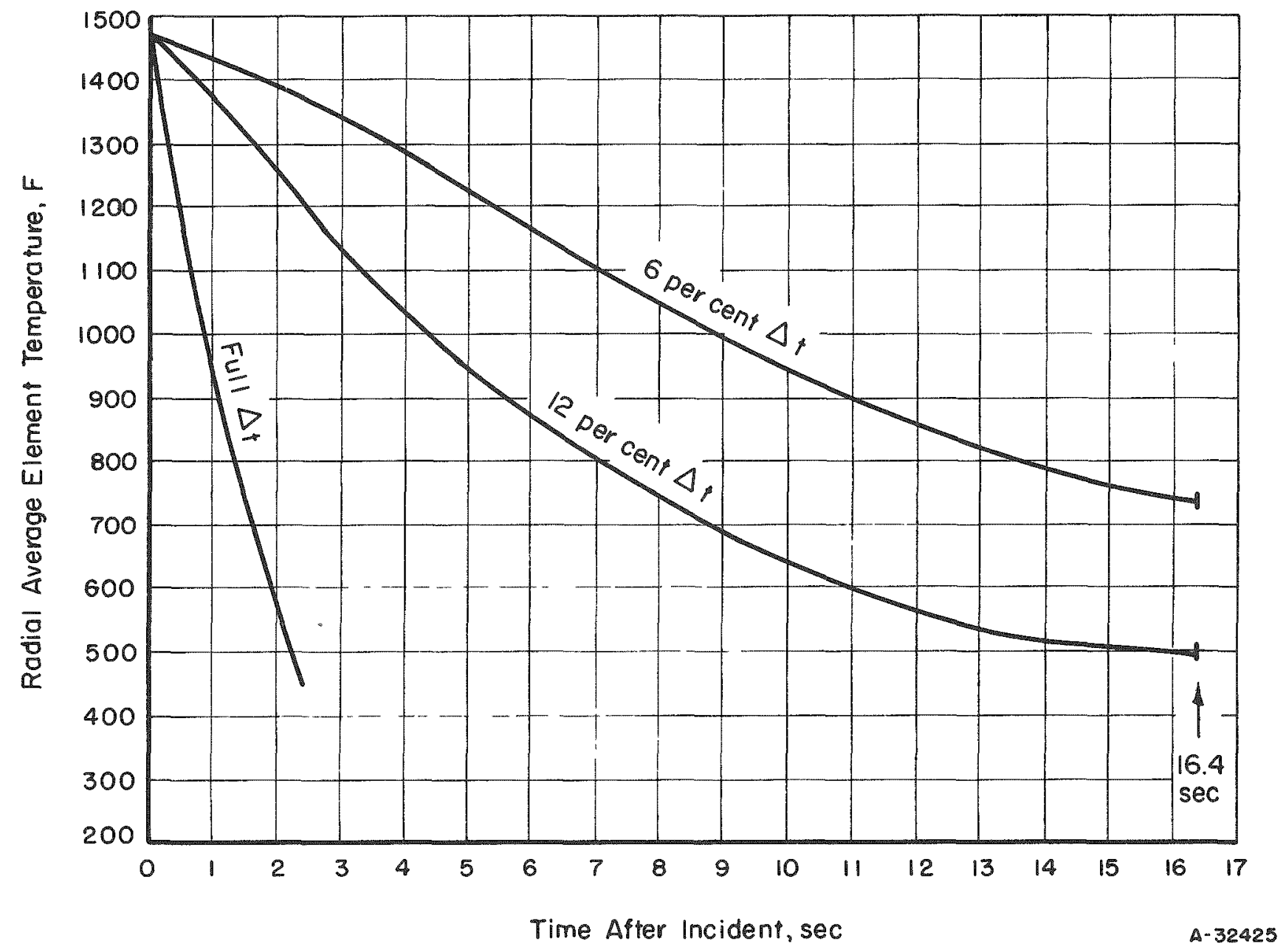

FIGURE 5. TEMPERATURES OF THE HOTTEST POINT OF A 6-ROD ELEMENT OF A 19-ROD CLUSTER DURING BLOWDOWN

Case I. 
6-rod $\mathrm{UO}_{2}$ element and then began to decline. A similar situation was found for the outer concentric ring of the concentric element, the 12-rod $\mathrm{UO}_{2}$ element, and the 6-rod Pu-Al element. Figure 6 shows a comparison of the cooling rates of various elements during blowdown. The temperature of a $\mathrm{Pu}-\mathrm{Al}$ element would decrease rapidly and would be essentially at the coolant temperature within $2.5 \mathrm{sec}$ while the temperature of a $\mathrm{UO}_{2}$ element would decrease much more slowly. At $16.4 \mathrm{sec}$, the maximum temperature of a $6-\mathrm{rod} \mathrm{UO}_{2}$ element would be about $485 \mathrm{~F}$ and that of the outer concentric ring element about $800 \mathrm{~F}$. The much higher heat capacity of the concentric ring element in comparison with its surface area is responsible.

During the early part of the blowdown steam-flow period (from 16.4 to 30 sec), cooling continues because a high rate of flow exists ( 30 to $40 \mathrm{lb}$ per sec). However, during the latter part of this period when the steam-flow rates are approximately 1 to 3 $1 \mathrm{~b}$ per sec and approaching zero flow at $30 \mathrm{sec}$, the temperatures of the fuel elements begin to $x$ ise once again. This is shown for the $\mathrm{UO}_{2} 6$-rod element in Figure 7 .

Adiabatic Phase

The defined adiabatic phase for Case I would begin $30 \mathrm{sec}$ after the postulated incident (when flow of coolant through the reactor has stopped) and continue until injected light water reached the bottom of the fuel elements or until the geometry of the reactor was changed by melting of the fuel element. At $30 \mathrm{sec}$, providing no injection had occurred, the bottom ring header would still be half full of liquid heavy water: the remainder of the reactor primary coolant system would contain steam; however, this amount of steam would be insufficient to provide measurable cooling of the reactor fuel elements or permit a significant amount of reaction.

The adiabatic phase would normally end upon the introduction of the emergency back-up coolant; however, the adiabatic phase computations were continued until the melting points of the various fuel elements were reached. Computed maximum fuel element temperatures as a function of time are shown in Figure 8 . The critical element is the Pu-Al element; it would reach the melting point of aluminum (1220 F) at $219 \mathrm{sec}$ after this postulated incident. It is estimated that sufficient heat would be developed by $262 \mathrm{sec}$ to completely melt the $\mathrm{Pu}-\mathrm{Al}$ alloy. The $\mathrm{UO}_{2}$ elements would not be expected to reach the melting point of zirconium $(3314 \mathrm{~F})$ before 830 to $1000 \mathrm{sec}$. Thus, to prevent any melting of the Pu-Al elements cooling must be provided before 219 sec have passed. A delay in injection of light water coolant for a period up to 3 min would have no serious consequences. With delays of much longer duration the possibility exists that the Pu-Al element would melt and could conceivably spill out in a molten state into the pool of heavy water. Release of fission products into the containment vessel would still be the maximum hazard since the melting temperature of aluminum is too low to permit any known metal-water reaction.

The computed temperature profiles of a $6-\mathrm{rod} \mathrm{UO}_{2}$ element during the blowdown and adiabatic phases for various times are shown in Figure 9. 


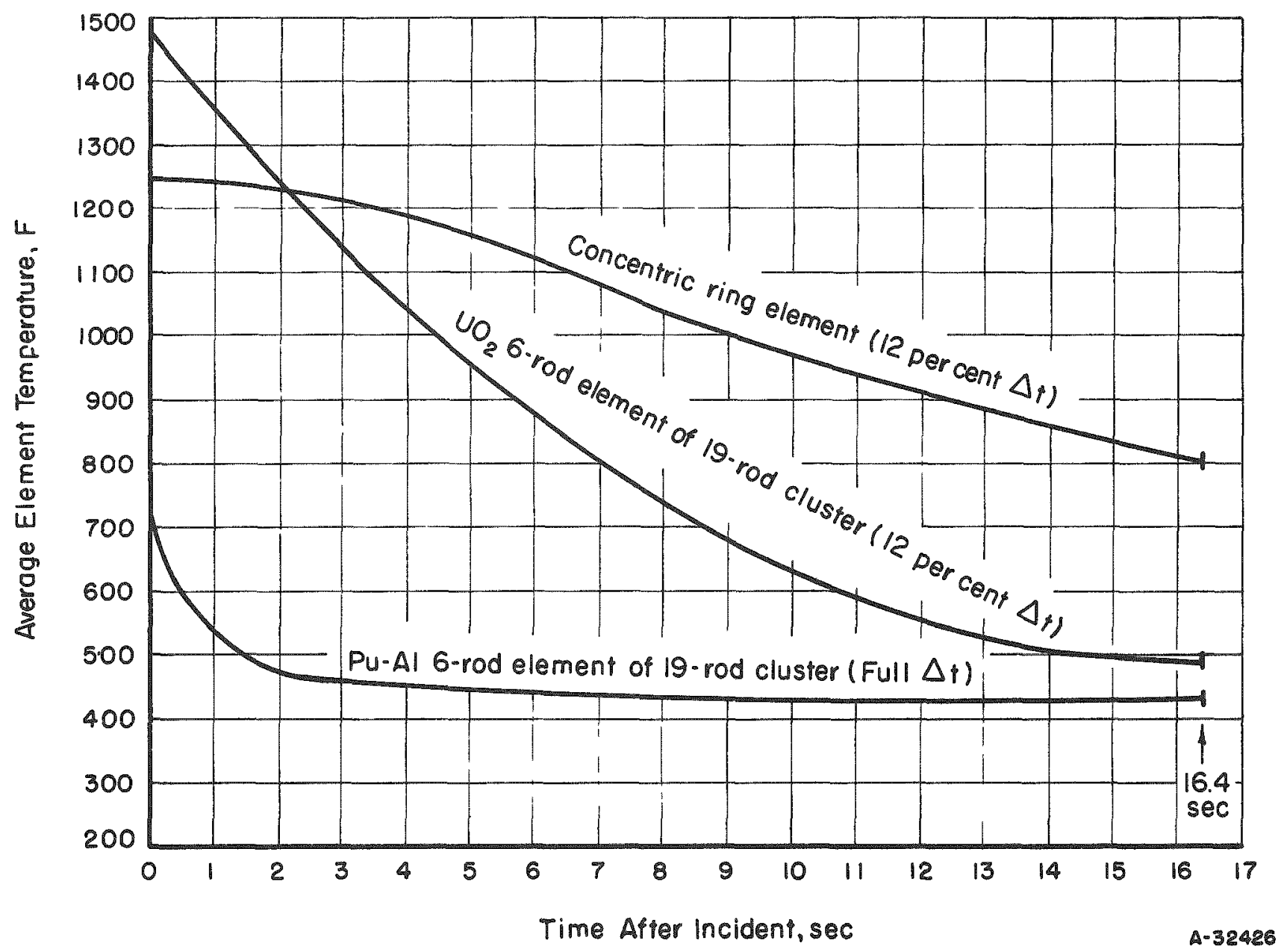

FIGURE 6. TEMPERATURES OF THE HOTTEST POINT OF VARIOUS FUEL ELEMENTS DURING BLOWDOWN FOR A 1.2-MEGAWATT PROCESS TUBE

Case I. 


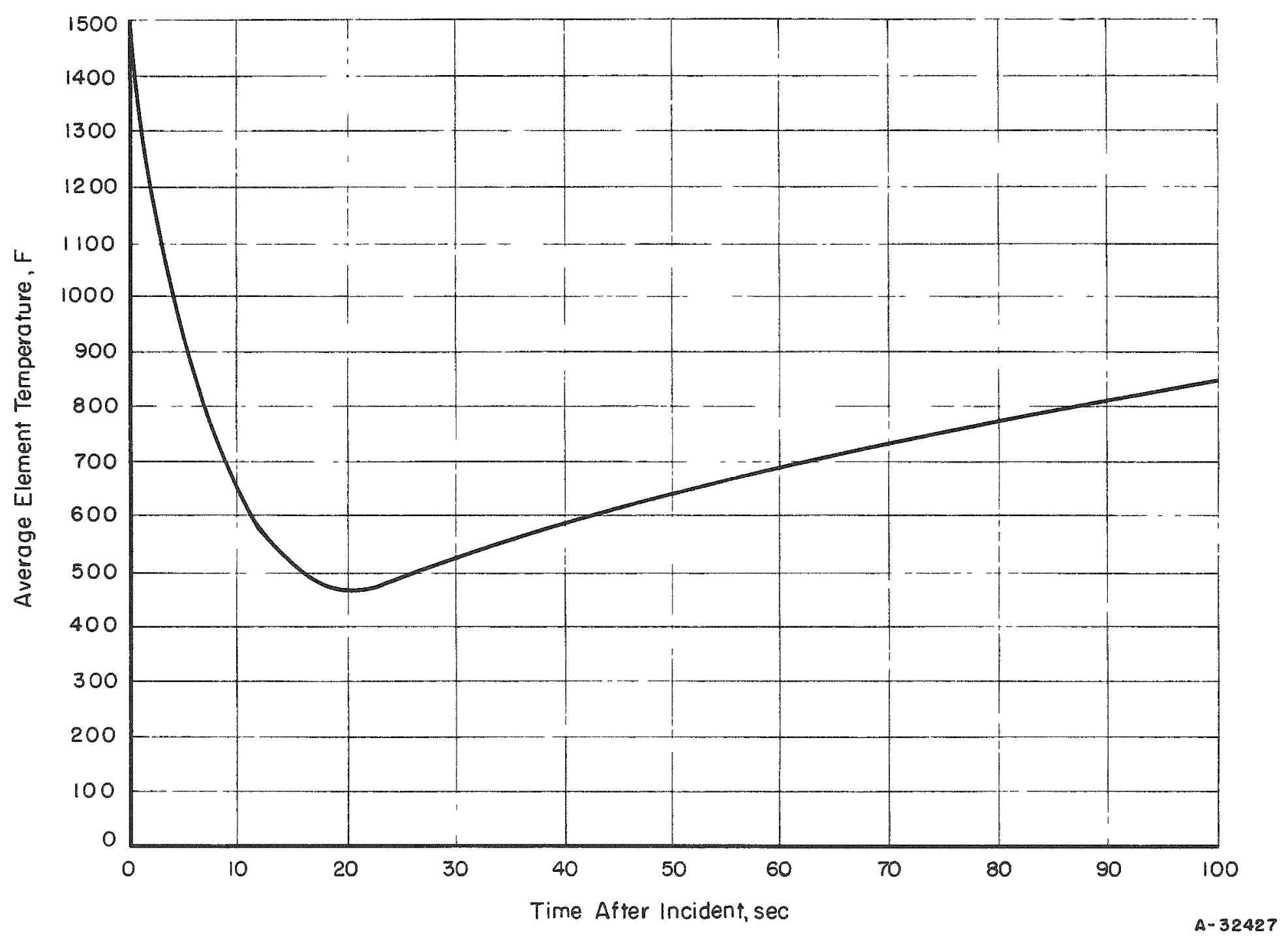

FIGURE 7. MAXIMUM TEMPERATURE OF A 6-ROD UO 2 FUEL ELEMENT DURING BLOWDOWN FOR A 1.2-MEGAWATT PROCESS TUBE

Case I. 


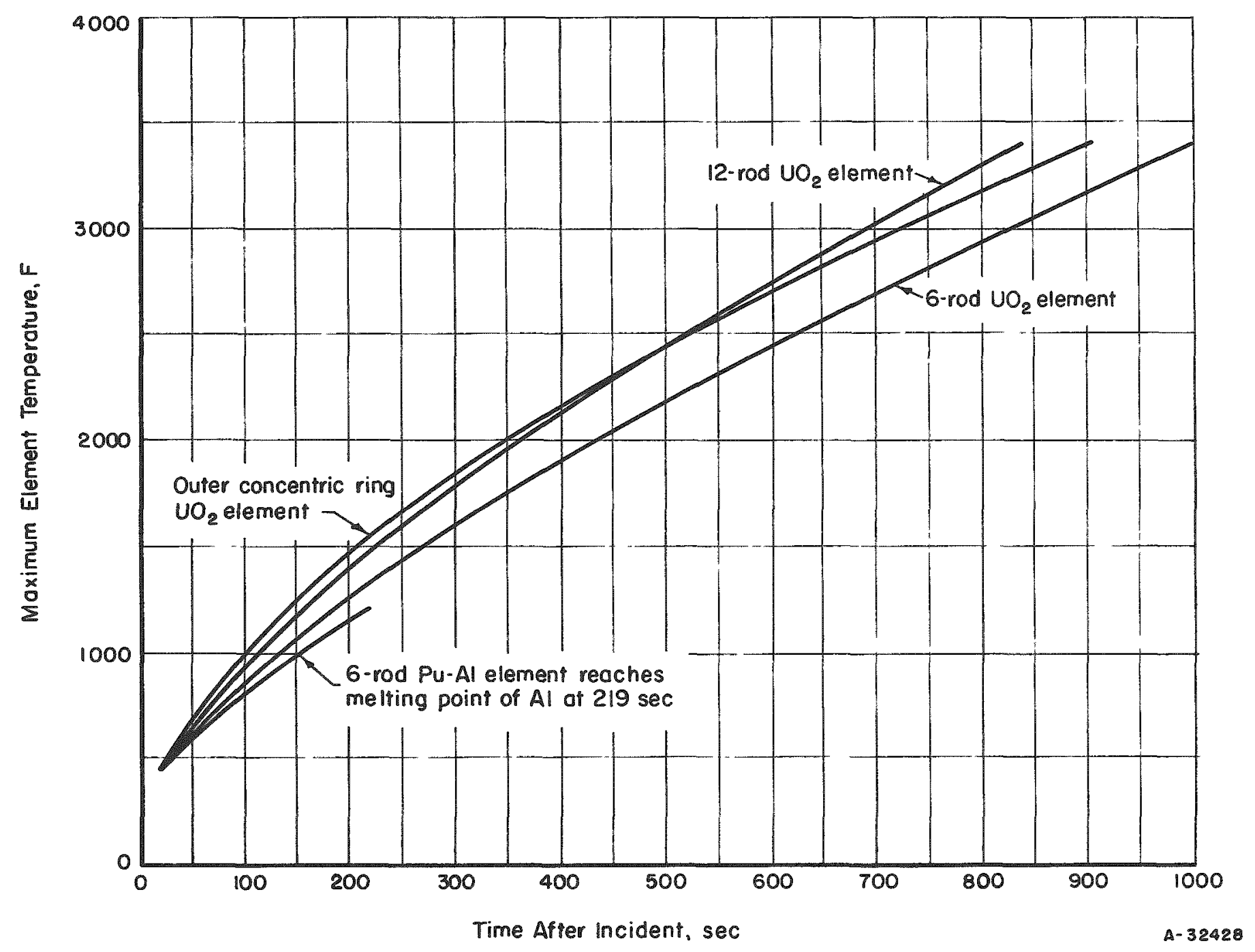

FIGURE 8. ADIABATIC TEMPERATURE RISE OF THE HOTTEST POINT OF VARIOUS ELEMENTS FOR A 1.2-MEGAWATT PROCESS TUBE

Case I. 


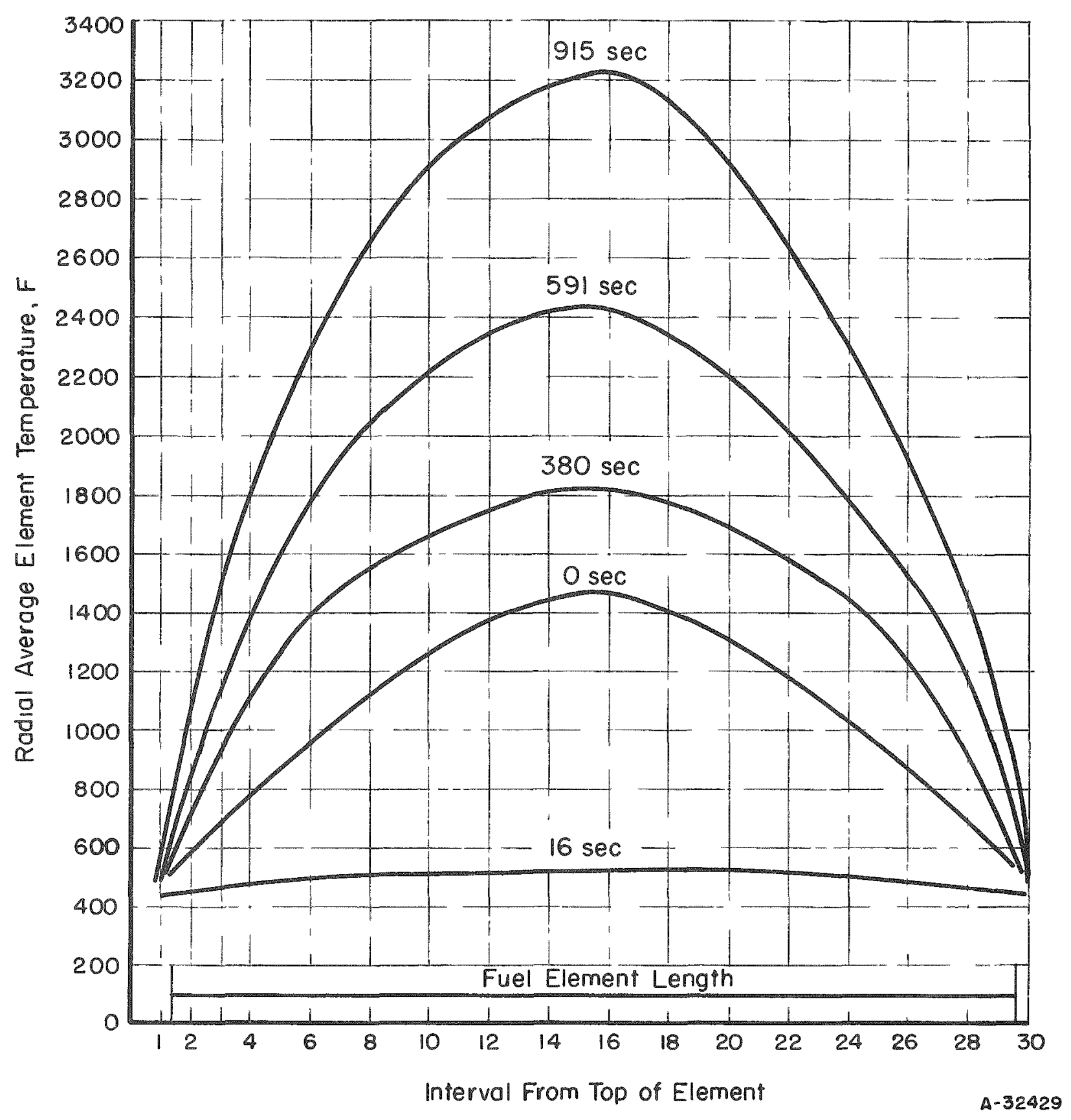

FIGURE 9. TEMPERATURE PROFILE ALONG A 6-ROD UO 2 ELEMEN T Case I. 
Injection Phase

The proposed injection system consists of pumps capable of pumping 750 gpm into a line connected to each ring header, with half of this flow ( $375 \mathrm{gpm}$ ) going to each ring header. The pumps are capable of pumping against a pressure of $100 \mathrm{psig}$, and the time at which injection could be begun is governed by the time at which the system pressure would reach 100 psig. For Case I, the pressure was predicted as reaching 100 psig at $24 \mathrm{sec}$ afte $x$ the postulated incident. With the top rupture, injection would be effective only in the bottom $x$ ing header. Before the water would reach the base of the fuel elements, it would be necessary that the bottom header and the jumper tubes be filled with the emergency coolant. From the prediction that the bottom ring header would be filled with liquid to its center line when injection would be begun at 24 sec and at the designed flow rate of emergency coolant, it was computed that the water level would be at the base of the fuel elements at 86 sec after the incident.

The IBM 653 was programmed to compute the water level in the process tubes once the level reached the base of the fuel elements. It indicated that, with injection starting at $24 \mathrm{sec}$, the fuel elements would be covered at 120 sec after the incident. With this relatively slow rise of the emergency coolant through the core, it was considered that the mode of heat transfer was film boiling. A heat transfer coefficient of $22 \mathrm{Btu} /(\mathrm{hr})\left(\mathrm{ft}^{2}\right)(\mathrm{F})$ was used during this injection phase as previously discussed.

The computed temperature of a $6-\mathrm{rod} \mathrm{UO}_{2}$ element after injection at three different injection times has been initiated is shown in Figure 10 superimposed on the adiabatic curve. Also shown are the temperatures for injection starting at later times so that coolant reaches the bottom of the fuel elements at 10 min and 15 min after the incident. In these two cases, the temperature rises above the adiabatic curve upon initiation of injection wate $x$ due to the heat evolution from the reaction of water with Zircaloy-2. Although the effects of the heat evolution are readily apparent, in neither case is an appreciable amount of the Zircaloy -2 present reacted.

The necessity of initiating injection of auxiliaxy coolant within about 2 min to prevent melting of the Pu-Al elements has already been specified. However, this melting is not a serious hazard, so the problem of a possible serious hazard due to metal-water reaction at later times and at much higher temperatures needed to be investigated. The conclusion is reached that for this postulated large top rupture in the primary coolant system, the proposed injection system would be adequate to prevent any serious damage to the core from occurring provided the emergency coolant reached the bottom of the fuel elements before $15 \mathrm{~min}$ had elapsed.

Analysis would also indicate that had the rupture been postulated to occur at the bottom rather than at the top the proposed injection system still would be adequate. In this case, it would not be necessary to fill the tubes, but only the top ring header and outlet pipe before coolant would flow through the process tubes. This would occur in a time shorter than the $62 \mathrm{sec}$ required for the coolant to reach the bottom of the fuel element for the top-break situation. Automatic closure of the valve isolating the heat exchanger and pressurizer would insure that adequate coolant would reach the fuel elements rather than flowing into the heat exchanger leg. 


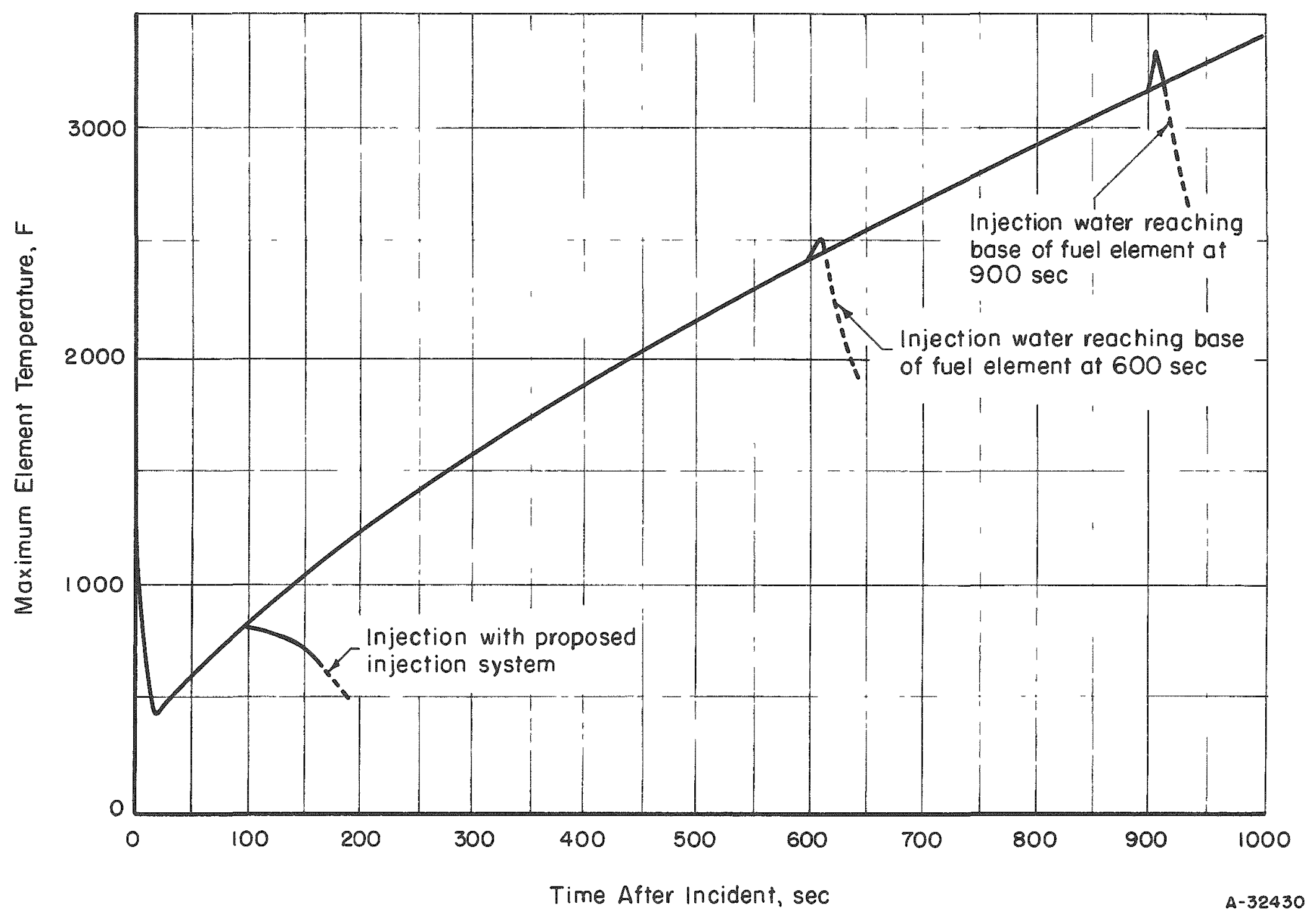

FIGURE 10. TEMPERATURE OF THE HOTTEST POINT OF A 6-ROD UO 2 CLUSTER ELEMENT Case I. 
Sensitivity Analysis

Although the best available data were utilized for purposes of computing the extent of the contribution of the zirconium-water reaction to the temperature excursion and the potential hazard, a degree of uncertainty exists in the reaction rate correlation. In an effort to eliminate the obvious uncertainty which this might introduce into the results of this study, a so-called sensitivity analysis was performed. This sensitivity analysis consisted of recalculating the $10-$ and 15 -min injection cases with all inputs the same with the exception of the chemical reaction rate. This was arbitrarily fixed at a value 5 times larger than the accepted correlation. The value of 5 was selected because no known experimental point was higher than these extreme values, although some isolated ones approached these.

A comparison of the computed temperature excursion for $6-\mathrm{rod} \mathrm{UO}_{2}$ fuel element is shown in Figures 10 and 11 . For the injection situation in which the coolant would reach the bottom of the fuel element at $10 \mathrm{~min}$ after the postulated incident, the maximum temperature was $2625 \mathrm{~F}$, for the reaction rate set at 5 times the accepted correlation, while the normal maximum temperature was 2514 F. In both cases the maximum temperature dropped below the adiabatic curve within 20 sec after the coolant first touched the bottom of the fuel element.

For the injection situation in which the coolant would reach the bottom of the fuel element at 15 min after the postulated incident, the difference was somewhat greater. The melting point of zirconium was reached in both cases, the normal and the 5 -times normal reaction rate assumptions. However, in the normal case, only a small per centage ( $<2$ per cent) of the Zircaloy -2 cladding might actually melt before cooling became effective and resolidified the metal. No structural deformation would be expected.

In the 5-times normal case, approximately 20 per cent of the Zircaloy-2 cladding might be expected to melt. Some deformation and loss of fission products might be expected before the metal would resolidify in this situation.

At this higher temperature, a somewhat longer time, about $25 \mathrm{sec}$, would be required before the temperature fell below the adiabatic curve.

The conclusion from this sensitivity analysis is encouraging: postulated reaction rates 5 times higher than those that would be predicted from experiment-based correlations will not lead to a possibly catastrophic situation.

A comparison of the hydrogen generation rate for the reactor with the normal reaction rate correlation and 5 times the normal value is shown in Figure 12 . As can be seen, the higher reaction rate would result in less than an order of magnitude change in the total amount of reaction.

Effect of Radiation

Heat transferred by radiation from the elements of a process tube to each other or to the Zircaloy -2 process tube wall may also be important at higher temperatures. This contribution has been considered in Appendix D. The analysis performed indicates 


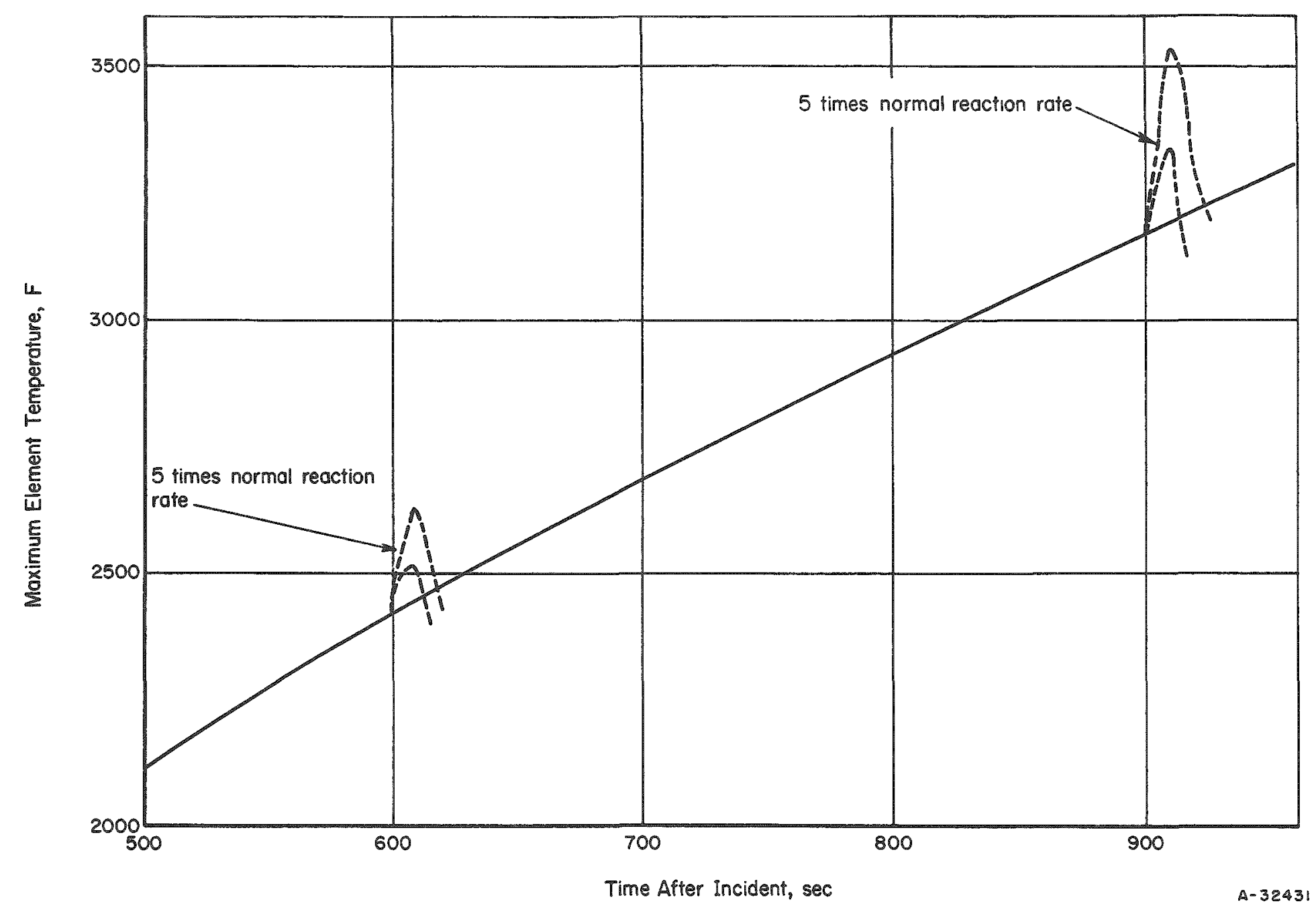

FIGURE 11. HOTTEST POINT OF A 6-ROD UO 2 ELEMENT TEMPERATURE INCREASE UNDER ADIABATIC CONDITIONS DUE TO REACTION OF WATER WITH ZIRCALOY

Case I. 


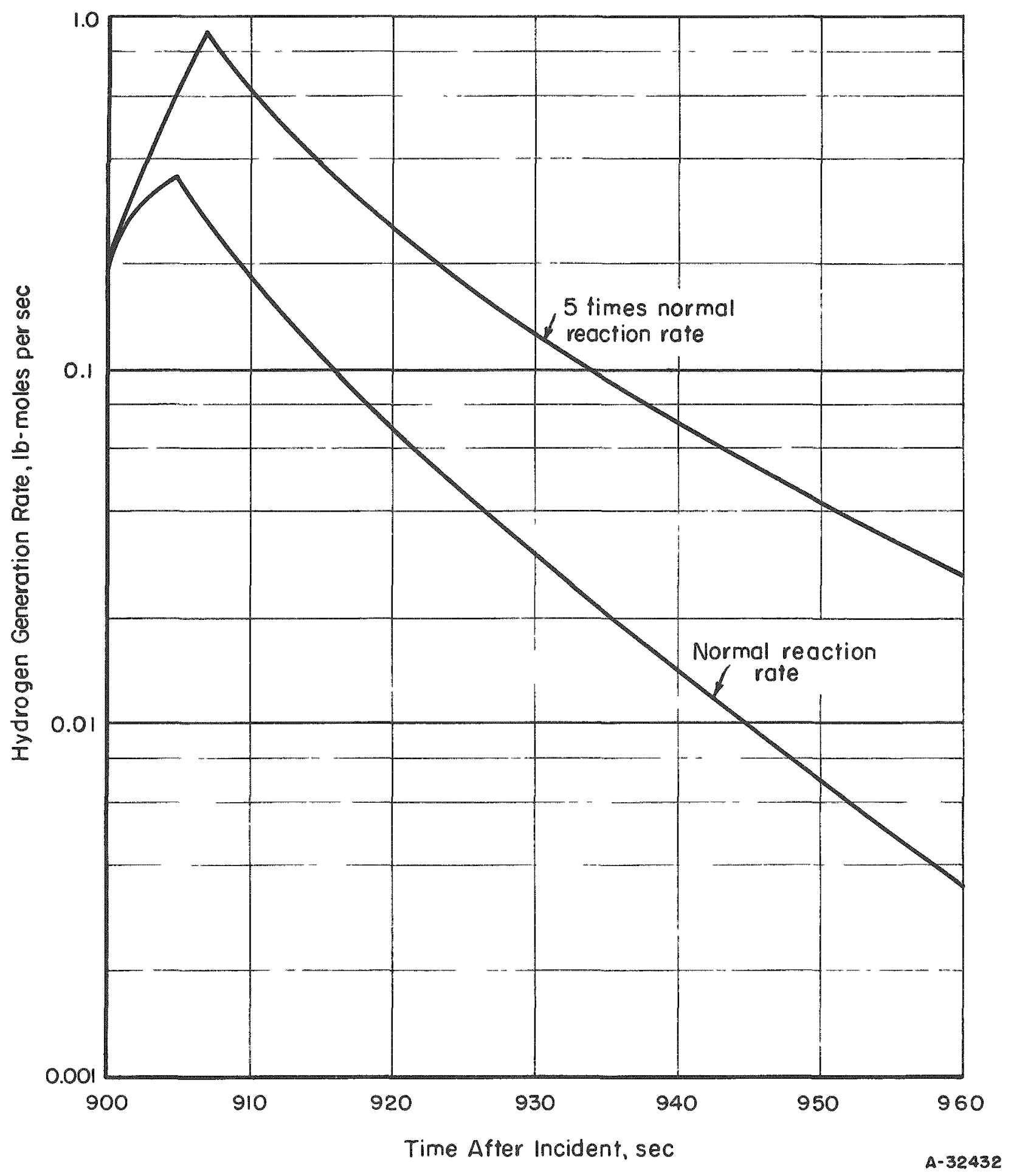

FIGURE 12. HYDROGEN GENERATION RATE FOR COOLANT INJECTION AT 900 SEC Case I. 
that the heat transferred from the $12-r o d$ ring elements would be of considerable importance at temperatures of over $1400 \mathrm{~F}$. Although the heat generation in these elements of the 12 -rod ring is greater than the 6 -rod ring elements the temperatures would be lower through radiative losses to the Zircaloy -2 process tube wall. The above analysis was extended to include radiation from the process tube wall to the alluminum shroud tube wall of the calandria.

Results indicate that there would be no appreciable effects on the heating curves of the Pu-Al elements. They would be expected to reach the melting point of aluminum $(1220 \mathrm{~F})$ at the same time $(219 \mathrm{sec})$. However, there would probably be quite an increase in the time required for the $\mathrm{UO}_{2}$ elements to reach the melting point of zirconium $(3314 F)$, thus introducing an additional safety factor against the failure of these elements. However, the loss of heat from the fuel elements by radiation would result in a gain in heat by the Zircaloy -2 process tube and the aluminum shroud tube. Considering the radiation mode alone, with no losses externally, the aluminum shroud tube would be expected to reach the melting point in $710 \mathrm{sec}$. If conduction through the helium gap is also considered, the aluminum tube would reach the melting point in 450 to 500 sec.

Thus, radiation and conduction between process tube components will tend to level out the predicted temperatures. However, this is accomplished with no benefit to the $\mathrm{Pu}-\mathrm{Al}$ elements because their melting point is comparatively low and to the detriment of the aluminum shroud tube which would not be in danger of melting without the effect of the radiation and conduction modes of transfer.

\section{Case II}

Case II was postulated as that of a single hole in the outlet pipe of an area of 0.80 $\mathrm{ft}^{2}$, equal to that of a single 14-in. rupture. With this smaller rupture the blowdown as predicted by Ambrose(3) would be slower in that both the discharge rate and pressure decay would be less than that predicted for the double 14-in. rupture (Case I). However, it was found that so much similarity existed between Cases I and II that it was necessary to compute only the critical phase, blowdown, for the 6-rod $\mathrm{UO}_{2}$ element for Case II. Other results could be predicted with a high degree of certainty once this had been done, and a significant saving in machine computing time and cost could be accomplished.

Blowdown Phase

Loss of Coolant. The initial discharge rate for Case II would be about $3000 \mathrm{lb}$ per sec, and after the initial surge of coolant through the rupture the flow through the reactor $l e g$ would vary between 350 and $550 \mathrm{lb}$ per sec, somewhat less than that of Case I. Coolant mixed-phase flow, however, would continue for 26 sec as compared to 16 sec in Case I. Steam would continue to flow until $42 \mathrm{sec}$ after the incident. Rates would be about $57 \mathrm{lb}$ per sec initially and decrease to zero flow. At 42 sec after the incident, the pressure in the reactor would reach 24 psia, which would be equal to that in the containment building. 
Fuel Element Temperatures. As in Case I there was a calculated temperature rise of about $2 F$ during the first second after the incident, and then the temperatures steadily" declined, so the maximum temperature of the 6-rod $\mathrm{UO}_{2}$ element was less than $700 \mathrm{~F}$ at the end of the water flow. This part of blowdown (26 sec) is shown in Figure 13.

\section{Adiabatic Phase}

The adiabatic and injection phases of this case would parallel those of Case I. However, since the cooling during blowdown is not as effective as in Case I for the $\mathrm{UO}_{2}$ elements, shorter times to melting would be expected.

It is estimated from Figure 8 that the $\mathrm{UO}_{2}$ fuel elements would reach the melting point of zirconium (3314 F) in about 100 sec less time than in Case I. This would be about $740 \mathrm{sec}$ for the $12-\mathrm{rod} \mathrm{UO}_{2}$ element, $800 \mathrm{sec}$ for the outer concentric ring element, and $900 \mathrm{sec}$ for the 6-rod UO 2 element. The Pu-Al elements which have a higher the $\mathrm{r}_{-}$ mal conductivity and a lower heat capacity would be at the coolant temperature long before the end of the mixed-phase flow portion of the blowdown phase. Times to melting are estimated to be the same for Case II as for Case I.

Chemical reaction considerations would be similar at equal element temperatures a.s would radiation heat transfer effects.

\section{Injection Phase}

The delay from time of start of injection till the water reached the base of the fuel elements would be approximately the same as Case I, hence the behavior during injection for this case would be the same as Case I, only injection would begin at 36 sec after the incident rather than at 24 sec. The proposed injection system would be adequate to prevent any hazards developing during this incident.

\section{Case III}

Case III was postulated as the complete parting of one of the small jumpers that connect each process tube to the upper ring header. With this rupture, discharge would occur through the pipe stub from the upper ring header and through the stub from the process tube, hereafter called the victim tube.

Blowdown Phase

Conditions Before Pump Stalling. The analysis of conditions in the reactor after rupture, as predicted by Ambrose(4), differ somewhat from those encountered in laxger ruptures. With the rupture associated with a specific victim tube, both conditions within the victim tube and the intact tubes in the rest of the reactor must be considered separately in the analysis. 


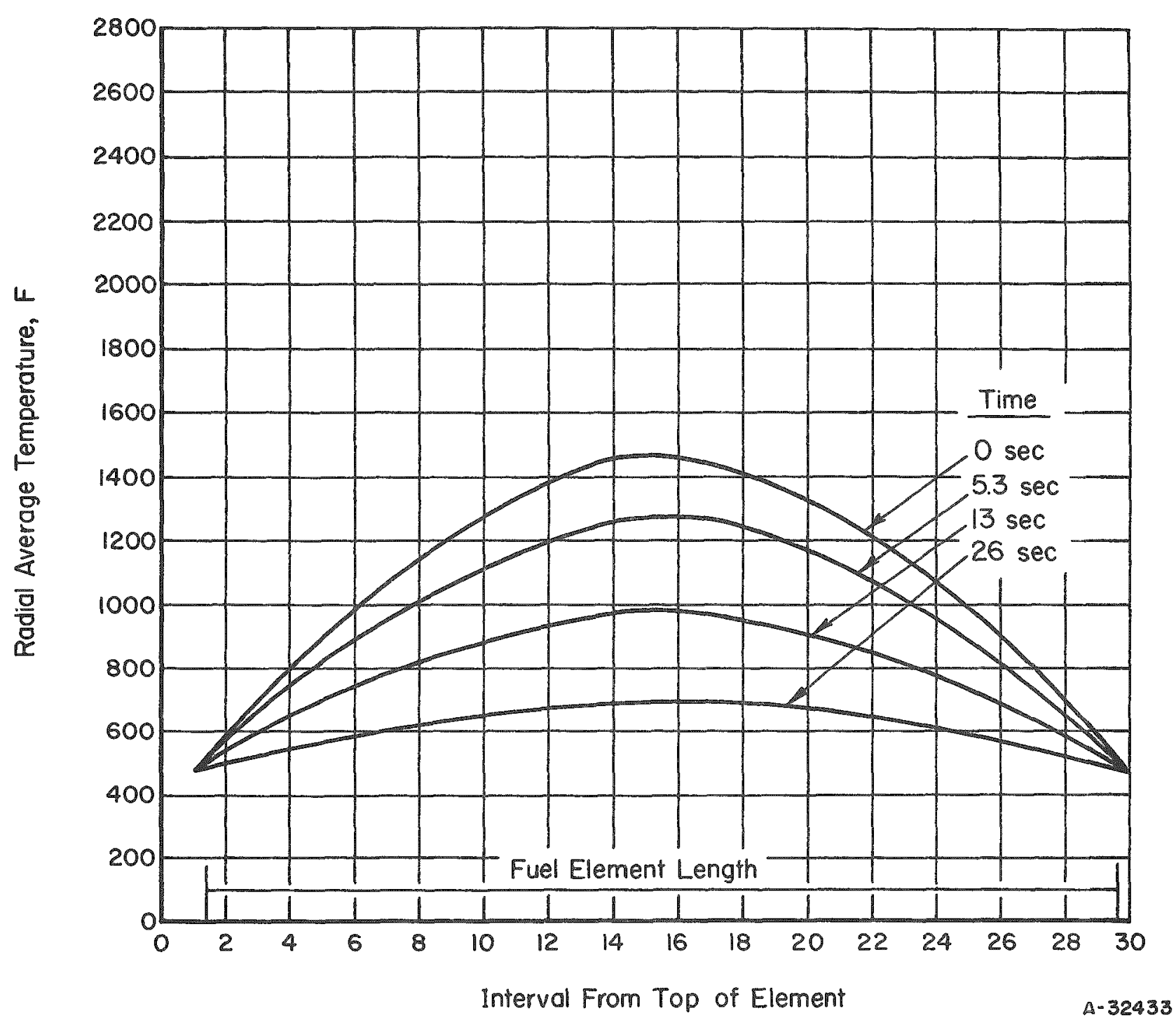

FIGURE 13. TEMPERATURE PROFILES ALONG A UO 2 6-ROD ELEMENT DURING BLOWDOWN

Case II. 
For this case, the pumps would not fail at the time of incident as for the larger ruptures but would continue to pump for $52 \mathrm{sec}$ after the incident, when it is computed they would become vapor locked. Since scram would occur in this case on a signal from the damaged tube rather than from a low -pressure signal in the primary coolant system, scram would occur as rapidly in this case as in previous cases.

With pumping continuing for $52 \mathrm{sec}$ through the intact tubes, no temperature excursion could occur during this phase of operation in the intact tubes since the flow of coolant would be close to the normal flow rate and more than adequate to remove the sensible heat in the elements and the decay heat generated.

In the victim tube, the mass flow rate would be greater than normal for this period of 52 sec so cooling would occur in the victim tube as well.

Conditions After Pump Stalling. For a considerable length of time after pump stalling the victim tube would present no hazard because flow rates would still be higher than normal. By the time injection could begin, the fuel elements in the victim tube would be essentially at the coolant temperature. In any case, the temperature of the fuel elements in the victim tube would be lower than those in the intact tubes due to the higher flow rates at all times through the victim tube.

Using the predicted flow rates through the intact tubes in the reactor as provided by Ambrose(4), the fuel element temperatures we re computed as a function of time for this blowdown phase. Temperature profiles of a $6-\mathrm{rod} \mathrm{UO}_{2}$ element are shown in Figure 14 from time of incident to $200 \mathrm{sec}$. It should be noted that the temperature would drop during the time that pumping would continue but would rise again after pumping stops, even when the fuel elements are covered by a stagnant pool of water. This would be due to the predicted low heat transfer coefficient from the elements to the stagnant pool.

At 202 sec after the incident, the system pressure would be 100 psig, so injection of emergency coolant could begin. The water level at this time would be at the bottom of the fuel elements.

Adiabatic Phase

With operation of the safety injection system as planned, there would be no adiabatic phase for Case III. The water level would fall only as low as the bottom of the fuel elements before beginning to rise once again by injection of emergency coolant. However, if the injection system did not operate, there would be an adiabatic phase which would parallel that shown for Case I. The only difference would be that Case III would lag Case I by about 40 sec.

Injection Phase

Commencing at $202 \mathrm{sec}$, a flow of $375 \mathrm{gpm}$ of auxiliary coolant could be added both to the top and bottom ring header. This situation is quite similar to that of the larger ruptures in that bottom injection would be added to cover the fuel elements, but in the case of the larger rupture there would be no difficulty in the steam produced from the 


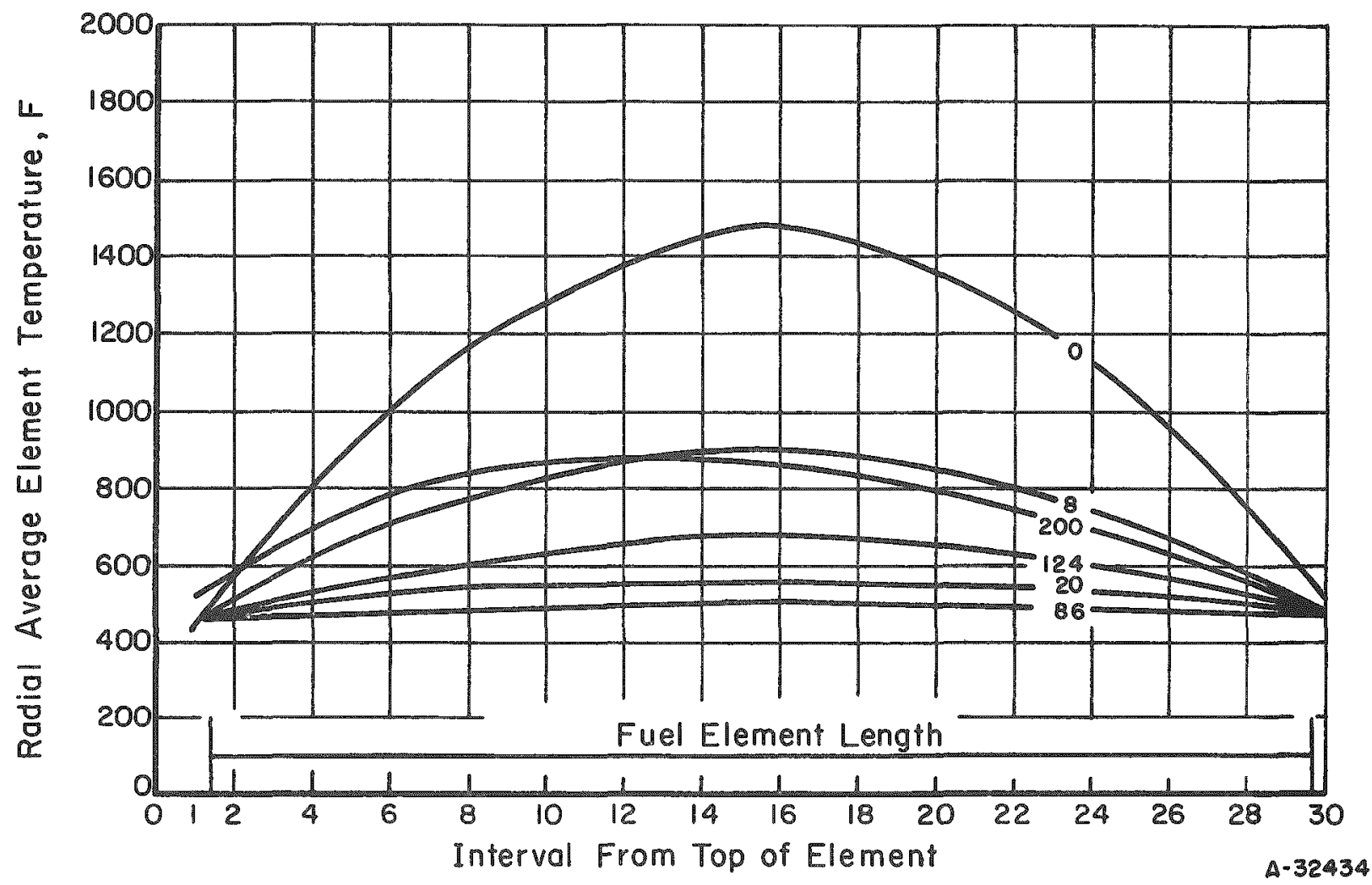

FIGURE 14. TEMPERATURE PROFILES ALONG A 6-ROD UO 2 ELEMENT OF AN INTACT PROCESS TUBE AFTER A COMPLETE PARTING OF A. TOP JUMPER

Case III 
injection water in contact with the fuel elements escaping through the large rupture. Due to the small size of the rupture in this case, however, no more steam can be produced in cooling the fuel elements than can escape through the rupture or be condensed in other portions of the primary system without raising the system pressure.

Exploratory Calculations. In an attempt to set limits on the behavior of the system during the injection phase, the stepwise temperature-excursion computation was performed as in Case I to determine the steam generation rate. It was found that during the early stages of injection steam would be generated at a rate 4 times greater than critical flow at $100 \mathrm{psig}$ out the header-leg stub of the failed jumper. Of course, it would not be possible for steam to leave the system at this rate. If steam could not be condensed, the system pressure rise and injection would stop when the pressure exceeded 100 psig.

The next approach was to modify the computer program so that injection could occur only so long as the steam generation rate was below the rate through the rupture. This analysis showed that the $\mathrm{UO}_{2}$ elements could be cooled, but the time required to cover the fuel elements would be sufficiently long that preventing the melting of the Pu-Al elements would be questionable.

Detailed Enthalpy Computation. It was finally realized that neither of the cases above would be representative of conditions within the reactor. Consequently, a stepby -step heat balance and mass balance of the water in both headers was made. The calculation entailed computing the enthalpy of the water in the bottom ring header at 1 sec intervals after injection was started. It was assumed that fluid would leave the bottom header by loss out the victim tube or by vaporizing and either condensing in the upper ring header or by being lost from the header leg of the rupture. For each $1-s e c$ increment about $50 \mathrm{lb}$ of the $68 \mathrm{~F}$ water was added by the safety injection system. Knowing the saturation pressure at the computed time, the amount of fluid flowing out the victim tube (critical flow) was subtracted from this.

Since about $50 \mathrm{lb}$ of water would also be added to the upper ring header, its enthalpy was calculated at $1-s e c$ increments also. Its enthalpy was less than that of the liquid in the bottom ring header, so the amount of steam necessary to condense in the upper ring header to equalize the enthalpy (saturation pressure) of the top and bottom ring headers was calculated, as was the critical steam flow out the header leg at the saturation pressure.

The amount of steam computed to be evaporating from the bottom ring header was found to be from 7 to $12 \mathrm{lb}$ per sec. This was the same order of magnitude as the steam generation rate as was computed from the machine calculation in which critical flow was not considered. The reas on the simple computation gives a true picture is that the majority of the steam being generated would condense in the water in the upper ring header rather than passing out through the hole in the header leg. The results of combining the steam generation rates from the machine calculations with the enthalpy and mass balance described above allows the water level in the reactor to be computed. Figure 15 shows the computed water level at times after injection until the upper ring header becomes filled with water. 


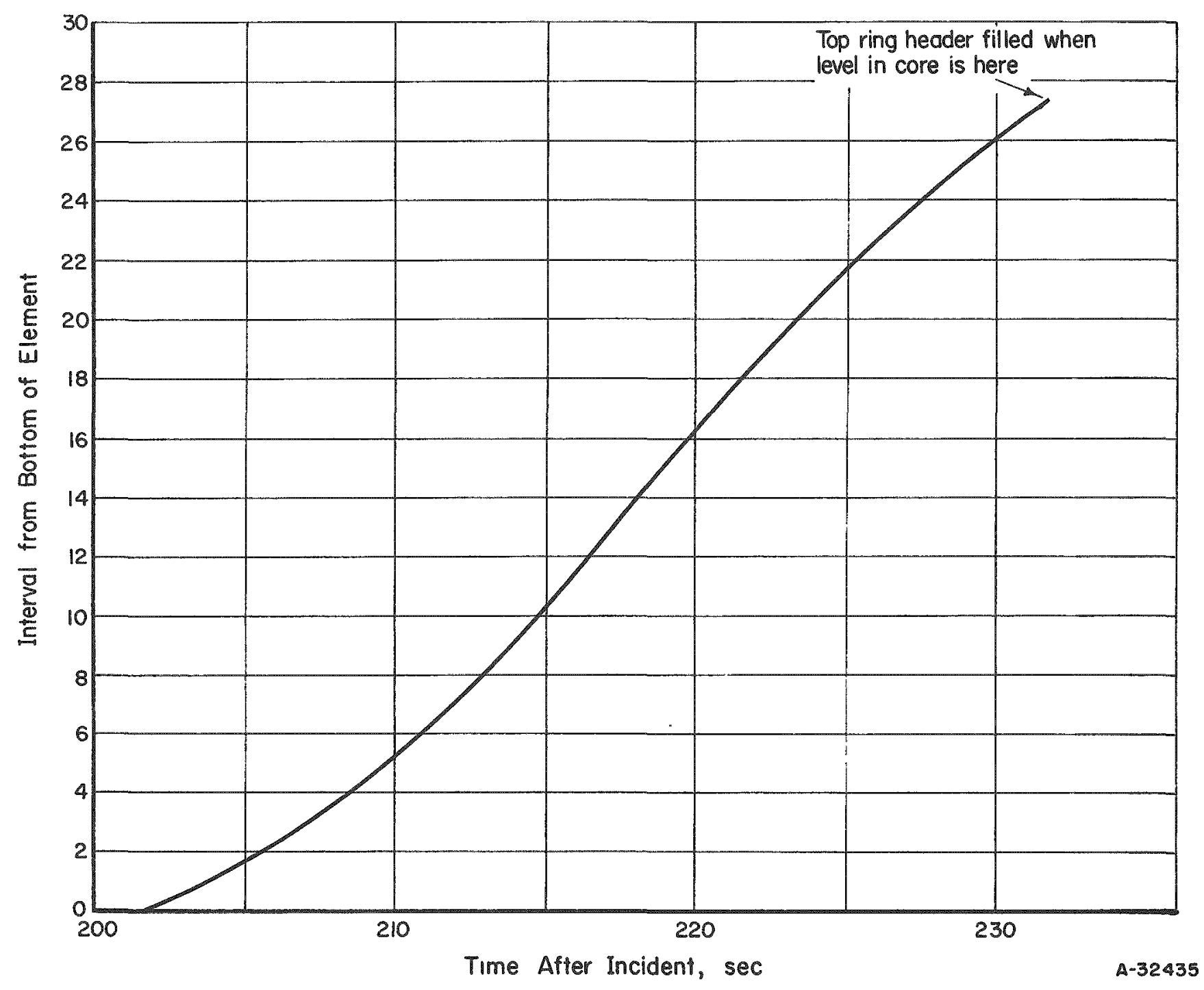

FIGURE 15. WATER LEVEL IN REACTOR WITH 375-GPM INJECTION INTO TOP AND BOTTOM RING HEADERS

Injection begins at 202 seconds. Case III. 
Conditions After the Upper Ring Header is Filled. Once the upper ring header would become filled, the water would begin to overflow through the jumpers into the process tubes. This would be possible because the water would be subcooled and could condense any steam remaining. At $232 \mathrm{sec}$ after the incident the fuel elements would be covered to 90 per cent of their length and the upper ring header would be filled. The water temperature would be $223 \mathrm{~F}$ and the pressure would be about 24 psia.

Critical flow of water out the rupture would be approximately equal to the injection rate when the primary system pressure is equal to $100 \mathrm{psig.} \mathrm{As} \mathrm{long} \mathrm{as} \mathrm{the} \mathrm{pressure} \mathrm{in}$ the reactor remains below $100 \mathrm{psig}$, the coolant will continue to rise. Computations based upon the injection rate and heat transfer rate to the water indicate that the process tubes would be filled with water before sufficient heat has been transferred to the water to raise its temperature to the saturation temperature at $100 \mathrm{psig.} \mathrm{Thus,} \mathrm{it} \mathrm{is} \mathrm{con-}$ sidered that the reactor could be filled with water.

Conditions After Filling Reactor. Although the process tubes would be filled with water, very little circulation would occur since the rate of injection of coolant water would be just sufficient to flow out the rupture, that coming in the bottom going out the victim tube and that coming in the top going out the jumper stub. It may be possible that sufficient mixing of the coolant water in the upper ring header with the water in the proces tubes would occur to remove the relatively small amount of decay heat being generated by this time.

A more pessimistic assumption would be to consider that steam would form in a process tube and drive out the water. After the water would be driven out, steam would come in contact with cooler water in the headers, condense, and fill the tube again. Since there are 84 intact tubes with different heat generation rates, this probably would be a cyclical occurrence with different tubes discharging at different times. This could continue for an extremely long time after the incident. In no case, however, is any danger anticipated so long as the injection system can be kept operating.

\section{Case IV}

Case IV is the situation for which it was postulated that a jumper tube connecting a process tube to the bottom ring header had parted and the primary coolant would be lost from the victim tube stub and the bottom ring header stub. The pumps would not be expected to fail for a considerable time after the incident. After pump failure there would be a period of time during which the process tubes would be filled with a stagnant pool of water, and the level of this stagnant pool would slowly drop until the fuel elements became uncovered. As before, when the pressure in the system was computed to be 100 psig, emergency coolant would be injected into the two ring headers.

Blowdown Phase

Conditions Before Pump Stalling. Conditions within the reactor for this case would be quite similar to those of Case III. Ambrose has predicted that the pumps would continue to operate until $58 \mathrm{sec}$ after the incident. Cooling of all process tubes, including the victim tube, would be observed. 
Conditions After Pump Stalling. In this case it is necessary to consider both the intact process tubes and the victim tube. Considering the intact tubes, the pumps would fail at $58 \mathrm{sec}$ but the fuel would remain covered with a stagnant pool until $137 \mathrm{sec}$ after the incident, when the level of primary coolant would fall to the top of the fuel. It was computed that the fuel elements would be completely uncovered by 200 sec after the incident. Ambrose (4) has computed that the system pressure would decay to 100 psig at $270 \mathrm{sec}$ after the incident.

At $137 \mathrm{sec}$ after the incident the maximum temperature of a 6-rod Pu-Al element was computed to be $683 \mathrm{~F}$. By the time the fuel elements became completely uncovered at $200 \mathrm{sec}$, the maximum temperature would rise to $801 \mathrm{~F}$.

The flow rate through the victim tube would still be approximately $10 \mathrm{lb}$ per sec at 4 min after the incident; hence, the victim tube would not be in danger at any time.

\section{Adiabatic Phase}

Since the fuel elements would become uncovered at $200 \mathrm{sec}$ and injection could not be begun until $270 \mathrm{sec}$ after the incident, there would be a considerable period of time during which the fuel elements would be steam blanketed and an adiabatic phase would occur. Computations indicated that the maximum temperature of a 6-rod Pu-Al element would be $1005 \mathrm{~F}$ at 270 sec.

Injection Phase

The adiabatic phase would end when the injection water reached the fuel elements. In previous cases with top ruptures this time was determined by the rate at which the injection water rises in the process tubes. With a bottom rupture, however, the coolant would reach the fuel elements by first filling the upper ring header and then flowing down the top jumpers onto the fuel elements.

To determine when the injection wate $r$ would fill the top ring header and what the system pressure would be at this time, a stepwise computation was made. The results of this computation indicated that about $7 \mathrm{sec}$ after injection would start, the pressure in the bottom ring header would be 24 psia and the water temperature in the header would be $228 \mathrm{~F}$. Pressure at times after injection would begin are shown in Figure 16.

A computation of the rate of filling the upper ring header and outlet pipe indicated that the emergency coolant starting at $270 \mathrm{sec}$ could spill out the top ring header at 305 sec after the incident. This was based upon the assumption that the valve in the $14-i n$. outlet pipe to the heat exchanger would be closed so that it would not be necessary to first fill the heat exchanger leg of the primary system.

At the time injection could begin the maximum surface temperature at the middle of a 6-rod Pu-Al element was computed to be $1100 \mathrm{~F}$. The machine computations indicated that this temperature would drop $6 \mathrm{~F}$ during the first $5 \mathrm{sec}$ of injection and continue to drop the reafter.

The amount of steam generated during this period was computed to be about 15 times the amount that could flow out the bottom-ring-header leg of the rupture under 


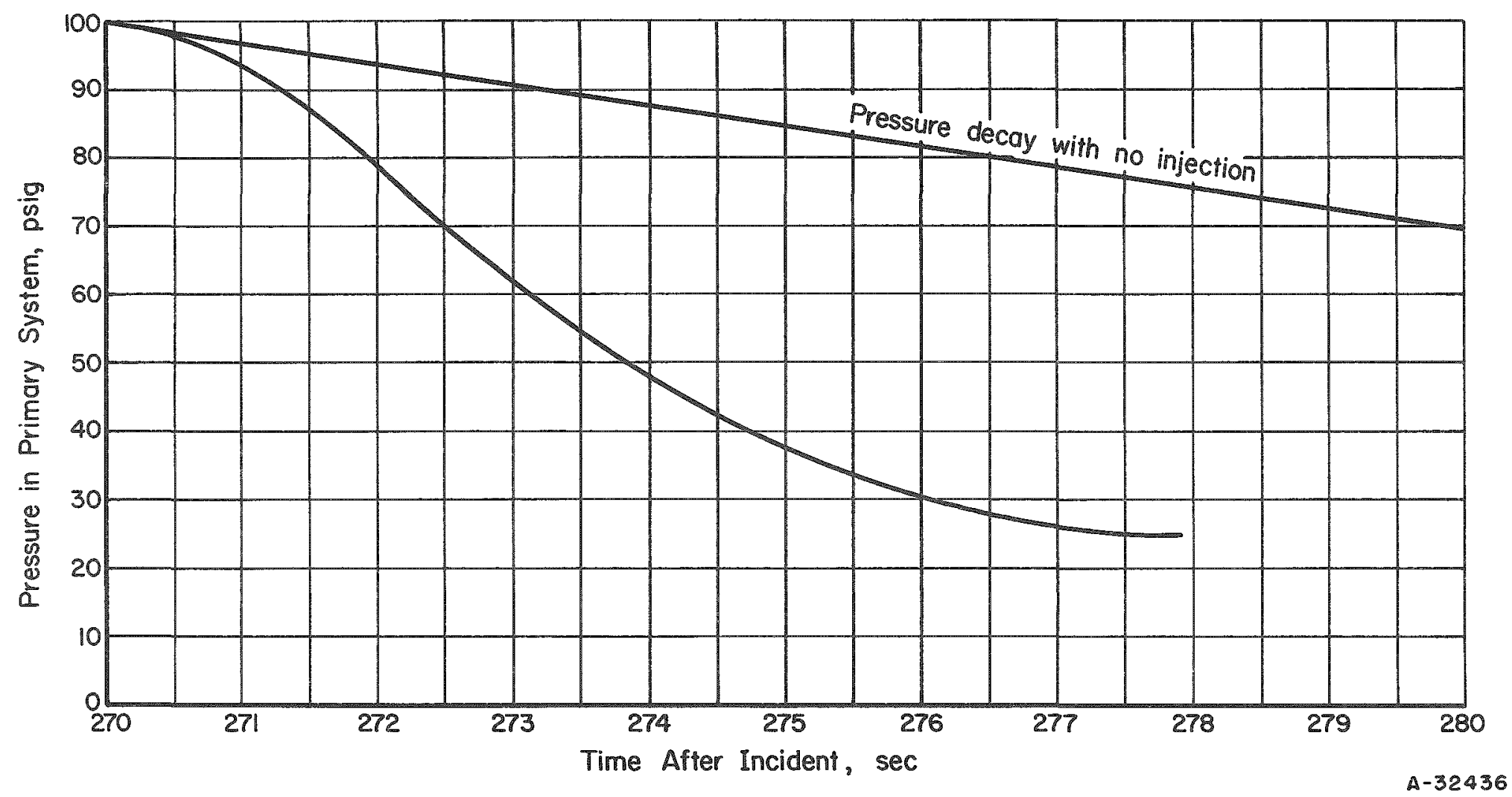

FIGURE 16. PRESSURE DECAY IN BOTTOM RING HEADER UPON INJECTION OF 375-GPM OF 68 F WATER STARTING AT 270 SEC

Case IV. 
critical flow conditions at 100 psig. Since a large pool of $228 \mathrm{~F}$ water would exist in the bottom ring header, an appreciable portion of this steam would condense.

The situation that would appear most likely in the process tubes during top injection would be that injection water would flow downward over the tubes and approximately 65 per cent of the water would be vaporized. With this sudden generation of steam the pressure in the tubes would rise. Since the water in the headers would be at a temperature lower than the saturation temperature of the steam in the tubes, a nonequilibrium state would exist. The steam would condense by coming in contact with the relatively cool water in the headers. Thus the pressure of the steam in the tubes would tend to approach the saturation pressure of the cooler water in the header.

Again, computations showed that cooling of all process tubes would continue so long as emergency coolant was being injected.

\section{CONCLUSIONS AND RECOMMENDATIONS}

By considering several postulated ruptures in the primary coolant system of the PRTR, it was concluded that proper operation of the emergency light water backup cooling system would be sufficient to prevent failure of any fuel elements. Of course, for this conclusion to be valid, proper operation of the reactor scram system must also be assumed. Four cases were considered.

In the first case, that of a complete parting of the 14-in. outlet pipe, it was found that fuel element temperatures would fall during the blowdown phase, rise again during the adiabatic phase, and then fall to a low level after a period of injection. If the injection system did not operate as planned, the $\mathrm{Pu}-\mathrm{Al}$ elements would be expected to $\mathrm{reach}$ the melting point of aluminum at $219 \mathrm{sec}$ after the incident. The $\mathrm{UO}_{2}$ elements would reach the melting point of zirconium at from 850 to $1000 \mathrm{sec}$. Allowance for heat trans fer by radiation would lengthen this latter time but would lead to the prediction of failure of the aluminum shroud tube by reaching its melting point in 710 sec. Conduction through the helium gap might decrease this time to 450 to 500 sec.

Chemical reaction between the water coolant and the fuel element materials, principally zirconium, would not cause difficulties even if the emergency coolant did not reach the fuel elements until 15 min after the incident, when the maximum fuel element temperature would be over $3100 \mathrm{~F}$. Reaction rates 5 times higher than those which would be predicted from experimental data would not change this conclusion materially.

The second case, postulated as that of a 14-in.-diameter hole in the outlet pipe, was found to be similar to the first case. The only measurable difference was the slightly less cooling effected of the $\mathrm{UO}_{2}$ elements during the blowdown phase. This would serve to decrease the time to melting for the Zircaloy-clad UO 2 elements by about $100 \mathrm{sec}$.

The third case was postulated as a top jumper break and the fourth as a bottom jumper break. These two cases were similar in two respects. First, blowdown was slow. Second, an adiabatic period occurred because injection shortly after the core would become uncovered, as in the first cases, would be prevented by failure of the 
pressure to drop below 100 psig, the limiting pressure on the safety water injection pumps. Injection of safety water by the planned system would be sufficient to cool the elements initially and to keep them cool as long as it was in operation.

As a means of insuring adequate cooling for small ruptures an injection system capable of higher pressure injection would be recommended.

\section{REFERENCES}

(1) Wittenbrock, N.G., "Plutonium Recycle Test Reactor, Preliminary Safeguards Analysis", HW-48800 REV (June, 1958).

(2) Wittenbrock, N. G., private communication.

(3) Reginbal, J. J., "Effect of Moderator Height on Reactivity and Vertical Flux Dis tribution in PRTR", HW-59373 (March, 1959).

(4) Ambrose, T. W., "Water Loss Rate Following a Piping Failure in the Plutonium Recycle Test Reactor", HW-60654 (June, 1959).

(5) McAdams, W. H. Heat Transmission, Third Edition, McGraw-Hill Book Co., Inc., New York (1954), p 219.

(6) Bonilla, C. F., Nuclear Engineering, McGraw-Hill Book Co., Inc, New York $(1957), \mathrm{p} 400$.

(7) Lemmon, A. W., Jr., "Studies Relating to the Reaction Between Zirconium and Water at High Temperatures", BMI-1154 (January 3, 1957).

(8) Swartz, L. M. (Bettis Plant), and Lemmon, A. W., Jr., and Hulbert, L. E. (Battelle Memorial Institute), "PWR Loss of Coolant Accident-Core Meltdown Calculations", WAPD-SC-544 (May, 1957).

AW L:CAA:LEH:RBF/mmk 
APPENDIX A

PHYSICAL AND THERMODYNAMIC PROPERTIES OF REACTOR MATERIALS 


\section{APPENDIX A}

\section{PHYSICAL AND THERMODYNAMIC PROPERTIES OF REACTOR MATERIALS}

In performing the analysis on the reactor, certain physical properties of the reactor materials were needed as functions of temperature. The properties needed have been tabulated in this appendix:

Table A-1, Thermal Conductivity

Table A-2, Density

Table A-3, Specific Heat

Table A-4, Is othermal Heat of Reaction

Since no thermal conductivity data for Pu-A1 were available, the thermal conductivity of aluminum was used. A literature search indicated that there was no reliable data for thermal conductivity of aluminum at temperatures approaching the melting point, and even at lower temperatures large discrepancies exist between values reported by different investigators. The thermal conductivity used in this analysis was based on the most recent low-temperature values as reported in $A E C D-3647 \%$ and on values at higher temperatures computed from the electrical conductivity by the WiedemannFranz ratio. Values of electrical conductivity were compiled in WADC Technical Report 58-476. A smooth curve drawn through the low-temperature measurements extrapolated. nicely to the high-temperature values computed from electrical conductivity. $*$ \%\%

The densities of solids at room temperatures were employed since density changes of solids are relatively small.

For the condition of molten Pu-Al it was considered that the Zircaloy -2 jacket would fail at the aluminum melting point through the reaction of zirconium with excess aluminum. No kinetic data on this reaction were available, but from an examination of the zirconium-aluminum phase diagram it appears that the se metals are not compatible at a temperature much above the melting point of aluminum.

Specific heat data for $\mathrm{H}_{2}, \mathrm{H}_{2} \mathrm{O}, \mathrm{UO}_{2}$, and Zircaloy-2 were obtained from the data of Kelley, U. S. Bureau of Mines, Bulletin 476. The molar specific heat of $\mathrm{D}_{2}$ was taken to be the same as $\mathrm{H}_{2}$. The thermal properties of $\mathrm{D}_{2} \mathrm{O}$ were considered to be equal to those of $\mathrm{H}_{2} \mathrm{O}$ on a pound basis and thus differed by about 10 per cent on the $1 \mathrm{~b}-\mathrm{mole}$ basis used in the computation.

\footnotetext{
Reactor Handbook, Vol. 3, "General Properties of Materials", AECD 3647 . McGraw wHill Book Company, Inc., New York (1955). Subsequent to performing the calculations and preparing this report, it was brought to the authors' attention that room temperature (about 15 C) measurements of themal conductivity of plutonium aluminum alloys had been made and reported by Gibney, R. B., and Sandenan, T. A. "Preliminary Report on Thermal and Electrical Conductivities of Some Plutonium -Aluminum Alloys". LAMS-1080 (1950). Predictions based on these data indicate that the thermal conductivity values used in these calo culations for the plutonium-aluminum alloy (about 2 a/o plutonium) may be as much as 10 per cent high at the lower tempera tures but may have less error at the higher temperatures near the melting point of aluminum. No significant change in the results in this report would be expected from this minor change in the thermal conductivity because steep temperature gradients, meaning a large dependence on the themal conductivity, were not observed in the plutonium-aluminum elements.
} 


$$
A-2
$$

The isothermal heat of reaction had been previously computed and given by Battelle.*

TABLE A-1. THERMAL CONDUCTIVITIES OF SOLIDS

\begin{tabular}{|c|c|c|c|c|}
\hline & & \multicolumn{3}{|c|}{ Thermal Conductivity, Btu/(hr) $\left(\mathrm{ft}^{2}\right)(\mathrm{F} / \mathrm{ft})$} \\
\hline Ter & are & \multirow{2}{*}{$\begin{array}{c}\mathrm{UO}_{2}, \\
95 \text { Per Cent Theoretical } \\
\text { Density (a) }\end{array}$} & \multirow[b]{2}{*}{ Zircaloy-2(b) } & \multirow[b]{2}{*}{$P u-A I(c)$} \\
\hline C & $F$ & & & \\
\hline 20 & 68 & $-\infty$ & 8.44 & 120 \\
\hline 100 & 212 & 5.26 & 8.09 & -- \\
\hline 200 & 392 & 4.68 & 7.98 & 128 \\
\hline 300 & 572 & $-\infty$ & 8.03 & -- \\
\hline 400 & 752 & 3.70 & 8.15 & 132 \\
\hline 500 & 932 & $-\infty$ & 8.17 & -- \\
\hline 600 & 1112 & 2.89 & 8.26 & 128 \\
\hline 700 & 1292 & $=$ & 8.35 & $=$ \\
\hline 800 & 1472 & 2.25 & 8.5 & $-\infty$ \\
\hline 1000 & 1832 & 1.79 & 8.7 & \\
\hline 1200 & 2192 & 1.39 & 8.9 & \\
\hline 1400 & 2552 & 1.10 & 9.1 & \\
\hline 1600 & 2912 & 0.867 & 9.3 & \\
\hline 1800 & 3272 & 0.694 & 9.5 & \\
\hline 2000 & 3632 & 0.520 & 9.8 & \\
\hline 2200 & 3992 & 0.405 & $=$ & \\
\hline
\end{tabular}

(a) Vasilos, MIT, unpubliahed work.

(b) H. Deem, Battelle.

(c) Assumed equal to thermal conductivity of aluminum. Computed from the Wiedemann-Franz ratio, $K=L \sigma T$. See text.

Swartz, L. M. (Bettis Plant), and Lemmon, A. W.,Jr.. and Hulbert, L. E. (Battelle Memorial Institute), "PWR Loss of Coolant Accident Core Melidown Calculations", WAPD-SCm544 (May, 1957). 
TABLE A-2. DENSITIES OF SOLIDS AT ROOM TEMPERATURE

\begin{tabular}{lll}
\hline Material & Density, 1b/cuft & Source \\
\hline $\mathrm{UO}_{2}$ & $641(95$ per cent theoretical) & J. Am. Ceram. Soc., 37, 108 (1954) \\
Zircaloy-2 & 410 & Nuclear Eng. Handbook, 1958 \\
Pu-Al & $168(100$ per cent aluminum) & Nuclear Eng. Handbook, 1958 \\
\hline
\end{tabular}

TABLE A-3. SPECIFIC HEAT, $C_{p}, B t u /(1 b-m o l e)(F)$

\begin{tabular}{|c|c|c|}
\hline Material & $\begin{array}{l}\text { Expression for Determining } C_{p} \text { in } \\
\text { Btu/(Lb-Mole)(F); } T \text { in Degrees Kelvin }\end{array}$ & $\begin{array}{c}\text { Temperature } \\
\text { Range, } \mathbb{K}\end{array}$ \\
\hline \multicolumn{3}{|c|}{ Solids } \\
\hline $\mathrm{UO}_{2}$ & $C_{p}=19.20+1.62 \times 10^{-3} \mathrm{~T}-3.96 \times 10^{5} \mathrm{~T}^{-2}$ & 298 to 1500 \\
\hline \multirow[t]{2}{*}{ Zircaloy-2 } & $C_{p}=6.83+1.12 \times 10^{-3} \mathrm{~T}-0.87 \times 105 \mathrm{~T}^{-2}$ & 298 to 1135 \\
\hline & $C_{p}=7.27$ & Above 1135 \\
\hline Pu-Al (aluminum) & $C_{p}=4.02+2.203 \times 10^{-3} \mathrm{~T}+2.494 \times 10^{5} \mathrm{~T}^{-2}$ & 298 to 950 \\
\hline $\mathrm{ZrO}_{2}(\alpha)$ & $C_{p}=16.64+1.80 \times 10^{-3} \mathrm{~T}-3.36 \times 10^{5} \mathrm{~T}^{-2}$ & 298 to 1478 \\
\hline $\mathrm{ZrO}_{2}(\beta)$ & $C_{p}=17.80$ & Above 1478 \\
\hline \multicolumn{3}{|c|}{ Gases } \\
\hline $\mathrm{H}_{2}(\mathrm{~g}), \mathrm{D}_{2}(\mathrm{~g})$ & $\mathrm{C}_{\mathrm{p}}=6.52+0.78 \times 10^{-3} \mathrm{~T}+0.12 \times 10^{5} \mathrm{~T}^{-2}$ & 298 to 3000 \\
\hline $\mathrm{H}_{2} \mathrm{O}(\mathrm{g}), \mathrm{D}_{2} \mathrm{O}(\mathrm{g})$ & $C_{p}=7.17+2.56 \times 10^{-3} \mathrm{~T}+0.08 \times 10^{5} \mathrm{~T}^{-2}$ & 298 to 2500 \\
\hline
\end{tabular}


TABLE A-4. ISOTHERMAL HEAT OF REACTION

$$
\mathrm{Zr}(\mathrm{c})+2 \mathrm{H}_{2} \mathrm{O}(\mathrm{g}) \rightarrow \mathrm{ZrO}_{2}(\mathrm{c})+2 \mathrm{H}_{2}(\mathrm{~g})
$$

\begin{tabular}{ll}
\hline Temperature, $K$ & $H_{\mathrm{T}}(\mathrm{a}), \mathrm{cal} / \mathrm{g}$-mole \\
\hline 298 & $-145,900$ \\
600 & $-144,120$ \\
1000 & $-141,880$ \\
$1135\left(\mathrm{Zr}_{\mathrm{r}} \alpha\right)$ & $-141,180$ \\
$1135(\mathrm{Zr} \beta)$ & $-142,130$ \\
1200 & $-141,750$ \\
1300 & $-141,260$ \\
1400 & $-140,720$ \\
$1478\left(\mathrm{ZrO}_{2} \alpha\right)$ & $-140,360$ \\
$1478\left(\mathrm{ZrO}_{2} \beta\right)$ & $-138,910$ \\
1500 & $-138,820$ \\
1600 & $-138,470$ \\
1700 & $-138,160$ \\
1800 & $-137,780$ \\
2000 & $-137,490$ \\
& $-137,180$ \\
\hline \hline
\end{tabular}

Note: The effect of pressure on the $\mathrm{C}_{\mathrm{p}}$ of $\mathrm{H}_{2}$ and $\mathrm{H}_{2} \mathrm{O}$ was neglected but introduces an error of less than $0.5 \%$.

(a) The above data can be approximated within an error of $0.6 \%$ by the following equation:

$$
\mathrm{H}_{\mathrm{T}}=-147.600+5.34 \mathrm{~T}(\mathrm{~T}=\mathrm{K})
$$


APPENDIX B

MATHEMATICAI MODEL AND METHODS

OF MACHINE COMPUTATION 


\section{NOMENCLATURE}

$z=$ the distance from the top of the core, ft

$t=$ time after scram, sec

$T_{a}=T_{a}(z, t)=$ temperature of the fuel element, $F$

$T_{g}=T_{g}(z, t)=$ temperature of the coolant, $F$

$A_{g}=$ cross-sectional area of the coolant channel, $\mathrm{ft}^{2}$

$A=$ cross-sectional area of the fuel element, $f t^{2}$

$\mathrm{D}_{\mathrm{g}}=$ hydraulic diameter of the coolant channel, $\mathrm{ft}$

$\rho C_{p}=\rho C_{p}\left(T_{a}\right)=$ average heat capacity of the fuel element, $B t u /\left(\mathrm{ft}^{3}\right)(\mathrm{F})$

$C_{g}=C_{g}\left(T_{g}\right)=$ heat capacity of the coolant, Btu/(1b-mole $)(F)$

$C_{g}=C_{g}\left(T_{g}\right)=$ heat capacity of stean, $B t u /(1 b-120 l e)(F)$

$C_{H}=C_{H}\left(T_{g}\right)=$ heat capacity of hydrogen, Btu/(1b-mole)(F)

$\rho_{\mathrm{g}}=\rho_{\mathrm{g}}\left(\mathrm{T}_{\mathrm{G}}\right)=$ density of coolant, lb mole pex $\mathrm{ft}^{3}$

$q_{d}=q_{d}(z, t)=$ decay heat generation, Btu/(ft) (Goc)

$y=$ anount of airconium reacted, $1 b$-mole per st 2

$y^{\prime}=y^{\prime}\left(T_{a}, y\right)=$ rate of zirconium $-H_{2} O$ reaction, $1 b-m o l e /\left(f^{2}\right)(s e c)$

$\Delta H_{Y}=\Delta H_{Y}\left(T_{2}\right)=$ heat of reaction, Btu per lb-mole

$q_{x}=q_{x}\left(T_{a}, y\right)=\left(\Delta H_{Y}\right)\left(y^{\circ}\right)=$ xate of reaction heat generation, Btu/(ft' $\left.{ }^{2}\right)($ sec $)$

$\mathrm{k}_{\mathrm{a}}=\mathrm{k}_{\mathrm{a}}\left(\mathrm{T}_{\mathrm{a}}\right)=$ average longitudinal thermal conductivity along the fuel element, $\mathrm{Btu} /(\mathrm{sec})(\mathrm{ft})^{2}(\mathrm{~s} / \mathrm{ft})$

$W_{1}=W_{1}(t) \equiv$ inlet velocity of coolant, lb-mole per sec

$W_{g}=W_{g}\left(W_{i}, T_{2}\right)=$ velocity of coolant, $1 \mathrm{~b}-$ mole per sec

$\mathrm{M}=\mathrm{M}\left(\mathrm{W}_{\mathrm{g}}, \mathrm{y}^{\circ}\right)=$ mole fraction of hydrogen in coolant, moles per mole

$h=$ heat transfer coefficient, fuel element to coolant, $B$ tu $/\left(f t^{2}\right)(\sec )(F)$

$p=2 \pi a=$ perimeter of fuel element, ft 


\title{
APPENDIX B
}

\author{
MATHEMATICAL MODEL AND METHODS \\ OF MACHINE COMPUTATION
}

The physical problem to be investigated was that of finding the conditions on and adjacent to a given fuel element as a function of time and position. The first step in solving such a problem is to construct a mathematical model that corresponds as nearly as possible to the physical system under consideration. Once a model is obtained it must be solved, either by obtaining an analytical solution in closed form or by obtaining an approximate solution by numerical methods. The model that was derived consisted of a set of four highly nonlinear simultaneous differential equations, together with a set of time-dependent boundary conditions. Because of the nonlinearity of the differential equations and the fact that simultaneous solution of four such equations was necessary, it was not possible to obtain an analytical solution adequately describing the physical problem. Thus it was necessary to resort to the use of numerical methods. Each of the differential equations was approximated by a difference equation defined at a finite number of points of the fuel element. The system of difference equations was then translated into a program for a high-speed, automatic, digital computing machine. Solutions were computed for a variety of initial and boundary conditions.

In programming the problem for solution on the computing machine, it was necessary to consider separately the cases for which the fuel element was surrounded by a liquid or gaseous coolant or by no coolant at all. The problem of the fuel element surrounded by a gaseous coolant was the most complex. The other two problems could be considered as modifications of the problem of the gaseous coolant.

Therefore, the problem of the gas-cooled element will be discussed first and then the modifications necessary in order to solve the other two problems will be indicated.

\section{Heat Balance for the Fuel Element}

Figure B-1 illustrates schematically the quantities that pertain to the heat balance of the fuel element. Figure B-la shows conductive and convective heat transfer and Figure $B-1 b$ shows the reaction heat generation and the mass heat transfer by the materials involved in the metal-water reaction.

The mass heat transfer, represented by the quantities $2 p y{ }^{\circ} \mathrm{T}_{\mathrm{g}} \mathrm{C}_{\mathrm{A}} \Delta \mathrm{z}$ and $2 p y^{\prime} T_{a} C_{H} \Delta z$ is dependent on the reaction rate $y^{\prime}$. The reaction rate was given in terms of moles of zirconium reacted per sec. The factor two was needed in the quantities showing mass heat transfer since two moles of steam react with one mole of zirconium to generate two moles of hydrogen in accordance with the equation

$$
2 \mathrm{H}_{2} \mathrm{O}+\mathrm{Zr} \rightarrow 2 \mathrm{rO}_{2}+2 \mathrm{H}_{2}
$$

The heat content of the fuel element at any time is given by $A C_{p} \rho T_{a}$. Equating the rate of change in heat content of the rod with time to the sum of all of the mechanisms of heat transfer given in Figure $B-1$ results in the equation 


$$
\frac{\partial}{\partial t}\left[A C_{p} \rho T_{a}\right]=\frac{\partial}{\partial z}\left[k_{a} \frac{\partial T_{a}}{\partial z}\right]-p h\left(T_{a}-T_{g}\right)+2 p y^{\prime}\left(T_{g} C_{s}-T_{a} C_{H}\right)+A q_{d}+p q_{r^{\circ}}(B-1)
$$

\section{Heat Balance for the Gas Stream}

Figure B-2 illustrates schematically the heat balance for an elemental volume of the gas stream. (The only new quantity involved here is $\mathrm{C}_{\mathrm{g}} \mathrm{W}_{\mathrm{g}} \mathrm{T}_{\mathrm{g}}$ ) The sum of all of the mechanisms of heat transfer shown in Figure B-2 is equal to the rate of change of heat content of the element of gas $\frac{\partial}{\partial t}\left[\mathrm{~A}_{\mathrm{g}} \rho_{\mathrm{g}} \mathrm{C}_{\mathrm{g}} \mathrm{T}_{\mathrm{g}}\right]$ :

$$
\frac{\partial}{\partial t}\left[A_{g} C_{g} \rho_{g} T_{g}\right]=\frac{\partial}{\partial z}\left[C_{g} W_{g} T_{g}\right]+p h\left(T_{a}-T_{g}\right)-2 p y^{\prime}\left(T_{g} C_{s}-T_{a} C_{H}\right),
$$

where

$$
C_{g}=M C_{H}+(1-M) C_{S}
$$

(It is seen from this equation that $\mathrm{C}_{\mathrm{g}}$ is a function of both the temperature and the composition of the gas coolant.)

\section{Material Balance for the Gas Stream}

The material balance for the gas stream is specified by two equations. The first, relating composition and reaction rate, is

$$
\frac{\partial}{\partial t}\left[A_{g} M_{g} \rho_{g}\right]=2 p y^{\circ}-\frac{\partial}{\partial z}\left[W_{g} M\right]
$$

The second, relating density change and velocity, is

$$
A_{g} \frac{\partial \rho_{g}}{\partial t}=-\frac{\partial w_{g}}{\partial t} \text {. }
$$

Quantities such as $\rho_{\mathrm{g}}$ and $\mathrm{W}_{\mathrm{g}}$ are given in $\mathrm{lb}-$ mole units. Since, as a result of the metalwater reaction, a mole of steam is replaced by a mole of hydrogen gas, the reaction has no effect on the molar density. equations:

It can be shown that these equations can be transformed into the following

$$
\begin{gathered}
{\left[T_{a} \frac{\partial\left[C_{p} \rho\right]}{\partial T_{a}}+C_{p} \rho\right] \frac{\partial T_{a}}{\partial t}=\frac{\partial}{\partial z}\left[k_{a} \frac{\partial T_{a}}{\partial z}\right]+A q d-p h\left(T_{a}-T_{g}\right)} \\
+2 p y^{\prime}\left(T_{g} C_{s}-T_{a} C_{H}\right) .
\end{gathered}
$$




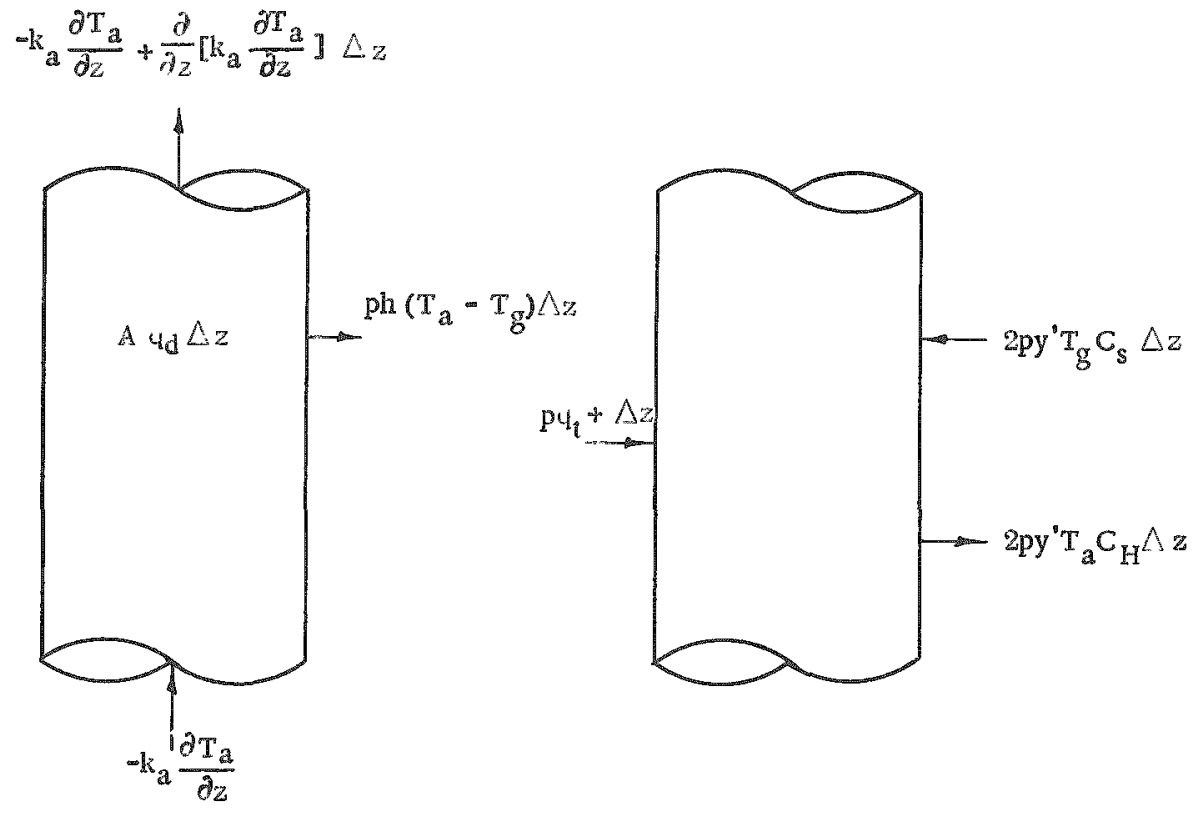

a. Conductive and convective heat transfer. b. Reaction heat generation and mass heat transfer.

FIGURE B-1. SCHEMATIC OF HEAT BALANCE AROUND FUEL ELEMENT

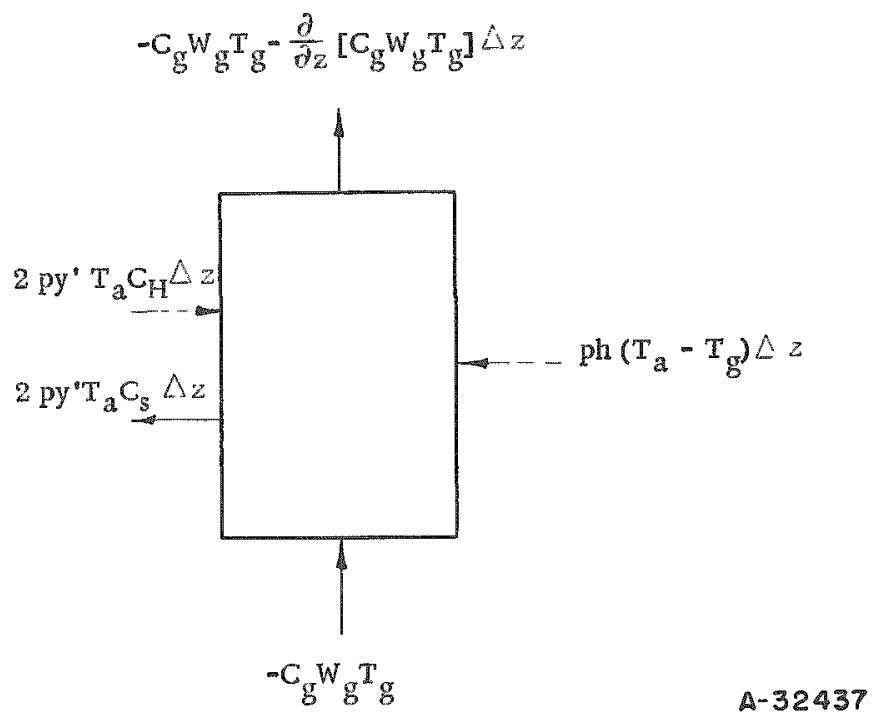

FIGURE B-2. SCHEMATIC OF HEAT BALANCE FOR GAS STREAM 


$$
\psi A_{g} \rho_{g} \frac{\partial T_{g}}{\partial t}=\rho\left(T_{a}-T_{g}\right)\left(h+2 y^{\prime} C_{H}\right)-W_{g} \psi \frac{\partial T_{g}}{\partial z}
$$

where $\psi$ is given by

$$
\begin{aligned}
& \psi\left(T_{g}, M\right)=(1-M)\left(C_{S}+T_{g} \frac{\partial C_{s}}{\partial T_{g}}\right)+M\left(C_{H}+T_{g} \frac{\partial C_{H}}{\partial T_{g}}\right) \\
& A_{g} \rho_{g} \frac{\partial M}{\partial t}=2 p y^{\prime}-W_{g} \frac{\partial M}{\partial z} \text {. } \\
& \frac{\partial W_{\mathbf{g}}}{\partial \mathbf{z}}=-\mathrm{A}_{\mathbf{g}} \frac{\partial \rho_{\mathbf{g}}}{\partial \mathrm{T}_{\mathbf{g}}} \frac{\partial \mathrm{T}_{\mathbf{g}}}{\partial \mathrm{t}} \text {. }
\end{aligned}
$$

It was known from experience with similar sets of equations that because of the extremely small values of $\mathrm{Ag}_{\mathrm{g}} \rho_{\mathrm{g}}$, the values of $\mathrm{T}_{\mathrm{g}}$ and $\mathrm{M}$ fluctuated widely in a machine calculation unless $\Delta t$ was kept impossibly small. This difficulty was circumvented by assuming $\mathrm{Ag}_{\mathrm{g}} \rho_{\mathrm{g}}$ to be zero in Equations $(\mathrm{B}-6)$ and $(\mathrm{B}-7)$, which resulted in two approximate equations:

$$
\begin{gathered}
W_{g} \psi \frac{\partial T_{g}}{\partial z}=p\left(T_{a}-T_{g}\right)\left(h+2 y^{\prime} C_{H}\right) \\
W_{g} \frac{\partial M}{\partial t}=2 p y^{\prime} .
\end{gathered}
$$

Equations $(B-6),(B-9),(B-10)$, and $(B-11)$ can be considered as four simultaneous differential equations in the four unknowns $T_{a}, T_{g}, M$, and $W_{g}$. As will be shown, the other quantities are either known constants or can be expressed as functions of these four variables. (It is assumed that $q_{d}(z, t)$, which is an independent quantity, is known for all $z$ and $t$.

Since the system of differential equations was highly nonlinear and complicated, it was decided that a numerical solution would be more feasible than an analytic solution. Consequently, the four equations were replaced by difference equations.

In converting differential equations to difference equations, each space and time derivative was replaced by a corresponding difference. For instance, $\frac{\partial T_{a}}{\partial t}$ was replaced by $\frac{T_{a}(z, t+\Delta t)-T_{a}(z, t)}{\Delta t}$, where $\Delta t$ was some small but finite time interval. The interval in length was chosen to be $1 / 29$ of the length of the element, and the temperatures, velocities, etc., were evaluated at 30 points of the fuel element and coolant channels. The number of points chosen was a compromise between the requirements of economy and accuracy. The resulting difference equations will be discussed later. 
To complete the statement of the problem, a number of boundary conditions must be specified. The initial values of the four unknowns, $\mathrm{T}_{\mathrm{a}}, \mathrm{T}, \mathrm{W}, \mathrm{g}$, and $\mathrm{M}$, must be given at each point of the element at the initial time, and the values of $\mathrm{T}_{\mathrm{g}}, \mathrm{W}_{\mathrm{g}}$, and $\mathrm{M}$ at the inlet point of the coolant channel must be given for all times. In addition, a condition must be imposed on the value of $\mathrm{T}_{\mathrm{a}}$ at the ends of the fuel element. In the cases for which there is coolant passing the ends, some heat will be lost through these ends. The amount of heat transferred will depend on the velocity and kind of coolant. In the adiabatic case a small amount of heat may be lost from the ends by radiation to cooler portions of the reactor. However, such losses were neglected, and the ends of the fuel element were as sumed to be insulated in the adiabatic case.

An approximate method of taking these end conditions into account was constructed in the following way.

Thirty equally spaced points were maxked off along the fuel element in such a way that the first and last points were at the ends of the element. Then the element was divided into sections in such a way that each point except the two end points was in the middle of its section (see Figure $\mathrm{B}-3$ ). The points I and 30 were associated with sections of the actual rod only one half as large as the sections associated with interior points. A "fictitious" half-interval of zero heat capacity and zero heat generation was
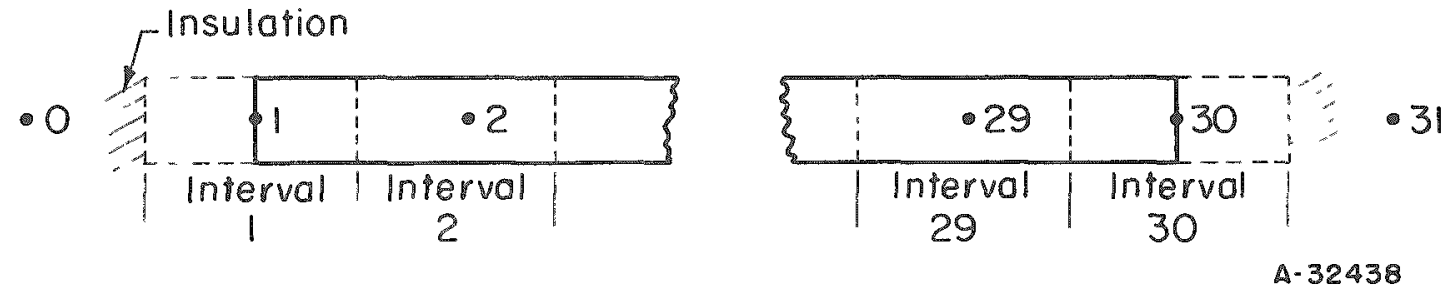

\section{FIGURE B-3. SCHEMATIC DIAGRAM OF THE LOCATION OF REFERENCE POINTS ALONG TIIE FUEL ELEMENT}

then added to each end of the rod. The ends of these extensions we re considered to be insulated $\left(\frac{\partial T_{a}}{\partial z}=0\right)$. In this way, the machine program for the two end sections was identical with the program for the other 28 sections with the exceptions that the heat capacity and heat generation of the end sections were halved and the outside end of each end section was insulated. The condition of no heat conduction through the ends was satisfied by requiring that at the fictitious points $z_{0}$ and $z_{31}, T_{a}\left(z_{0}, t\right)=T_{a}\left(z_{1}, t\right)$ and $\mathrm{T}_{\mathrm{a}}\left(\mathrm{z}_{31}, t\right)=\mathrm{T}_{\mathrm{a}}\left(\mathrm{z}_{30}, t\right)$

The solution of the problem was carried out numerically on the IBM 650 Electronic Computer. Beginning at the point $z=0, t=0$ and moving stepwise along the element, the values of the parameters were computed for each section at the time $t_{1}=0+\Delta t_{\text {. }}$ When the last point of the element was reached, all of the necessary data had been computed and stored for the calculation of the parameters at the end of the second time increment, and the calculation began again at the point $z=0, t=0+\Delta t$. By repeating this operation a sufficient number of times, the conditions at any point of the element at any time could be calculated. 
Some method had to be used in specifying the size of $\Delta t$ in going from one time interval to the next. Instead of choosing $\Delta t$ constant over the entire time of a calculation, a subroutine was written into the machine computation that automatically selected the time interval so that the largest change in the values of $T_{a}$ at any point of the element during one time interval was $30 \mathrm{~F}$. (Of course, the same time increment had to be used for every point of the element for any one time interval.) Thus, during periods of time when the temperatures of the element were varying rapidly, the time intervals were small, and when the temperatures were varying slowly, the time intervals were larger. Allowing the computer to choose the time interval at each step of the calculation resulted in a more efficient program. It was found duxing the operation of the program that this method of choosing the time interval also had the power to restabilize the calculation if some abrupt change of conditions had to be introduced into the problem during the course of the calculation.

All of the conditions necessary for writing the machine program for the case of the gas-cooled element have now been developed, and the other cases will now be considered. As will be shown later, the se may all be considered as special cases of the problem of the gas-cooled element.

\section{Injection of Liquid Coolant}

If all or part of the fuel element was surrounded by liquid, the program for the gas-cooled element had to be modified to use the correct metal-to-liquid heat transfer coefficient and to provide for the larger heat capacity of the liquid.

If the core was only partially covered with liquid, it was necessary to determine the position of the interface between the liquid and vapor phases and to use the heat transfer and heat capacity relations appropriate to each phase. In the machine program, completely different techniques had to be used for locating this interface, depending on whether the coolant was injected into the top or the bottom of the core.

\section{Top Injection}

If the re was a bottom break and liquid coolant was injected into the top of the core, it was assumed that the liquid would run rapidly down each element until it had all been evaporated. In this case, the entire fuel element could be liquid cooled before the core has been filled. The liquid-vapor interface is at the point where enough heat has been supplied to the liquid to overcome its latent heat.

It was decided to account for the latent heat by specifying a fictitious inlet tem perature, $T_{g i}$, for the injected coolant. This can be written as:

$$
\Delta \mathrm{H}_{\mathrm{W}}=\psi * \int_{\mathrm{T}_{\mathrm{gi}}}^{\mathrm{T}_{\mathrm{g}} *} \mathrm{~d} \mathrm{~T}_{\mathrm{g}}=\psi *\left(\mathrm{~T}_{\mathrm{g}} *, 0\right)\left(\mathrm{T}_{\mathrm{g}} *-\mathrm{T}_{\mathrm{gi}}\right)
$$


or

$$
\mathrm{T}_{\mathrm{gi}}=\mathrm{T}_{\mathrm{g}^{*}}-\frac{\Delta \mathrm{H}_{\mathrm{w}}}{\psi *\left(\mathrm{~T}_{\mathrm{g}}{ }^{*}, 0\right)},
$$

where $\mathrm{T}_{\mathrm{g}}$ is the boiling point of the coolant, $\psi *\left(\mathrm{~T}_{\mathrm{g}} *, 0\right)$ is the specific heat function given in Equation $(B-7)$ evaluated at the boiling point temperature for pure coolant vapor, and $\Delta H_{\mathrm{W}}$ is the latent heat of the coolant at the inlet temperature.

In the region where the coolant was liquid, Equations $(B-6)$ and $(B-10)$ were replaced by

$$
\begin{aligned}
& {\left[T_{a} \frac{\partial C_{p} \rho}{\partial T_{a}}+C_{p} \rho\right] \frac{\partial T_{a}}{\partial t}=\frac{\partial}{\partial z}\left[k_{a} \frac{\partial T_{a}}{\partial z}\right]+A q_{d}-p h_{w}\left(T_{a}-T_{g^{*}}\right)} \\
& -2 p y^{\circ}\left(T_{g} * C_{S}-T_{a} C_{H}\right)
\end{aligned}
$$

and

$$
w_{g} \psi * \frac{\partial T_{g}}{\partial z}=p\left(T_{a}-T_{g} *\right)\left(h_{w}+2 y^{\prime} C_{H}\right)
$$

where $h_{w}$ is the heat-transfer coefficient between the element and the liquid coolant.

As these equations imply, for all heat transfer between the element and the liquid phase it was assumed that the coolant was at the boiling point. The enthalpy of the coolant was traced through Equation $\left(B-7 \%\right.$. At the inlet point $T_{g}$ was set equal to $T_{g i}$ • When $T_{g}$, as determined by Equation $(B-7 \%$, became greater than the boiling -point temperature, it was assumed that all of the liquid was evaporated. The machine program reverted then to the original equations for the gaseous coolant. Thus, by using a fictitious temperature to monitor the enthalpy of the coolant, it was relatively easy to make the proper program modifications for this case.

\section{Bottom Injection}

For a top break and injection of the coolant into the bottom of the core, it was necessary to use a different method to determine the liquid-vapor interface.

Consider a situation in which coolant has been introduced into the bottom of the core and partially covers the core. The heat lost from that part of the core covered by liquid would be used to evaporate the liquid, while heat lost from the core above the interface would go to heat the vapor thus formed.

In this case, it was possible to determine the location of the liquid-vapor interface directly. If the location of the liquid-vapor interface is known at time $t$, the rate at which vapor is generated at time $t$ is found by dividing the rate at which heat is trans ferred from the core to the liquid phase of the coolant by the latent heat of vaporization of the coolant. The rate at which the liquid rises in the core is found by subtracting the rate of vaporization from the known rate of injection of the coolant. Thus we can write: 


$$
\left(\frac{d L}{d t}\right)_{t=t_{1}}=\frac{W_{g}}{\rho_{W} A_{g}}-\frac{p h_{W}}{\rho_{W} A_{g} \Delta H_{W}} \int_{0}^{z^{2} L}\left[T_{a}\left(z, t_{1}\right)-T_{g}\left(z, t_{I}\right)\right] d z
$$

where $\rho_{\mathrm{w}}$ is the liquid coolant density in $\mathrm{lb}-$ moles per $\mathrm{ft}^{3}, \Delta \mathrm{H}_{\mathrm{w}}$ is the latent heat of vaporization of the coolant in terms of $B$ tu per $1 b-m o l e$, and $z_{L}$ is the position of the interface at time $t$. Integration of this rate from the time at which coolant was injected into the core to time $t$ gave the position of the interface at time $t$.

Once again Equation ( $\mathrm{B}-6)$ was used for element temperatures below the interface: $h_{w}$ was in this case a stagnant-boiling heat-transfer coefficient. It was assumed that the liquid was at the boiling point below the interface. Equation $\left(B-7^{\prime}\right)$ was not used. The rate of heat transfer at each point below the interface was given by the expression $\mathrm{ph}_{\mathrm{w}}\left(\mathrm{T}_{\mathrm{a}}-\mathrm{T}_{\mathrm{g}} \%\right)$ in Equation $(\mathrm{B}-6 \%$

Above the interface, the original system of equations was valid for the gas phase. The gas velocity at the first point above the intexface was taken to be the rate at which the coolant was vaporized by the immersed part of the core.

This program could also be used for the case in which the core was partially covered by stagnant liquid simply by setting the injection rate to zero.

\section{The Adiabatic Case}

For the case in which the fuel elements wexe surrounded by stagnant gas, it was assumed that no heat transfer and an insignificant amount of reaction could occur. Then we have immediately instead of Equations $(B-6),(B-9),(B-10)$, and $(B-11)$ only the relation

$$
\left\{\mathrm{T}_{\mathrm{a}} \frac{\partial\left[\mathrm{C}_{\mathrm{p} \rho]}\right.}{\partial \mathrm{T}_{\mathrm{a}}}+\mathrm{C}_{\mathrm{p}} \rho\right\} \frac{\partial \mathrm{T}_{\mathrm{a}}}{\partial \mathrm{t}}=\frac{\partial}{\partial z}\left[\mathrm{k}_{\mathrm{a}} \frac{\partial \mathrm{T}_{\mathrm{a}}}{\partial \mathrm{z}}\right]+\mathrm{q}_{\mathrm{d}}
$$

This equation, with appropriate initial and boundary conditions, constituted the mathematical model of the adiabatic problem.

\section{$\underline{\text { Detailed Equations }}$}

It was shown above that four basic nonlinear differential equations were needed to determine the temperature excursion of the reactor core when coolant is flowing through the core. For the adiabatic case only the equation for the heat balance of the rod was needed.

In developing the program, the basic problem was considered to be the case in which the reactor element was cooled by a gas flowing past it, with reaction occurring between the element and the gas. The other problems discussed above could be considered as variations of this case. Therefore, we will consider first the gas-cooled element and then indicate the changes needed to calculate the other cases. 
The Gas-Cooled Element

For this case, the four differential equations $(B-6),(B-9),(B-10)$, and $(B-11)$ were used. These were approximated by difference equations which were then rearranged to give the following equations:

$$
\begin{aligned}
T_{a}\left(z_{o}, t_{1}\right) & =\Delta t\left\{A\left(T_{a} \frac{\partial\left[C_{p} \rho\right]}{\partial T_{a}}\right)+C_{p} \rho\right\}^{-1}\left\{A R\left(z_{1}, t_{o}\right)-A R\left(z_{o}, t_{o}\right)+p q_{r}\right. \\
& -p h\left[T_{a}\left(z_{o}, t_{0}\right)-T_{g}\left(z_{0}, t_{0}\right)\right]+2 p y^{\prime}\left[T_{a}\left(z_{o}, t_{o}\right) C_{s}-T_{g}\left(z_{0}, t_{o}\right) C_{H}\right] \\
& \left.+q\left(z_{0}, t_{0}\right)\right\}+T_{a}\left(z_{0}, t_{0}\right),
\end{aligned}
$$

where

$$
\begin{gathered}
R\left(z_{i}, t_{0}\right)=\frac{k_{a}\left(z_{i}, t_{0}\right)}{(\Delta z)^{2}}\left[T_{a}\left(z_{i}, t_{0}\right)-T_{a}\left(z_{i-1}, t_{0}\right)\right] \\
T_{g}\left(z_{0}, t_{1}\right)=\left[S_{1} T_{a}\left(z_{0}, t_{1}\right)+S_{2} T_{g}\left(z_{-1}, t_{1}\right)\right] /\left(S_{1}+S_{2}\right)
\end{gathered}
$$

where

$$
\begin{gathered}
s_{1}=p h_{1}+2 p y^{\prime} C_{H} \\
s_{2}=w_{g}\left(z_{0}, t_{0}\right) \psi / \Delta z \\
M\left(z_{0}, t_{1}\right)=M\left(z_{-1}, t_{1}\right)+2 p y^{\prime} \Delta z / W_{g}\left(z_{0}, t_{0}\right)
\end{gathered}
$$

and

$$
W_{g}\left(z_{0}, t_{1}\right)=W_{g}\left(z_{-1}, t_{0}\right)-\frac{\Delta z}{\Delta t} \mathbb{A}_{g} \frac{\partial \rho_{g}}{\partial T_{g}}\left[T_{a}\left(z_{0}, t_{0}\right)-T_{g}\left(z_{0}, t_{0}\right)\right] .
$$

In these equations, the point $\left(z_{0}, t_{0}\right)$ is some arbitrary point in the space-time plane, and we define $z_{-1}=z_{0}-\Delta z, z_{1}=z_{0}+\Delta z, t_{1}=t_{0}+\Delta t$. For simplicity, the arguments of a number of functions have been omitted. In such cases, the particular function is to be evaluated at the point $\left(z_{0}, t_{0}\right)$.

These four equations may be considered as four equations in the four unknowns, $T_{a}\left(z_{0}, t_{1}\right), T_{g}\left(z_{0}, t_{1}\right), M\left(z_{0}, t_{1}\right)$ and $W_{g}\left(z_{0}, t_{1}\right)$. Excluding these unknown quantities and the power generation $q_{d}\left(z_{0}, t_{0}\right)$, which is as sumed completely specified at every point of the zt-plane, the remaining quantities are either geometrical constants, such as $\Delta z, A$, and $\mathrm{A}_{\mathrm{g}}$, depending only on the reactor geometry or are properties of the component materials that may be defined in terms of the four unknowns at an appropriate point. The material properties may be properties of the coolant vapor or properties of the reactor element, as described in the sections that follow. 
Material Properties of the Coolant. In all of the calculations discussed in this report, the coolant was light as well as heavy water and their mixtures. As an example, the coolant properties will be evaluated here for light water. The coolant properties that appear in Equations $(B-13)$ through $(B-16)$ are $C_{S}, C_{H}, h, \frac{\partial \rho g}{\partial T_{g}}$, and $\psi\left(T_{g}, M\right)$.

The relations for $C_{S}$ and $C_{H}$ are given in Appendix $A$ as

$$
C_{s}=7.17+1.422 \times 10^{-3} \mathrm{~T}_{\mathrm{ga}}+2.59 \times 10^{4} \mathrm{~T}_{\mathrm{ga}}{ }^{-2}
$$

and

$$
\mathrm{C}_{\mathrm{H}}=6.52 \times 0.433 \times 10^{-3} \mathrm{~T}_{\mathrm{ga}}+3.89 \times 10^{4} \mathrm{~T}_{\mathrm{ga}}{ }^{-2},
$$

where $\mathrm{T}_{\mathrm{ga}}$ is the absolute steam temperature in degrees Rankine.

The standard Dittus-Boelter equation was used for the heat-transfer coefficient:

$$
\frac{\mathrm{h} \mathrm{D}}{\mathrm{k}_{\mathrm{g}}}=(0.76)(0.023)\left(\frac{\mathrm{D}_{\mathrm{g}} W_{\mathrm{g}}}{\mathrm{A}_{\mathrm{g}} \mu_{\mathrm{g}}}\right)^{0.8}\left(\frac{\mathrm{C}_{\mathrm{g}} \mu_{\mathrm{g}}}{\mathrm{k}_{\mathrm{g}}}\right)^{0.4},
$$

where $\mathrm{k}_{\mathrm{g}}$ is the thermal conductivity of the gas in $\mathrm{Btu} /(\mathrm{ft})(\mathrm{F})(\mathrm{sec})$, and $\mu_{\mathrm{g}}$ is the gas viscosity in $\mathrm{ft}-\mathrm{sec}$ per $\mathrm{lb}$-mole. The factor 0.76 was introduced because of the noncircular cross section of the coolant passages.

Rearranging this equation, we obtain

$$
\mathrm{h}=(0.76)(0.023) \mathrm{W}_{\mathrm{g}}^{0.8} \mathrm{C}_{\mathrm{g}}^{0.4} \mathrm{~A}_{\mathrm{g}}{ }^{-0.8} \mathrm{D}_{\mathrm{g}}{ }^{0.2}\left(\frac{\mu_{\mathrm{g}}^{0.4}}{\mathrm{k}_{\mathrm{g}} 0.6}\right) .
$$

If the fuel element becomes hot enough that there is a significant chemical reaction between the element and the steam, the coolant will become a mixture of steam and hydrogen. It is then necessary to determine the values of $\mu_{\mathrm{g}}, \mathrm{k}_{\mathrm{g}}$, and $\mathrm{C}_{\mathrm{g}}$ for this mixture. For the specific heat, $\mathrm{C}_{\mathrm{g}}$, it was felt that a linear correlation was sufficiently accurate:

$$
C_{g}=M C_{H}+(1-M) C_{S},
$$

where $C_{S}$ and $C_{H}$ are given by Equations $(B-17)$ and $(B-18)$.

The values of $\mu_{\mathrm{g}}$ and $\mathrm{k}_{\mathrm{g}}$, were obtained by using reduced temperatures, viscosities, and conductivities. The "reduced temperature" of a gas is found by dividing the absolute temperature by the absolute temperature of the gas at its critical point. The other reduced values are found similarly. A relation between the ratio $\mathrm{kg}_{\mathrm{g}} 0.6 / \mu_{\mathrm{g}} 0.4$ and $\mathrm{M}$ and $\mathrm{Tg}$ was derived from known correlations. Denoting the reduced temperature, the rmal. conductivity and viscosity of the mixture by $T_{Y}, k_{r}$, and $\mu_{Y}$, respectively, and the critical values of the thermal conductivity and vis cosity of the mixture by $k_{c}$ and $\mu_{c}$, the following correlations were obtained:

$$
T_{I}=\frac{T_{g a}}{1165.14-1105.38 M}
$$




$$
\begin{aligned}
& \frac{k_{x}^{0.6}}{\mu_{r} 0.4}=\frac{-0.10532+2.7204 T_{r}+0.17840 T_{r}{ }^{2}}{1+2.5283 T_{r}+0.07153 T_{r}{ }^{2}} \\
& \frac{k_{c}^{0.6}}{\mu_{c}^{0.4}}=1.6123-0.25277 M-0.12494 M^{2}
\end{aligned}
$$

and

$$
\frac{k_{g} 0.6}{\mu_{g} 0.4}=\frac{k_{c}^{0.6}}{\mu_{c} 0.4} \cdot \frac{k_{r}^{0.6}}{\mu_{r} 0.4}
$$

Thus, if the values of $\mathrm{M}$ and $\mathrm{T}_{\mathrm{g}}$ are known at any point, the ratio $\mathrm{k}_{\mathrm{g}} 0.6 / \mu_{\mathrm{g}}{ }^{0.4}$ can be determined. Substituting this ratio into Equation $(B-19)$, together with the value of $C_{g}$ determined by Equations $(B-17),(B-18)$, and $(B-20)$ and the known values of $W_{g}, A_{g}$, and $\mathrm{Dg}$, then gives the value of $\mathrm{h}$.

The quantity $\frac{\partial \rho_{\mathrm{g}}}{\partial \mathrm{T}_{\mathrm{g}}}$ was obtained from the ideal gas law. If we assume a pressure of 50 psia and express $\rho g$ in $\mathrm{lb}-$ moles per $\mathrm{ft}^{3}$,

$$
\frac{\partial \rho_{\mathrm{g}}}{\partial \mathrm{T}_{\mathrm{g}}}=-4.66 \mathrm{~T}_{\mathrm{g}}^{-2}
$$

The variation of this quantity with pressure was neglected since the only place that the quantity appears is in Equation $(B-15)$ for $W_{g}$. Past experience had shown that the contribution of this term to a variation in $W_{g}$ was negligible over the range of pressure involved when there was gaseous coolant present in the reactor.

The quantity $\psi\left(\mathrm{T}_{\mathrm{g}}, \mathrm{M}\right)$ was defined in Equation $(\mathrm{B}-9)$ as

$$
\psi\left(T_{g}, M\right)=(1-M)\left(C_{s}+T_{g} \frac{\partial C_{s}}{\partial T_{g}}\right)+M\left(C_{H}+T_{g} \frac{\partial C_{H}}{\partial T_{g}}\right)
$$

Substitution of Equations $(B-17)$ and $(B-18)$ into this expression gives:

$$
\begin{aligned}
\psi\left(\mathrm{T}_{\mathrm{g}}, \mathrm{M}\right) & =6.52+2.844 \times 10^{-3} \mathrm{~T}_{\mathrm{ga}}-2.59 \times 10^{4}\left(\mathrm{~T}_{\mathrm{g}}-459.688\right) \mathrm{T}_{\mathrm{ga}}{ }^{-3} \\
& -\mathrm{M}\left[0.20+1.978 \times 10^{-3} \mathrm{~T}_{\mathrm{ga}}+1.30 \times 10^{4}\left(\mathrm{~T}_{\mathrm{g}}-459.688\right) \mathrm{T}_{\mathrm{ga}}{ }^{-3}\right]
\end{aligned}
$$

Equations $(B-17)$ through $(B-26)$ define a11 of the properties of the gaseous coolant in terms of the unknowns and the geometrical parameters. The liquid coolant properties are considered later. 
Material Properties of the Fuel Element. The quantities appearing in Equations $(B - 1 3 \longdiv { \text { through } ( B - 1 6 ) }$ that depend on the composition of the fuel element are the longim tudinal the rmal conductivity $k$, the heat capacity expression $T_{a} \frac{\partial\left[C_{p} \rho\right]}{\partial T_{a}}+C_{p} \rho$, the reaction heat generation $q_{r}$, and the reaction rate $y^{\prime}$.

Three basically different elements were considered in this study. However, two of these, the standard cylindrical element and the concentric-ring element, differed only in geometry and not in composition. Both were constructed of uranium oxide ceramic with Zircaloy- 2 cladding. The third element was of plutonium-aluminum alloy; its properties differed completely from those of the uranium oxide fuel elements. We will the refore obtain the material properties for an arbitrary Zircaloy-2-clad $\mathrm{UO}_{2}-$ ceramic element and for the plutonium-aluminum element.

The longitudinal coefficient of thermal conductivity for the Zircaloy-2-UO 2 element was obtained by taking an average of the conductivities of $\mathrm{UO}_{2}$ and Zircaloy -2 (given in Table A-1, Appendix A) weighted according to the cross-sectional areas of each material in the element. If $A_{U O}$ is the cross-sectional area of the uranium oxide and $A_{Z r}$ is the cross-sectional area of the Zircaloy-2 cladding, we obtain the following equation for the conductivity:

$$
\begin{aligned}
\mathrm{Ak}_{\mathrm{a}} & =2.1474156 \times 10^{-3} \mathrm{~A}_{\mathrm{Zr}}+1.6643421 \times 10^{-3} \mathrm{~A}_{\mathrm{UO}}+\left(1.5020576 \times 10^{-7} \mathrm{~A}_{\mathrm{Zr}}\right. \\
& \left.-1.0211843 \times 10^{-6} \mathrm{~A}_{\mathrm{UO}}\right)^{\mathrm{T}} \mathrm{a}+\mathrm{A}_{\mathrm{UO}}\left(2.4980771 \times 10^{-10} \mathrm{Ta}_{\mathrm{a}}{ }^{2}\right. \\
& \left.-2.2958649 \times 10^{-14} \mathrm{Ta}^{3}\right)
\end{aligned}
$$

For the plutonium-aluminum element, the conductivity was found to be

$$
\begin{aligned}
& A k_{a}=7.920865 \times 10^{-4}+3.5718670 \times 10^{-7} \mathrm{~T}_{\mathrm{a}}-2.5513336 \times 10^{-10} \mathrm{~T}_{\mathrm{a}}^{2}(\mathrm{~B}-27 \mathrm{~T} \\
& \left(\mathrm{A}=1.734943 \times 10^{-3} \mathrm{ft}^{2}\right) .
\end{aligned}
$$

The heat capacities, $\mathrm{C}_{\mathrm{p}}$, for the Zircaloy-2-UO $\mathrm{U}_{2}$ elements were also obtained by taking an average of the heat capacities of the component materials weighted according to the cross-sectional area of each material in the element.

$$
\text { If } \begin{aligned}
\mathrm{T}_{\mathrm{a}} \leq 2043 \mathrm{~F} \\
\begin{aligned}
\mathrm{A}_{\mathrm{C}} \rho & =45.57040 \mathrm{~A}_{\mathrm{UO}}+30.26073 \mathrm{~A}_{\mathrm{Zr}}+\mathrm{T}_{\mathrm{aa}}\left(2.13611 \times 10^{-3} \mathrm{~A}_{U O}\right. \\
& \left.+2.6250455 \times 10^{-3} \mathrm{~A}_{\mathrm{Zr}}\right)-\left(3.045242 \times 10^{6} \mathrm{~A}_{\mathrm{UO}}\right. \\
& \left.+1.251495 \times 10^{6} \mathrm{~A}_{\mathrm{Zr}_{\mathrm{r}}}\right)\left(\mathrm{T}_{\mathrm{a}}-459.688\right) \mathrm{T}_{\mathrm{aa}}{ }^{-3}
\end{aligned}
\end{aligned}
$$

where $\mathrm{T}_{\mathrm{a}}$ is the element temperature in degrees Rankine.

$$
\text { If } \begin{aligned}
\mathrm{T}_{\mathrm{a}}>2043 \mathrm{~F} \\
\qquad \begin{aligned}
\mathrm{A} \mathrm{C}_{\mathrm{p}} \rho & =45.57040 \mathrm{~A}_{\mathrm{UO}}+32.2755 \mathrm{~A}_{\mathrm{Zr}}+2.13611 \times 10^{-3} \mathrm{~A}_{\mathrm{UO}} \mathrm{T}_{\mathrm{aa}} \\
& -3.045242 \times 10^{6} \mathrm{~A}_{\mathrm{UO}}\left(\mathrm{T}_{\mathrm{a}}-459.688\right) \mathrm{T}_{\mathrm{aa}}{ }^{-3}
\end{aligned}
\end{aligned}
$$


From which we derive:

$$
\begin{aligned}
\text { If } \mathrm{T}_{\mathrm{a}} \leq 2043 \mathrm{~F} & \\
\mathrm{~A}\left(\mathrm{~T}_{\mathrm{a}} \frac{\partial\left[\mathrm{C}_{\mathrm{p} \rho}\right]}{\partial \mathrm{T}_{2}}+\mathrm{C}_{\mathrm{p} \rho}\right) & =44.58846 \mathrm{AUO}_{\mathrm{U} O}+29.05403 \mathrm{~A}_{\mathrm{Zr}}+\mathrm{T}_{\mathrm{aa}}\left(4.27222 \times 10^{-3} \mathrm{AUO}\right. \\
& \left.+5.250999 \times 10^{-3} \mathrm{~A}_{\mathrm{Zr}}\right)+\left(3.045242 \times 10^{6} \mathrm{~A}_{U O}\right. \\
& \left.+1.251495 \times 10^{6} \mathrm{~A}_{\mathrm{Zr}}\right)\left(\mathrm{T}_{\mathrm{a}}-459.688\right) \mathrm{T}_{2 a}{ }^{-3}
\end{aligned}
$$

and if $\mathrm{T}_{\mathrm{a}}>2043 \mathrm{~F}$,

$$
\begin{aligned}
\mathrm{A}\left(\mathrm{T}_{\mathrm{a}} \frac{\partial\left[\mathrm{C}_{\mathrm{p} \rho}\right]}{\partial \mathrm{T}_{\mathrm{a}}}+\mathrm{C}_{\mathrm{p}} \rho\right) & =44.58846 \mathrm{~A}_{\mathrm{UO}}+32.2755 \mathrm{~A}_{\mathrm{Zr}}+4.27222 \times 10^{-3} \mathrm{~A}_{\mathrm{UO}} \mathrm{T}_{\mathrm{aa}} \\
& +3.045242 \times 10^{6} \mathrm{~A}_{\mathrm{UO}}\left(\mathrm{T}_{\mathrm{a}}-459.688\right) \mathrm{T}_{\mathrm{aa}}{ }^{-3}
\end{aligned}
$$

For the plutonium-aluminum element:

$$
\begin{aligned}
A\left(T_{a} \frac{\partial\left[C_{p} \rho\right]}{\partial T_{a}}+C_{p} \rho\right) & =0.032530844+4.7590684 \times 10^{-5} T_{a a} \\
& -2.6947882 \times 10^{3}\left(T_{a}-459.688\right) \mathrm{T}_{\mathrm{aa}^{-3}}
\end{aligned}
$$

The quantities $q_{r}$ and $y^{\prime}$ were included in this section even though they are affected by the type of coolant, as well as the type of surface metal, since for a given coolant and a given surface metal the reaction is a function of the element temperature. For the Zircaloy-2- $\mathrm{UO}_{2}$ elements:

$$
y^{\prime}\left(z_{i}, t_{i}\right)=\frac{1.1829 \times 10^{-4}}{y\left(z_{i}, t_{i}\right)} \exp \left[\frac{-30,800}{T_{a a}}\right],
$$

where now we use

$$
y\left(z_{i}, t_{i}\right)=y\left(z_{i}, 0\right)+\int_{0}^{t_{i}} y^{\prime}\left(z_{i}, t\right) d t
$$

and define

$$
y\left(z_{i}, t_{i}+1\right)=y\left(z_{i}, t_{i}\right)+y^{\prime}\left(z_{i}, t_{i}\right) \Delta t
$$

It was assumed that at zero sec $y=0.000032 \mathrm{lb}$-mole of zirconium per $\mathrm{ft}^{2}$ at all points of the surface of the element.

Also,

$$
\mathrm{q}_{\mathrm{r}}=\Delta \mathrm{H}_{\mathrm{r}} \mathrm{y}^{\circ}
$$

where

$$
\Delta H_{x}=263,135-5.34 T_{a}(\text { Btu/lb-mole zirconium reacted) } .
$$


In the plutonium-aluminum element the reaction is negligible at all temperatures below the melting point. Since Equation (B-30) also predicts negligible reactions at these temperatures and since the removal of Equation (B-30) would have been somewhat difficult, it was left in the calculations for the plutonium-aluminum element.

\section{The Liquid-Cooled Region}

In sections of the element covered by the liquid phase of the coolant, Equations $(B-13)$ and $(B-14)$ had to be adjusted to correspond to Equations $\left(B-6^{\prime}\right)$ and $\left(B-7^{\prime}\right)$; Equation (B-15) was not changed and Equation (B-16) was ignored. (It was assumed that at any given instant, the velocity was the same at all points of the water phase and was equal to the inlet velocity at that time.)

The change in Equation (B-13) is seen to be only that the boiling temperature $\mathrm{T}_{\mathrm{g}}{ }^{*}$ and the water heat-transfer coefficient $h_{\mathrm{w}}$ are to be substituted for all $\mathrm{T}_{\mathrm{g}}$ and $\mathrm{h}$, respectively.

Equation (B-14) was not used in the liquid phase for bottom injection. For top injection, Equation (B-14) was modified to read

$$
T_{g}\left(z_{0}, t_{1}\right)=\frac{S_{1}\left[T_{a}\left(z_{0}, t_{1}\right)-T_{g}^{*}\right]}{S_{2}}+T_{g}\left(z_{-1}, t_{1}\right)
$$

provided that $T_{g}\left(z_{0}, t_{1}\right)$ and $T_{g}\left(z_{-1}, t_{1}\right)$ were both less than $T_{g} *$. If $T_{g}\left(z_{0}, t_{1}\right)=T_{g} *>$ $T_{g}\left(z_{-1}, t_{I}\right)$, the following equation must be used:

$$
T_{g}\left(z_{0}, t_{1}\right)=\frac{\left(S_{1}-k\right) T_{a}\left(z_{0}, t_{1}\right)+S_{2} T_{g} *}{S_{1}-k+S_{2}}
$$

where

$$
k=\frac{\left[T_{g} *-T_{g}\left(z_{-1}, t_{1}\right)\right] S_{2}}{\left[T_{a}\left(z_{0}, t_{1}\right)-T_{g} *\right]} .
$$

It is seen that $k\left[T_{a}\left(z_{0}, t_{1}\right)-T_{g}{ }^{*}\right]$ is that part of the heat transferred from the considered interval of the element during the interval of time that is sufficient just to evaporate the water remaining at point $\left(z_{-1}, t_{1}\right)$. Equation ( $B-14-9$ ) then represents the amount of superheating of the steam in this interval after the water has been evaporated.

For the interval containing the water-steam interface, the following equation was used for $W_{g}$ for down flow:

$$
W_{g}\left(z_{0}, t_{1}\right)=W_{g}\left(z_{-1}, t_{1}\right)-\left[T_{g}\left(z_{0}, t_{1}\right)-T_{g} *\right]\left(\frac{\Delta z}{\Delta t}\right)\left(A_{g} \frac{\partial \rho_{g}}{\partial T_{g}}\right)_{T_{g} *}
$$

From these equations it is seen that for top injection a point was assumed to be in the liquid phase when $\mathrm{T}_{\mathrm{g}}<\mathrm{T}_{\mathrm{g}}$ and in the gas phase when $\mathrm{T}_{\mathrm{g}}>\mathrm{T}_{\mathrm{g}}$. It was then necessary only to compare these two numbers to determine which phase was present. 
For bottom injection, as was mentioned before, the level of the interface was calculated directly. Replacing Equation $(B-12)$ by a difference equation, we obtain

$$
L\left(t_{1}\right)=L\left(t_{0}\right)+\frac{W_{g} \Delta t}{\rho_{W} A_{g}}-\frac{p h_{W} \Delta z \Delta t}{\rho_{w} A_{g} \Delta H_{v}} \sum_{i=1}^{n}\left[T_{a}\left(z_{i}, t_{0}\right)-T_{g} *\right]
$$

where $n$ is the largest integer such that $z_{n}$ is less than $L\left(t_{1}\right)$. In the program, the first two terms on the right were added at the beginning of the calculation for each time

interval and the quantities $\frac{p h_{w} \Delta z \Delta t}{\rho_{W} A_{g} \Delta H_{V}}\left[T_{a}\left(z_{i}, t_{0}\right)-T_{g}{ }^{*}\right]$ were subtracted one by one for each interval of the element. When the point $Z_{n+1}$ was reached, the program reverted to the equations for the gas phase, and $W_{g}\left(z_{n}\right)$ was given by the relation:

$$
W_{g}=\frac{p h_{w} \Delta z}{\Delta H_{v}} \sum_{i=1}^{n}\left[T_{a}\left(z_{i}, t_{0}\right)-T_{g} *\right]
$$

Material Properties in the Liquid-Cooled Region. The properties of the fuel element are the same regardless of whether the element is surrounded by liquid or gas.

At all points in the liquid phase of the coolant, the three quantities, $T_{g} * W_{g}$, and $h_{\mathrm{W}}$ were assumed to be the same at any given instant of time and were precomputed for an entire calculation. In some cases they varied with time and in this event they had to be precomputed as functions of time and their values introduced into the program at the proper time as the computation progressed. At each instant of time the temperature $\mathrm{T}_{\mathrm{g}}$ was assumed equal to $\mathrm{T}_{\mathrm{g}}$ \% for all points of the liquid phase.

Because $h_{W}$ was precomputed it is seen that Equations (B-19) through (B-24) are not needed in the liquid phase and may be bypassed. Equation (B-25) is omitted whenever Equation (B-16) is not used. All other properties of the coolant are to be evaluated at $\mathrm{T}_{\mathrm{g}}=\mathrm{T}_{\mathrm{g}} *$. These include $\mathrm{C}_{\mathrm{s}}, \mathrm{C}_{\mathrm{H}}$, and $\psi\left(\mathrm{T}_{\mathrm{g}}, \mathrm{M}\right)$.

\section{The Adiabatic Case}

In the adiabatic case, it is assumed that there is no reaction and no heat transfer. Therefore, the only equation that is applicable is Equation (B-6\%). In the form of a difference equation this is written as:

$$
\begin{aligned}
T_{a}\left(z_{0}, t_{1}\right) & =T_{a}\left(z_{0} t_{0}\right)+\Delta t\left\{A_{a}\left(T_{a} \frac{\partial\left[C_{p} \rho\right]}{\partial T_{a}}+C_{\rho}\right)\right\}^{-I}\left\{A_{a} R\left(z_{1}, t_{0}\right)\right. \\
& \left.-A_{a} R\left(z_{0}, t_{0}\right)+Q\left(z_{0}, t_{0}\right)\right\}
\end{aligned}
$$

where the values of all of the quantities involved are the same as those given for the gas-cooled element. 
The machine program was designed so that the following numbers could be punched on cards for each point of the rod and at each time interval: index number of the point of the element, the element temperature $T_{a}$, the coolant temperature $T_{g}$, the mole fraction $M$, the coolant velocity $W_{g}$ and the amount of metal reacted $y$. For each time interval, the time and the moles of hydrogen accumulated to that time as a result of chemical reaction were also punched.

The index number denoting the points of the rod ranged from 2 through 31 . The point numbered two was the first point of the rod and the point numbered 31 was the last point. For the adiabatic case the first point was considered to be at the bottom of the rod. For the cases where coolant was flowing by the rod, the first point was at the end at which coolant was introduced. (The numbering system had to start at two to conform to the requirements of the automatic program assembly system used.)

The cards containing the results were processed on an IBM Type 402 Tabulator. This machine printed an asterisk (*) after a given number to indicate that it was negative. For cases in which water was injected at the top of the core the coolant temperature listed for the liquid phase was the fictitious temperature showing the enthalpy of the coolant at each point. In this case, a negative number or a small positive number indicated that the water had not been completely evaporated. For the case of bottom injection of water the coolant temperature listed for the liquid phase was the boiling temperature of the liquid at that time. This could be recognized easily since it was always an integral number.

A typical machine listing, obtained when the coolant was entirely gaseous, is shown in Table B-1. The output of the FORTRAN program will have a somewhat different format because its punch subroutines only punch 3 words per card. (The output subroutine of the program for the 650 was written in basic language for 8 words per card output.) 
TABLE Bm1. TYPICAL MACHINE COMPUTATION

\begin{tabular}{|c|c|c|c|c|c|}
\hline $\begin{array}{l}\text { Time After Incident, second } \\
20.002052(52)(\mathrm{a}) \\
\begin{array}{c}\text { Increment Plus One From Base } \\
\text { of Fuel Element }\end{array}\end{array}$ & 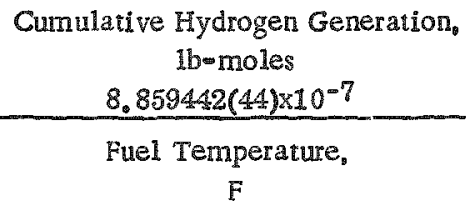 & $\begin{array}{c}\text { Coolant Temperature, } \\
\text { F }\end{array}$ & $\begin{array}{l}\text { Mole Fraction Hydrogen, } \\
\text { moles per mole }\end{array}$ & $\begin{array}{c}\text { Flow Rate, } \\
\mathrm{lb} \text {-mole/(sec) (channel) }\end{array}$ & $\begin{array}{l}\text { Total Chemical } \\
\text { Reaction. } \\
\text { lb-mole per } \mathrm{ft}^{2}\end{array}$ \\
\hline 2 & $426.96140(53)$ & $427.19005(53)$ & $2.3546407(37) \times 10^{-14}$ & $1.0279151(48) \times 10^{-3}$ & $3.2000000(46) \times 10^{-55}$ \\
\hline 3 & $431.38010(53)$ & $427.36488(53)$ & $5.6778957(37) \times 10^{-14}$ & $1.0279152(48) \times 10^{-3}$ & $3.2000000(46) \times 10^{-5}$ \\
\hline 4 & $443.10058(53)$ & $428,02003(53)$ & $1.1757248(38) \times 10^{-13}$ & $1.0284001(48) \times 10^{-3}$ & $3.2000026(46) \times 10^{-5}$ \\
\hline 5 & $446.09260(53)$ & $428.77249(53)$ & $1.9128591(38) \times 10^{-13}$ & $1.0288849(48) \times 10^{-3}$ & $3.2000150(46) \times 10^{-5}$ \\
\hline 6 & $448,69540(53)$ & $429.60198(53)$ & $2.7795431(38) \times 10^{-13}$ & $1.0293694(48) \times 10^{-3}$ & $3.2000507(46) \times 10^{-5}$ \\
\hline 7 & $451.32351(53)$ & $430.50637(53)$ & $3.8221665(38) \times 10^{-13}$ & $1.0298537(48) \times 10^{-3}$ & $3.2002300(46) \times 10^{-5}$ \\
\hline 8 & $453.68880(53)$ & $431.47158(53)$ & $5.0435725(38) \times 10^{-13}$ & $1.0303377(48) \times 10^{-3}$ & $3.2006826(46) \times 10^{-5}$ \\
\hline 9 & $455.76678(53)$ & $432.48311(53)$ & $6.4473352(38) \times 10^{-13}$ & $1.0308213(48) \times 10^{-3}$ & $3.2016508(46) \times 10^{-5}$ \\
\hline 10 & $457.67441(53)$ & $433.53195(53)$ & $8.0483696(38) \times 10^{-13}$ & $1.0313046(48) \times 10^{-3}$ & $3.2037084(46) \times 10^{-5}$ \\
\hline 11 & $459.41065(53)$ & $434.60942(53)$ & $9.8600550(38) \times 10^{-13}$ & $1.0317874(48) \times 10^{-3}$ & $3.2078042(46) \times 10^{-5}$ \\
\hline 12 & $460.91096(53)$ & $435.70451(53)$ & 1. $1862347(39) \times 10^{\circ 12}$ & 1. $0322698(48) \times 10^{-3}$ & $3.2132189(46) \times 10^{-5}$ \\
\hline 13 & $462.17325(53)$ & $436.80654(53)$ & $1.4051549(39) \times 10^{-12}$ & $1.0327517(48) \times 10^{-3}$ & $3.2216388(46) \times 10^{-5}$ \\
\hline 14 & $463.13153(53)$ & $437.90258(53)$ & 1. $6384295(39) \times 10^{-12}$ & $1,0332331(48) \times 10^{-3}$ & $3.2296931(46) \times 10-5$ \\
\hline 15 & $463.81880(53)$ & $438.98162(53)$ & $1.8841114(39) \times 10^{-12}$ & $1.0337140(48) \times 10^{-3}$ & $3.2400638(46) \times 10^{-5}$ \\
\hline 16 & $464.28895(53)$ & $440.03530(53)$ & $2.1389122(39) \times 10^{-12}$ & $1.0341943(48) \times 10^{-3}$ & $3.2497711(46) \times 10^{-5}$ \\
\hline 17 & $464.28895(53)$ & $441.04511(53)$ & $2.3937124(39) \times 10^{-12}$ & $1.0346740(48) \times 10^{-3}$ & $3.2497711(46) \times 10^{-5}$ \\
\hline 18 & $468.81880(53)$ & $441.99330(53)$ & 2. $6393943(39) \times 10^{-12}$ & $1.0351532(48) \times 10^{-3}$ & $3.2400638(46) \times 10^{-5}$ \\
\hline 19 & $463.13153(53)$ & $442.87340(53)$ & $2.8726689(39) \times 10^{-12}$ & $1.0356318(48) \times 10^{-3}$ & $3.2296931(46) \times 10^{-5}$ \\
\hline 20 & $462.17323(53)$ & $443.67694(53)$ & $3.0915886(39) \times 10^{-12}$ & $1.0361098(48) \times 10^{-3}$ & $3.2216388(46) \times 10^{-5}$ \\
\hline 21 & $460.91096(53)$ & $444.39449(53)$ & $3.2918178(39) \times 10^{-12}$ & $1.0365872(48) \times 10^{-3}$ & $3.2132188(46) \times 10^{-5}$ \\
\hline 22 & $459.41063(53)$ & $445.01969(53)$ & $3.4729859(39) \times 10^{-12}$ & 1. $0370641(48) \times 10^{-3}$ & $3.2078042(46) \times 10^{-5}$ \\
\hline 23 & $457.67441(53)$ & $445.54657(53)$ & $3.6330893(39) \times 10^{-12}$ & $1.0375405(48) \times 10^{-3}$ & $3.2037084(46) \times 10^{-5}$ \\
\hline 24 & $455.76678(53)$ & $445.97210(53)$ & $3.7734656(39) \times 10^{-12}$ & $1.0380163(48) \times 10^{-3}$ & $3.2016508(46) \times 10^{-5}$ \\
\hline 25 & $453.68879(53)$ & $446.29332(53)$ & $3.8956059(39) \times 10^{-12}$ & $1.0384916(48) \times 10^{-3}$ & $3.2006826(46) \times 10^{-5}$ \\
\hline 26 & $451.32377(53)$ & $446.50282(53)$ & $3.9998704(39) \times 10^{-12}$ & $1.0389665(48) \times 10^{-3}$ & $3.2002300(46) \times 10^{-5}$ \\
\hline 27 & $448.71390(53)$ & $446.59490(53)$ & $4.0867935(39) \times 10^{-12}$ & $1.0394409(48) \times 10^{-3}$ & $3.2000531(46) \times 10^{-5}$ \\
\hline 28 & $446.10278(53)$ & $446.57440(53)$ & $4.1606260(39) \times 10^{-1.2}$ & $1.0399149(48) \times 10^{-3}$ & $3.2000157(46) \times 10^{-5}$ \\
\hline 29 & $443.10734(53)$ & $446.43005(53)$ & $4.2214877(39) \times 10^{-12}$ & $1.0403885(48) \times 10^{-3}$ & $3.2000027(46) \times 10^{-5}$ \\
\hline 30 & $431.38354(53)$ & $445,80357(53)$ & $4.2547390(39) \times 10^{-12}$ & $1.0408618(48) \times 10^{-3}$ & $3.2000000(46) \times 10^{-5}$ \\
\hline 31 & $426.96142(53)$ & $445.01905(53)$ & $4.2782856(39) \times 10^{-12}$ & $1.0413349(48) \times 10^{-3}$ & $3.2000000(46) \times 10^{-55}$ \\
\hline
\end{tabular}

(a) Of the ten digits in each number, the last two digits (in parentheses) fix the decimal point. The number 50 would indicate the decimal poin goes before the number. For each number above 50 the decimal is moved one place to the right. The converse holds for numbers less than 50 . The decimal points and parentheses were typed in this listing for clarity and do not appear on the machine listing. 
APPENDIX C

THE FORTRAN PROGRAM 
$\mathrm{C}-1$

APPENDIX C

THE FORTRAN PROGRAM

Introduction

It was decided to use the IBM FORTRANSIT Automatic Coding System* in developing a computing program for the IBM Type 650 Electronic Computing Machine. The FORTRANSIT system was designed to be compatible with the IBM FORTRAN System for the 700 series machines. Because of this feature, the program that was written may be considered to be a FORTRAN program suitable for use on the appropriate larger size machine.

This Appendix contains a list of all the FORTRAN mnemonics defined for the computer program (Table $\mathrm{C}-1$ ), the flow chart for the program (Figure $\mathrm{C}-1$ ), the FORTRAN program, and a discussion of the input data needed for each of the various calculations made in this study.

"Programmers Reference Manual - FORTRANSIT Automacic Coding System for the IBM 650", IBM 32-7842. 
The FORTRAN Mnemonics

All FORTRAN mnemonics are listed in the order of their appearance in the FORTRAN program (Table C-2). A descriptive definition of each mnemonic is given and its dimension is given when applicable. A number of quantities always appear in the calculations grouped in the same way (e.g., $2 \pi a h, 4 \pi a y^{\prime}$, etc.). These groups were considered as entities in writing the FORTRAN program and each has been given a mnemonic designation in Table C-1. The FORTRAN fixed point - floating point rules for choosing the first letter of each mnemonic have been followed. 
$\mathrm{C}-3$

TABLE C-1. THE FORTRAN MNEMONICS

FORTRAN

Mnemonic

Description

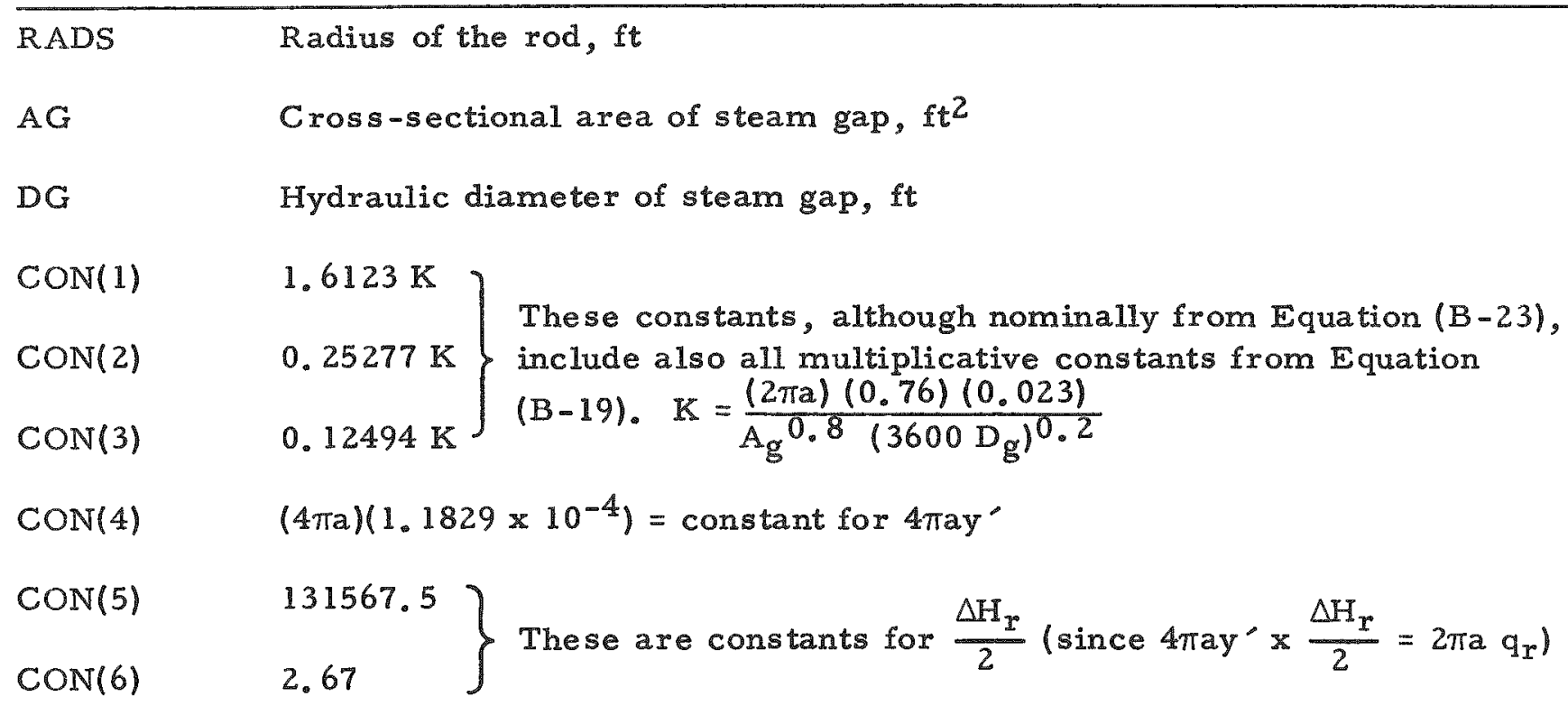

$\mathrm{DELZ} \quad \Delta \mathrm{z}, \mathrm{ft}$

$\operatorname{CON}(7)$

$\operatorname{CON}(8)$

$\operatorname{CON}(9)$

These are constants for determination of $A R\left(z_{i}, t\right)$. They are obtained from the coefficients of Equation $(B-27)$ by dividing by $(\Delta z)^{2}$. For Pu-Al

$\operatorname{CON}(10)$ element the coefficients of Equation $\left(B-27^{\circ}\right)$ must be used.

$\operatorname{CON}(11) \quad$ Constants from Equation $(B-28)$ used in determining $A\left[T_{a} \frac{\partial\left[C_{p} \rho\right]}{\partial T_{a}}+C_{p} \rho\right]$

$\operatorname{CON}(12)\}$ for $T \leq 2043 \mathrm{~F}$. Equation $\left(\mathrm{B}-28^{\circ}\right)$ is used for $\mathrm{Pu}-\mathrm{Al}$ element.

$\operatorname{CON}(13)$

$\operatorname{CON}(14)$

CON(15) Constants from Equation (B-29) used instead of Equation (B-28) for

$\operatorname{CON}(16)$

$T \geq 2043 \mathrm{~F}$. Not used for Pu-AI element.

$\operatorname{CON}(17)$

$\operatorname{CON}(18)$

$(4.66)\left(A_{g}\right)(\Delta z)$ - constant used in Equation $(B-16)$ for $A_{g} \frac{\partial \rho_{g}}{\partial T_{g}} \Delta z$.

This is the value of $A \bar{k}_{\mathrm{a}}(\Delta z)^{2}$ at ELMP

ELMP

The melting point of the metal (3313.4 F for zirconium; $1217 \mathrm{~F}$ for aluminum). 
TABLE C-1. (Continued)

\begin{tabular}{|c|c|}
\hline $\begin{array}{l}\text { FORTRAN } \\
\text { Mnemonic }\end{array}$ & Description \\
\hline $\operatorname{CON}(19)$ & $4 \pi \mathrm{a}=2 \mathrm{p}, \mathrm{ft}$. \\
\hline TIME & Time, $t$, sec \\
\hline TIMEX & $\begin{array}{l}\text { It was necessary to introduce certain quantities as functions of time dur- } \\
\text { ing the course of the calculation. TIMEX was the time in sec associated } \\
\text { with each value of these quantities. }\end{array}$ \\
\hline $\operatorname{CON}(20)$ & Constant used in Equation $\left(B-16^{\circ}\right) ; \operatorname{CON}(20)=-\left[\Delta \mathrm{z} \mathrm{A}_{\mathrm{g}} \frac{\partial \rho_{\mathrm{g}}}{\partial \mathrm{T}_{\mathrm{g}}}\right]_{\mathrm{T}_{\mathrm{g}}}^{*-1}$ \\
\hline DELT & Time interval, $\Delta t, \sec$ \\
\hline DELTM & The maximum value over $z_{i}$ of $\Delta T_{a} / \Delta t$ for one time interval. \\
\hline TSET & $\begin{array}{l}\text { Times at which discontinuous changes in conditions had to be made } \\
\text { (e.g., blowdown-adiabatic). This enabled the changes to be made } \\
\text { automatically at precisely the right time. It is noted that when time } \\
\text { became equal to TSET, the latter quantity had to be reset to its next } \\
\text { higher value. }\end{array}$ \\
\hline LAST, K & $\begin{array}{l}\text { Upper bounds on the DO loop }=\text { number of points }+1 \text {. They will always } \\
\text { indicate the last point of the rod except that for steam downflow or adiabatic } \\
\text { conditions when part of the rod has melted, they will automatically be } \\
\text { set to the next point of the rod above the point melted. }\end{array}$ \\
\hline $\mathrm{J}, \mathrm{M}$ & $\begin{array}{l}\text { Initial values of } i \text { in the DO loop. These must be } \geq 2 \text { since inlet values of } \\
\mathrm{M}, \mathrm{Tg} \text {, and } \mathrm{Wg} \text { are given at } \mathrm{i}=1 \text {. They will always be } 2 \text { unless, for } \\
\text { steam upflow, part of the rod has melted. In this case they are automat- } \\
\text { ically set equal to the next point of the rod above the point melted. }\end{array}$ \\
\hline R 1 & $A_{a} R\left(z_{i}, t_{0}\right)$, Btu per ft-sec \\
\hline $\mathrm{KEY}$ & $\begin{array}{l}\text { Number indicating type of calculation: }-1=\text { downflow, } 0=\text { adiabatic, } \\
1=\text { steam upflow, } 2=\text { bottom water injection. }\end{array}$ \\
\hline $\mathbf{N}$ & $\mathrm{KEY}+1$ \\
\hline W LEVT & $\begin{array}{l}\text { Distance of water-steam interface from bottom of core at the beginning } \\
\text { of the time interval added to the feet of water injected during the time } \\
\text { interval (used in bottom injection). }\end{array}$ \\
\hline W LEV & $\begin{array}{l}\text { "Instantaneous" distance of the water-steam interface from the bottom of } \\
\text { the core. This is obtained by subtracting from WLEVT the steam } \\
\text { generated from all points below and including the one being considered } \\
\text { at any instant. }\end{array}$ \\
\hline
\end{tabular}




\begin{abstract}
FORTRAN
Mnemonic

Description

DELTL "Instantaneous" rale at which steam is being formed in a given time interval by all points below and including point under consideration (1b-moles per sec)

DYDTS "Instantaneous" rate at which hydrogen is being formed by reaction at all points below and including the point under consideration. (WLEVT, WLEV, DELTL, and DYDTS are applicable in the liquid phase of bottom water injection.)
\end{abstract}

$\left.\begin{array}{l}\text { WGI } \\ \text { TGI } \\ \text { GCMPI }\end{array}\right\}$

These are inlet conditions for steam entering the top half of a melted rod for upflow and must be precomputed.

W(I)

Wg at arbitrary point $z_{i}:$ Ib-moles pex sec/channel

TG(I) $\quad \mathrm{T}_{\mathrm{g}}$ at axbitrary point $z_{i} ; \mathrm{F}$

GCOMP(I) M at arbitrary point zi: moles per mole

TA(I) $\quad \mathrm{T}_{\mathrm{a}}$ at arbitrary point $z_{j} ;$

IAC Value of $T$ a, in $F$, at point under consideration at beginning of the time interval.

TATEM The true element cemperature, in $F$. It is equal to the value of the melting point of the metal cladding if TAC $>\mathrm{mp}$; otherwise equal to IAC.

TAA Value of TATEM in degrees Rankine.

BPW Value of the boiling point of water at the considered time. This is a function of time in some calculations and must be precomputed.

WLEVI The water level at the beginning of the time interval, calculated as the final value of WIEV from the previous time interval (bottom injection only).

TGC The value of $\mathrm{T}_{\mathrm{g}}$ at the point under consideration and at the beginning of the time interval. In water downflow, TGC is used to monitor the enthalpy of the water and may be much less than BPW. In water upflow, $\mathrm{TGC}=\mathrm{BPW}$ in the water phase.

$Y(I) \quad T h e$ value of the amount of metal reacted, $Y$, at an arbitrary point of the rod up to the beginning of the time interval; lb-moles per ft2.

YC The value of $Y(I)$ at the point under consideration. 
C -6

TABLE C -1. (Continued)

\begin{tabular}{|c|c|}
\hline $\begin{array}{l}\text { FORTRAN } \\
\text { Mnemonic }\end{array}$ & Description \\
\hline TGTEM & $\begin{array}{l}\text { The true coolant temperature in } F \text {. If } T G C \leq B P W, T G T E M=B P W \text { : } \\
\text { otherwise, it is equal to } T G C \text {. }\end{array}$ \\
\hline TGA & Value of TGTEM in degrees Rankine. \\
\hline TGASQ & $(T G A)^{2}$ \\
\hline GCOMC & $\begin{array}{l}\text { The value of } M \text { at the point under consideration at the beginning of the } \\
\text { time interval. }\end{array}$ \\
\hline CS & $\mathrm{C}_{S}, \mathrm{Btu} /(\mathrm{Ib}-\mathrm{mole})(\mathrm{F})$ \\
\hline $\mathrm{CH}$ & $\mathrm{C}_{\mathrm{H}}, \mathrm{Btu} /(\mathrm{lb}-\mathrm{mole})(\mathrm{F})$ \\
\hline $\mathrm{MU}$ & $\begin{array}{l}\text { Constant used to bypass punch subroutines. If } \mathrm{MU}=0 \text {, values are } \\
\text { punched. If } \mathrm{MU}>0 \text {, punch is bypassed. }\end{array}$ \\
\hline $\mathrm{TR}$ & $\mathrm{T}_{\mathrm{r}}$, degrees Rankine \\
\hline $\mathrm{CG}$ & 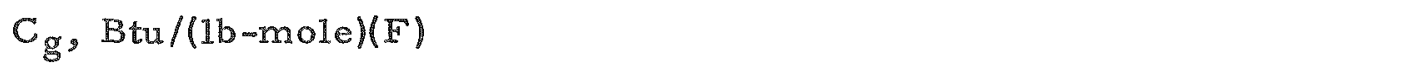 \\
\hline $\mathrm{HA}$ & $2 \pi a h, B t u /(f t)(F)(\mathrm{sec})$ \\
\hline HWA & $2 \pi a h_{w}, B t u /(f t)(F)(s e c)$ \\
\hline PSI & $\psi\left(\mathrm{T}_{\mathrm{g}}, \mathrm{M}\right), \mathrm{Btu} /(\mathrm{lb}-\mathrm{mole})(\mathrm{F})$ \\
\hline DYDTA & $4 \pi a y^{\circ}, 1 b-m o l e ~ p e r f t-s e c$ \\
\hline GCC & $\begin{array}{l}\text { Temporary value of } M \text { at end of time interval at point under considera- } \\
\text { tion (neglecting upper bound on } M \text { of } 1.0 \text { ) }\end{array}$ \\
\hline S1 & $\mathrm{S}_{1}$ \\
\hline $\mathrm{S} 2$ & $\mathrm{~S}_{2}$ \\
\hline QRA & $2 \pi a q_{r}$, Btu per ft-sec \\
\hline $\mathrm{R} 2$ & $A_{a} R\left(z_{i+1}, t_{0}\right)$, Btu per ft-sec \\
\hline DELR & $R 2-R 1$ \\
\hline TACPR & $A_{a}\left\{T_{a} \frac{\partial[C \rho]}{\partial T_{a}}+C \rho\right\}, B t u /(f t)(F)$ \\
\hline DELTA & $\begin{array}{l}\frac{\Delta \mathrm{T}_{\mathrm{a}}}{\Delta \mathrm{t}} \text {, the rate of change of the element temperature at the point under } \\
\text { consideration. }\end{array}$ \\
\hline
\end{tabular}




\section{$C=7$}

TABLE C-1. (Continued)

\begin{tabular}{|c|c|}
\hline $\begin{array}{l}\text { FOR TRAN } \\
\text { Mnemonic }\end{array}$ & Description \\
\hline $\mathrm{QD}(\mathrm{I})$ & Longitudinal variation of the decay heat generation, Btu per $\mathrm{ft}-\mathrm{sec}$ \\
\hline QDT & Time variation of decay heat generation, per cent $\left(q_{d}=Q D(I) \cdot Q D T\right)$ \\
\hline ABVDT & ABSF(DELTA) \\
\hline HTVAP & $\begin{array}{l}\Delta H_{v}-\text { heat of vaporization of water, } B \text { tu per } \mathrm{lb}-\text { mole (used in bottom } \\
\text { injection only). }\end{array}$ \\
\hline DELTL & $\begin{array}{l}\text { Instantaneous linear velocity of rate of steam generation from all points } \\
\text { below and including point under consideration (applicable only for points } \\
\text { in liquid phase of bottom injection) }\end{array}$ \\
\hline CRFLW & Critical rate of steam flow from small top break. \\
\hline TMELT & $\begin{array}{l}\text { Super temperature at which all of the metal of the rod is melted. If } \Delta \mathrm{H}_{\mathrm{f}} \\
\text { is the latent heat of fusion, in } B \text { tu per } \mathrm{ft}^{3}, \mathrm{~T}_{\mathrm{m}} \text { the melting temperature, } \\
\text { and } \mathrm{A}_{\mathrm{m}} \text { the cross-sectional area of the metal in the element, TMELT } \\
\mathrm{T}_{\mathrm{m}}+\left(\triangle \mathrm{H}_{\mathrm{f}}\right)\left(\mathrm{A}_{\mathrm{m}}\right) / \mathrm{TACPR} \text {, where } \mathrm{TACPR} \text { is evaluated at } \mathrm{T}_{\mathrm{m}} \text {. }\end{array}$ \\
\hline HDR GN & $\begin{array}{l}\text { Total amount of hydrogen evolved by the metal-water reaction up to the } \\
\text { time under consideration, lb-moles of hydrogen. }\end{array}$ \\
\hline NU & Constant used to punch every jth time interval. $N U=j-1$. \\
\hline
\end{tabular}




$$
\text { C }-8
$$

\section{The Flow Chart}

A flow chart is a device used to illustrate in a condensed and graphic way the flow of information and the logical operations performed during a computer program.

The flow chart for the loss-of-coolant analysis is given in Figure $\mathrm{C}-1$ on the pages that follow. 
FIGURE C-1. FLOW CHART FOR LOSS-OF-COOLAN I ANALYSIS

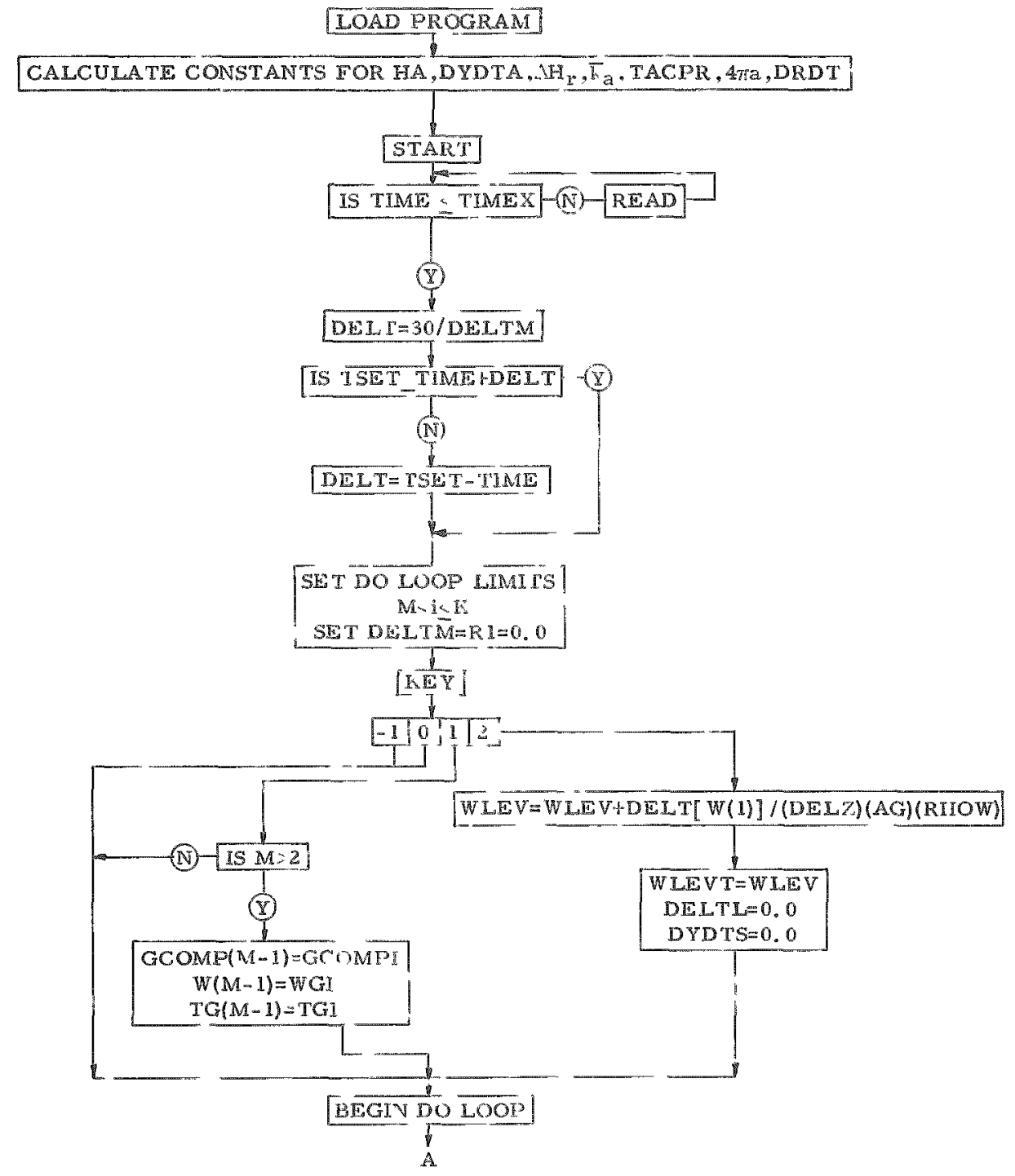


FIGURE C-1. (Continued)

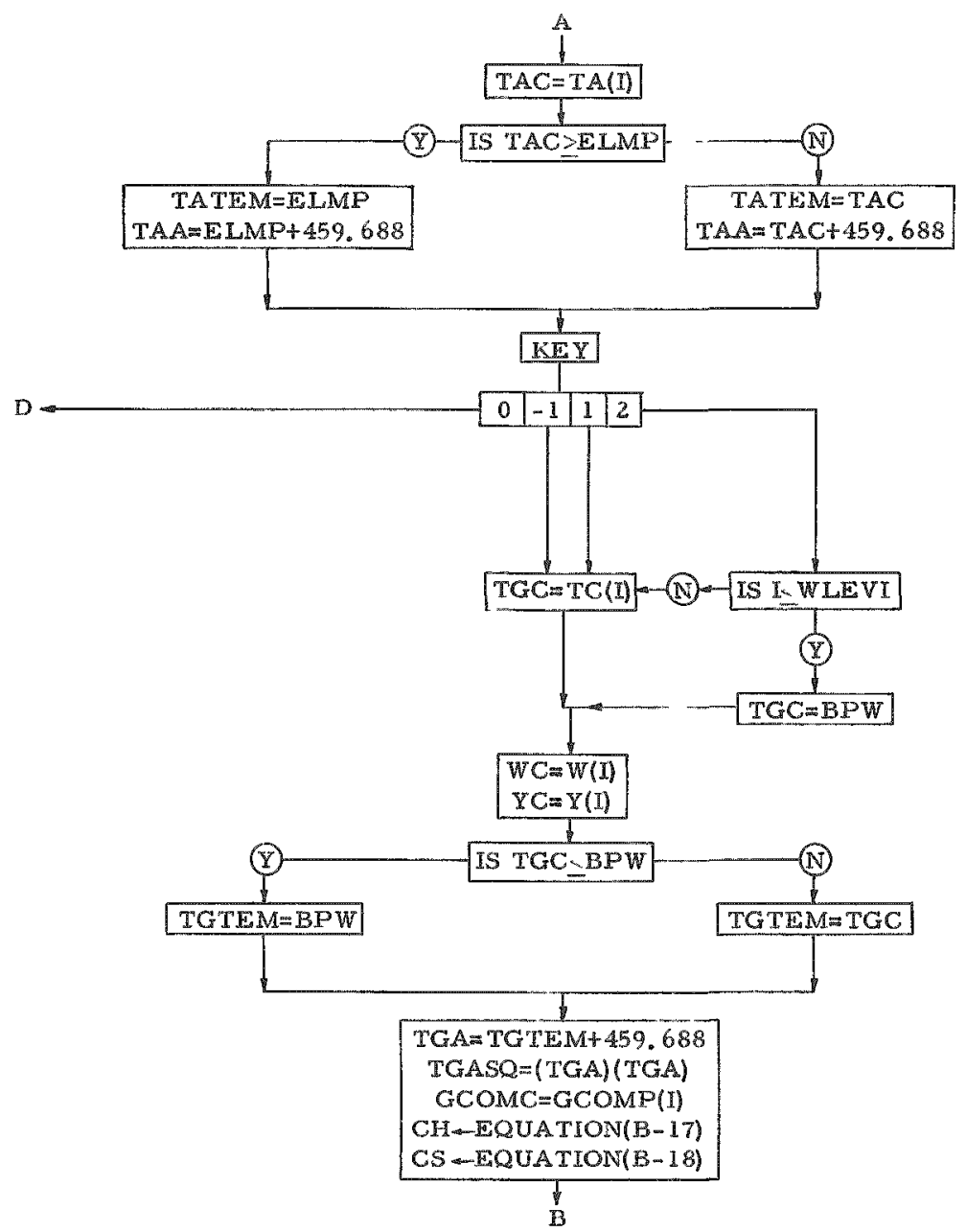


FIGURE C- 1 . (Continued)

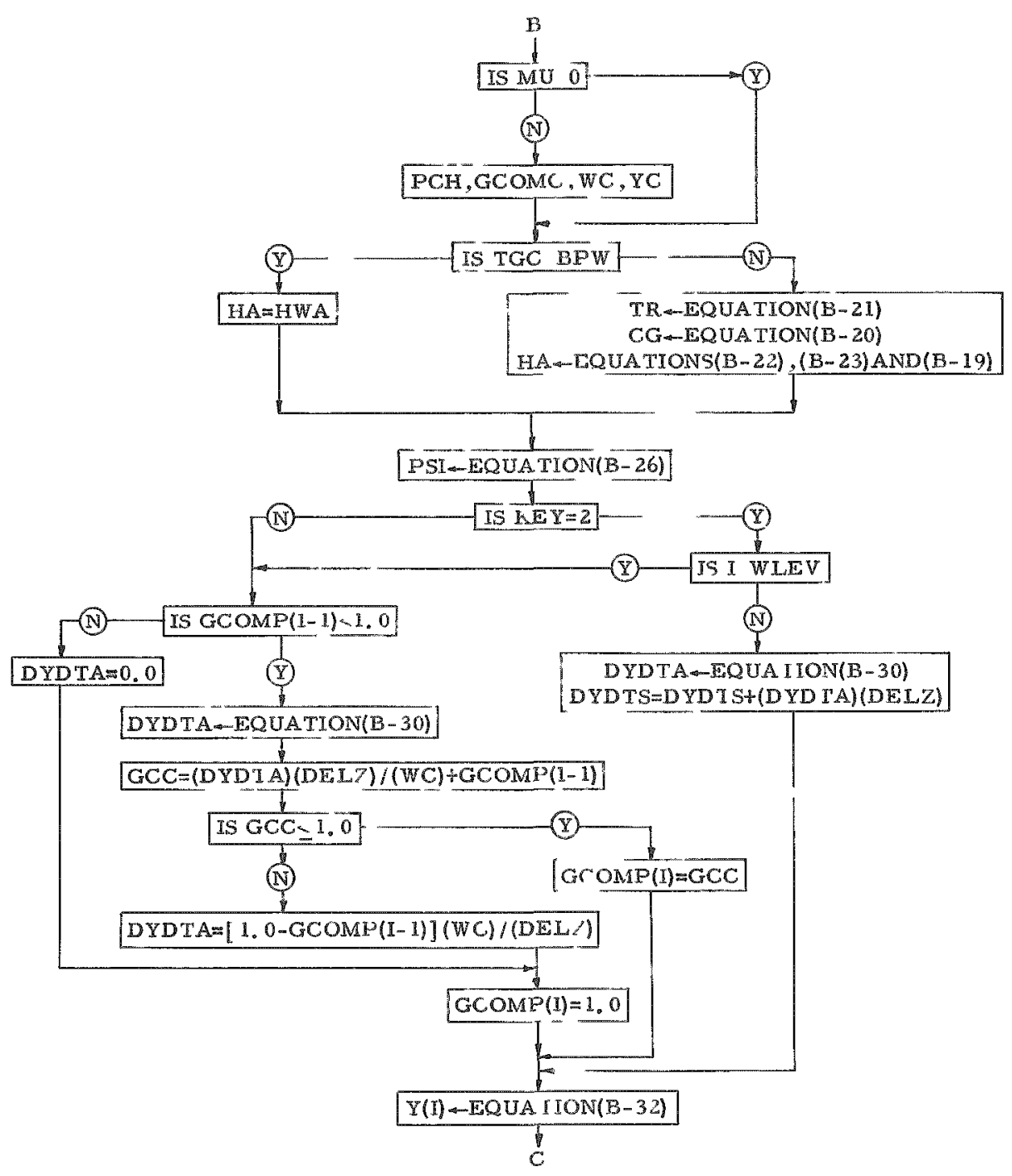


FIGURE C $\sim 1$. (Continued)

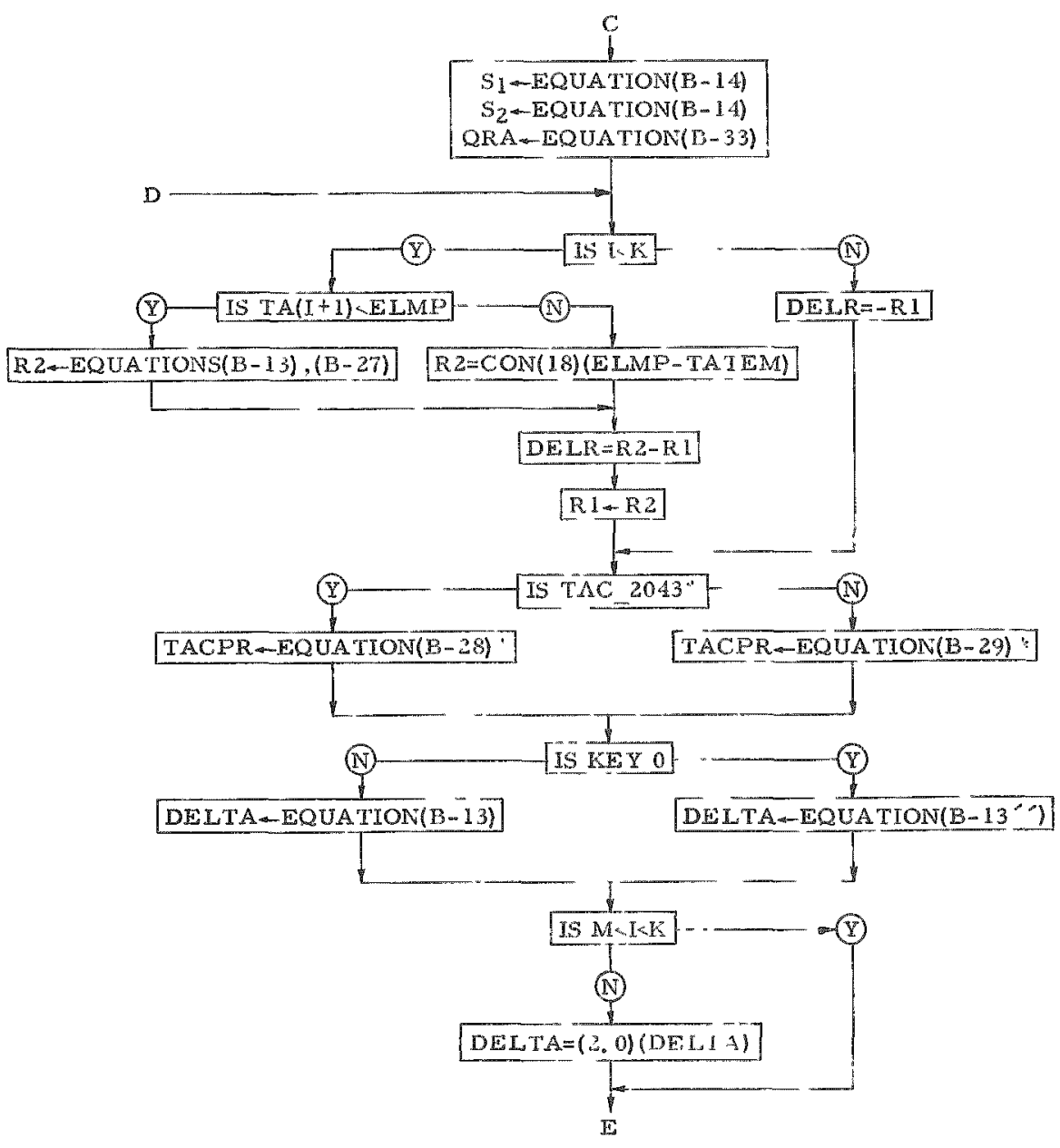

*These equations were evaluated for zirconium-UO 2 combinations. For Pu-Al rod,

Equation $(\mathrm{B}-28)$ is replaced by $\left(B-28^{\circ}\right)$; Fquation $(\mathrm{B}-29)$ and the branch are igno red. 
EIGURE C-1. (Continued)

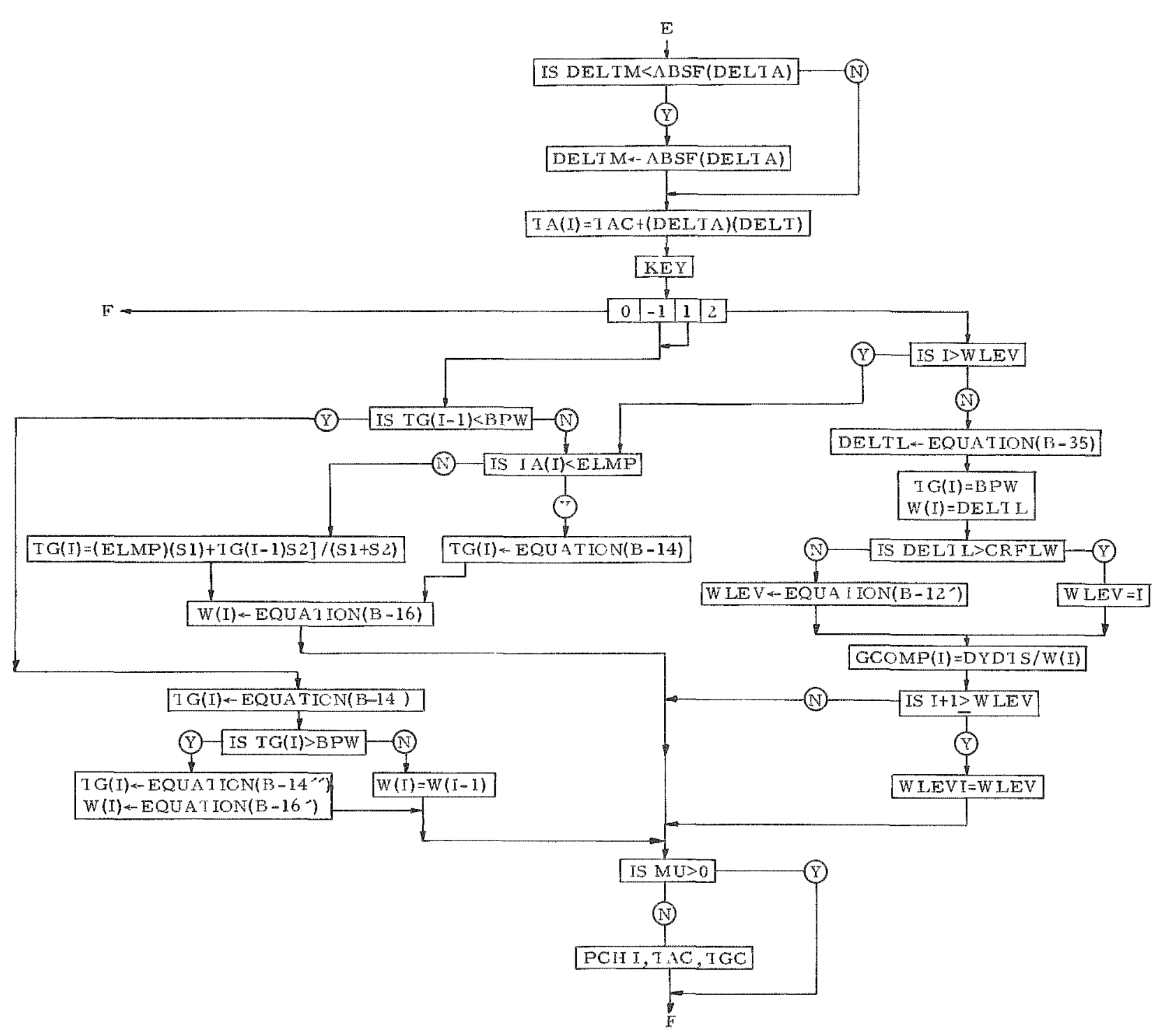




$$
\text { C }-14
$$

FIGURE C-1. (Continued)

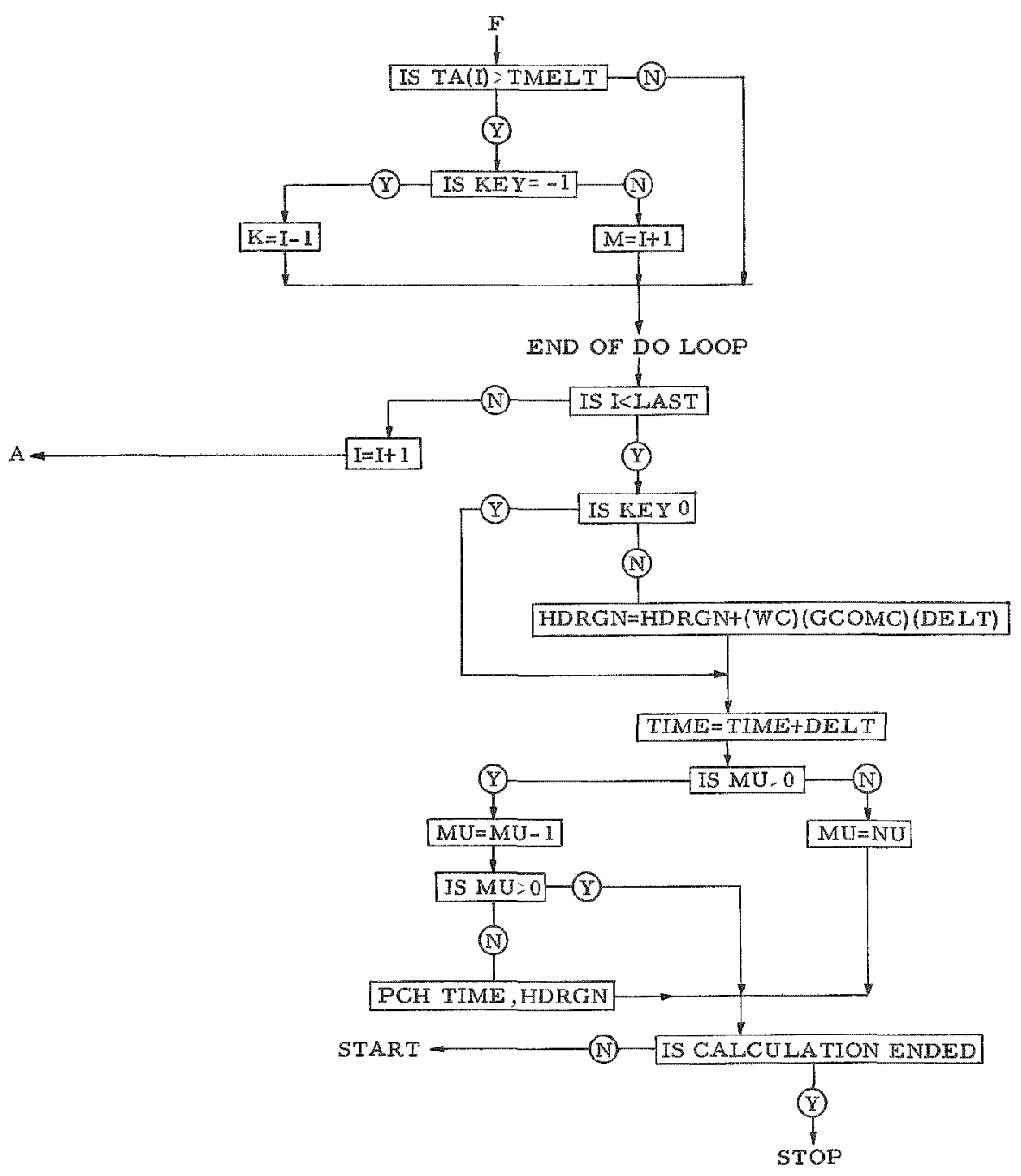


Input Data for the FORTRANSTT Program

Certain data must be read into the program regardless of the type of calculation that is to be made. These include the geometrical constants pertaining to the element and the material properties of the element.

The minimum amount of input data is necessary for the adiabatic case. Since all of the data needed for this case are also necessary for the other cases, we will discuss this case first.

\section{The Adiabatic Case}

(a) Initial data (read in with the program)

$$
\begin{aligned}
& \mathrm{KE} Y=0 \\
& \mathrm{M}=2 \\
& \mathrm{~K}=\text { number of points }+1 \\
& \mathrm{TA}(\mathrm{I}) \quad \mathrm{M} \leq \mathrm{I} \leq \mathrm{K} \\
& \mathrm{QD}(\mathrm{I}) \quad \mathrm{M} \leq \mathrm{I} \leq \mathrm{K} \\
& \Delta \mathrm{z}=\mathrm{L} /(\mathrm{K}-2)
\end{aligned}
$$

\section{RADS}

$A G$ Although not used in this case, these must be entered to prevent division by zero in calculating $C O N(1)$ to $C O N(3)$. In addition, in order to

DG prevent restarting the program these constants as well as the other constants, CON(4) through CON(19), should be computed, if an injection program is to follow the adiabatic phase without stopping the machine.

ELMP $=3313.4$ for zirconium, 1217. 0 for Pu-A1.

TMELT Value depends on materials of element and their amounts.

$$
M U=0
$$

$\mathrm{NU}=\mathrm{j}-1$ (punching is then every $\mathrm{jth}$ time interval)

DELTM $=30.0 / \Delta t_{i}$, where $\Delta t_{i}$ is the first chosen time interval.

TIME = Time after scram at the beginning of calculation.

TSET = Time at which adiabatic phase stops and another case begins.

We note that values of the time dependent functions at the beginning of the calculation must also be introduced with the initial conditions. 


\section{(b) Time-dependent functions}

The manner in which time-dependent functions are introduced is similar for all cases. The range of time over which the excursion is to be run is subdivided into intervals, and the values of the time-dependent functions are evaluated at the midpoints of these intervals. A deck of data cards is made up from the values of the functions and the times at the endpoints of the intervals. This deck must be assembled in such a way that the values of the functions are read at the same time that the end of the time interval is read. If values of times and functions are all put on one load card for each interval, then the value of the time at the end of that interval (not the beginning) is punched on the card. If the times are punched separately, they occupy their correct chronological position between the functional values in the intervals. In this case, each time card is punched as the end of the previous group of functional values, and the control reverts to the machine program only when it is read. The entire deck must be in chronological order. The times are identified in the FORTRAN program as TIMEX. The time intervals need not be uniform and are completely independent of the time interval $\Delta t$ chosen by the program for the calculation. It is thus advisable to choose the time intervals for the time-dependent functions so that approximately uniform increments of these functions are obtained.

The only time dependent function needed for the adiabatic case is QDT, which represents the power decay with time as a per cent of full power. It was assumed that the power decay curve was the same for all cases considered in this study.

The Case of Purely Steam Flow

(a) Initial data

In addition to the data specified in the adiabatic case, the following initial data must be introduced.

$\mathrm{KEY}=-1$ or +1 depending on whether steam is flowing down or up the element.

In addition to $T A(I)$ and $Q D(I)$, four more indexed variables are needed:

$$
\begin{aligned}
\mathrm{TG}(\mathrm{I}) & \mathrm{M} \leq \mathrm{I} \leq \mathbb{K} \\
\mathrm{GCOMP}(\mathrm{I}) & \mathrm{M} \leq \mathrm{I} \leq \mathbb{K} \\
\mathrm{Y}(\mathrm{I}) & \mathrm{M} \leq \mathrm{I} \leq \mathbb{K} \\
\mathrm{W}(\mathrm{I}) & \mathrm{M} \leq \mathrm{I} \leq \mathrm{K}
\end{aligned}
$$

It is noted that the points of the rod must be numbered beginning with the point of injection of the coolant, liquid or vapor. Thus, for $K E Y=-1$, the point $I=M$ is at the top of the element and for $K E Y=+1$ it is at the bottom. Although simplifying the program, this has the disadvantage that if the flow reverses the calculation must be stopped and the order of the six subscripted variables reversed. This occurred only in the calculations for 
Case 4 of the present study. (This is also the only instance for which it is not possible to transfer automatically from one type of calculation to another.)

HDRGN At time zero this is zero. At some other time, it depends on the previous history of the excursion.

(b) Time-Dependent Functions

BPW This is needed, even though the coolant is steam.

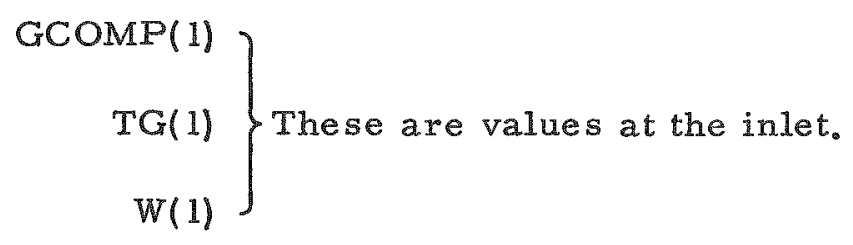

\section{Top Water Injection}

The only additional input needed for this case beyond that for the previous case is the specification of HWA. It is noted however, that $T G(1)$ is not now the true gas temperature but the value given by

$$
T G(1)=B P W-\frac{\Delta H_{1}}{\psi *(B P W, 0)}
$$

and must be recomputed for each boiling-point change. It is also advisable to adjust the initial values of $\mathrm{TG}(\mathrm{I})$ to give a gradual rise in $\mathrm{T} g$ from the boiling point over the first few intervals of the rod. If this is not done, the values of $W_{g}$ are very unstable in the first few time intervals. If they become negative the machine will stop.

(It is also noted that the only difference in the machine programs for $\mathrm{KE} Y=+1$ and $\mathrm{KEY}=-1$ occurs after the element has completely melted at one point. The blowdown calculations, where high water velocities occurred, were considered to fall under this case, even though the flow was upward.)

\section{Bottom Water Injection}

All quantities used in the case of top water injection are also needed for bottom water injection with the exception of the fictitious inlet temperature. $T G(1)$ is now simply set equal to BPW. In addition, the following quantities are now needed.

\section{(a) Initial conditions:}

$$
\begin{aligned}
W L E V I & =2.0 \\
W L E V & =2.0 \\
K E Y & =2
\end{aligned}
$$

\section{CRFLW}


(b) Time-dependent functions

HTVAP

\section{Stagnant Pool}

The same conditions apply here as in the case of bottom water injection, except of course that WLEVI and WLEV are some quantity greater than 2. They would be set equal to 31 if the top is just being uncovered or some quantity $>31$ if the elememt is to be covered for a finite period of time.

In the calculations performed in this study in which the core was uncovered, it was discovered that the water level dropped more slowly than had been reported if the coolant velocity was set equal to zero. Therefore, a negative velocity, [W(1)], was imparted to the coolant in an amount roughly calculated to uncover the core in the proper amount of time. (It is noted that if $W(1)$ is allowed to remain negative after the first point becomes uncovered, the machine will stop, since the program will attempt to compute the logarithm of this negative velocity in an attempt to compute HA.)

As has been mentioned, it is possible to transfer automatically from one program type to another without stopping the machine. In order to do this the exact time of the transformation is read in as TSET as an initial condition of the first part of the program. Then at the proper point in chronological sequence, a TIMEX card is inserted into the data deck of time-dependent functions. This value of TIMEX must be a fraction of a second smaller than the above value of TSET. All of the necessary modifications of the program are then inserted into the data deck immediately following the TIMEX card. These include a new value of TSET corresponding to the time of end of the second phase. At this time a third phase may then be started in the same way. 


\section{The FORTRAN Program}

71. $\operatorname{CON}(1)=3.4320714 \mathrm{E}-2 * \mathrm{RADS} /(\mathrm{AG} * * 0.8 * \mathrm{DG} * * 0.2)$

$0 \quad \operatorname{CON}(2)=\operatorname{CON}(1) * 0.25277 / 1.6123$

$0 \quad \operatorname{CON}(3)=\operatorname{CON}(1) * 0.12494 / 1.6123$

$0 \quad \operatorname{CON}(19)=12.566371 *$ RADS

$0 \quad \operatorname{CON}(4)=\operatorname{CON}(19) * 1.1829 E-4$

$0 \quad \operatorname{CON}(5)=131567.5$

$0 \quad \operatorname{CON}(6)=2.67$

$0 \quad \operatorname{CON}(7)=(2.1474156 \mathrm{E}-3 * \mathrm{AZR}+1.6643421 \mathrm{E}-3 * \mathrm{AUO} 2) / \mathrm{DELZ} * 2$

$0 \operatorname{CON}(8)=(1.5020576 \mathrm{E}-7 * A Z R-1.0211843 E-6 * A U O 2) / D E L Z * * 2$

$0 \quad \operatorname{CON}(9)=2.4980771 E_{-10}-10$ AUO2/DELZ**2

$0 \operatorname{CON}(10)=-2.2958649 \mathrm{E}-14 * \mathrm{AUO} 2 / \mathrm{DELZ} * 2$

$0 \quad \operatorname{CON}(11)=44.58846 * A U O 2+29.054030 * A Z R$

$0 \quad \operatorname{CON}(12)=4.27222 \mathrm{E}-3 * \mathrm{AUO} 2+5.5250999 \mathrm{E}-3 * \mathrm{AZR}$

$0 \quad \operatorname{CON}(13)=3.045242 \mathrm{E} 6 * \mathrm{AUO} 2+1.251495 \mathrm{E} 6 \% \mathrm{AZR}$

$0 \operatorname{CON}(14)=44.58846 * A U O 2+32.2755 * A Z R$

$0 \operatorname{CON}(15)=4.27222 \mathrm{E}-3 * \mathrm{AUOZ}$

$0 \quad \operatorname{CON}(16)=3.045242 \mathrm{E} 6 * \mathrm{AUO} 2$

$0 \operatorname{CON}(17)=4.66 * A G * D E L Z$

$0 \operatorname{CON}(18)=\operatorname{CON}(7)+E L M P *(\operatorname{CON}(8)+E L M P *(\operatorname{CON}(9)+E L M P * \operatorname{CON}(10)))$

0 GOTO1

1 IF(TIME-TIMEX) $73,73,72$

72 READ

- GOTOI

$73 \operatorname{CON}(20)=(\mathrm{BPW}+459.688) * 2 / \mathrm{CON}(17)$

0 DELT $=30.0 / \mathrm{DELTM}$ 
$0 \quad$ IF(TSET-TIME-DELT) $83,82,82$

83 DELT $=$ TSET-TIME

$82 \quad$ DELTM $=0.0$

$0 \quad \mathrm{LAST}=\mathrm{K}$

$0 \quad J \approx M$

$0 \quad \mathrm{R} l=0.0$

$0 \quad \mathrm{~N}=\mathrm{KE} \mathrm{Y}+1$

$3 \operatorname{GOTO}(5,5,2,87), \mathrm{N}$

$87 W L E V T=W L E V+D E L T * W(1) /(D E L Z * A G * R H O W)$

O WLEV $=W L E V T$

$0 \quad D E L T L=0.0$

$0 \quad \mathrm{DYDTS}=0.0$

$0 \quad$ GOTO5

$2 \operatorname{IF}(M-2) 5,5,4$

$4 \quad W(M-1)=W G I$

$0 \quad T G(M-1)=T G I$

$0 \quad \operatorname{GCOMP}(M-1)=\operatorname{GCMPI}$

5 DO $61 \mathrm{I}=\mathrm{J}, \mathrm{LAST}$

$6 \quad \mathrm{TAC}=\mathrm{TA}(\mathrm{I})$

$0 \quad \operatorname{IF}(\mathrm{TAC}-\mathrm{ELMP}) 8,7,7$

7 TATEM $=$ ELMP

$0 \quad T A A=E I M P+459.688$

- GOTO9

$8 \quad \mathrm{TATEM}=\mathrm{TAC}$

$0 \quad T A A=T A C+459.688$

$9 \operatorname{GOTO}(10,23,10,81), N$

81 IF(I-WLEVI) $82,82,10$ 


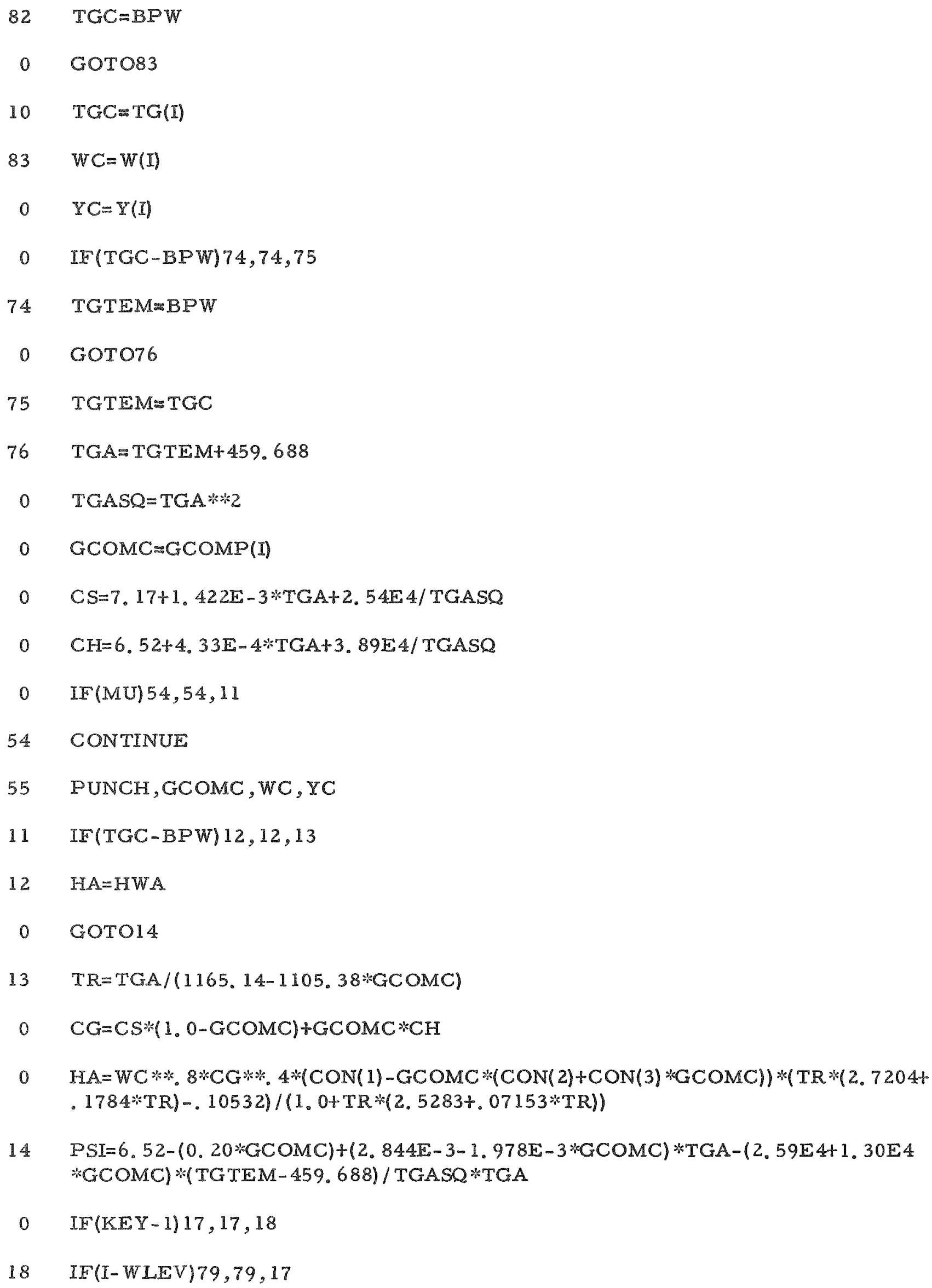


$79 \operatorname{DYDTA}=(\operatorname{CON}(4) / \mathrm{YC}) * \operatorname{EXPF}(-13337.627 / \mathrm{TAA})$

$0 \quad$ DYDTS=DYDTS+DYDTA*DELZ

- GOTO22

$17 \operatorname{IF}(G \operatorname{COMP}(\operatorname{Io} 1)-1.0) 16,15,15$

15 DYDTA 0.0

- GOTO20

$16 \operatorname{DYDTA}=(\operatorname{CON}(4) / \mathrm{YC}) * \operatorname{EXPF}(-13337.627 / \mathrm{TAA})$

- GCC=DYDTA*DELZ/WCHGCOMP(I-1)

$0 \quad \operatorname{IF}(\mathrm{GCC}-1.0) 21,21,19$

$21 \operatorname{GCOMP}(I)=\mathrm{GCC}$

- GOTO22

19 DYDTA $=(1.0-G C O M P(I-1)) * W C / D E L Z$

$20 \operatorname{GCOMP}(I)=1.0$

$22 Y(I)=D E L T * D Y D T A / C O N(19)+Y C$

$0 \quad S 1=H A+D Y D T A * C H$

$0 \quad \mathrm{SZ}=\mathrm{WC} * \mathrm{PSI} / \mathrm{DELZ}$

$0 \quad Q R A=(\operatorname{CON}(5)-\operatorname{CON}(6) * T A T E M) * D Y D T A$

$23 I F(I-L A S T) 25,24,24$

$24 D E L R=(-R \mathbb{1})$

- GOTO30

$25 \operatorname{IF}(\mathrm{TA}(\mathrm{I}+1)-\mathrm{ELMP}) 26,27,27$

$\left.26 R_{2}=\operatorname{CON}(7)+\mathrm{TA}(\mathrm{I}+1) *(\operatorname{CON}(8)+\mathrm{TA}(\mathrm{I}+1) *(\operatorname{CON}(9)+\operatorname{CON}(10) * \mathrm{TA}(\mathrm{I}+1)))\right) *(\mathrm{TA}(\mathrm{I}+1)-\mathrm{TA} T \mathrm{TEM})$

$0 \quad$ GOTO28

$27 R 2=\operatorname{CON}(18) *(E L M P-T A T E M)$

$28 \quad \mathrm{DE} L \mathrm{~L}=\mathrm{R} 2-\mathrm{R} 1$

$29 \quad \mathrm{R} 1=\mathrm{R} 2$

$30 \operatorname{IF}(\mathrm{TAC}-2043.0) 31,31,32$ 
$31 \mathrm{TACPR}=\mathrm{CON}(11)+\mathrm{CON}(12) * \mathrm{TAA}+\mathrm{CON}(13) *(\mathrm{TATEM}-459.688) / \mathrm{TAA} * * 3$

$0 \quad$ GOTO33

$32 \mathrm{TACPR}=\mathrm{CON}(14)+\mathrm{CON}(15) * \mathrm{TAA}+\mathrm{CON}(16) *(\mathrm{TATEM}-459.688) / \mathrm{TAA} * 3$

$33 \operatorname{IF}(\mathrm{KEY}) 35,34,35$

35 DELTA $=(D E L R-H A *(T A T E M-T G T E M)+D Y D T A *(T G T E M * C S-C H * T A T E M)+$ $Q D T \% Q D(I)+Q R A / / T A C P R$

0 GOTO36

34. DELTA=IDELR+QDT $* Q D(I) / T A C P R$

$36 \operatorname{IF}(\mathrm{I}-\mathrm{J}) 38,38,37$

37 IF(LAST T I) $38,38,39$

38 DELTA=DELTA+DELTA

$39 \quad A B V D T=A B S F(D E L T A)$

$0 \quad$ IF (DELTM-ABVDT) $40,41,41$

40 DELTM $=A B V D T$

$41 \mathrm{TA}(\mathrm{I})=\mathrm{TAC}+\mathrm{DELTA} * \mathrm{DELT}$

$0 \quad \operatorname{GOTO}(42,50,42,80), \mathrm{N}$

80 IF (I-WLEV $) 84,84,46$

84 DELTL=(TATEM-BPW)*HWA*DELZ/HTVAP+DELTL

$0 \quad \mathrm{TG}(\mathrm{I})=\mathrm{BPW}$

$0 \quad W(\mathrm{I})=\mathrm{DELTL}$

$0 \quad$ IF(DELTL-CRFLW) $85,85,86$

$86 W L E V=I$

- GOTO87

85 WLEV V WLEVT-DELTL*DELT/(DELZ*AG*RHOW)

$87 \operatorname{GCOMP}(\mathrm{I})=\mathrm{DYDTS} / \mathrm{W}(\mathrm{I})$

$0 \quad \operatorname{IF}(\mathrm{I}+1-\mathrm{WLEV}) 50,88,88$

88 WLEVI=WLEV

- GOTO50 


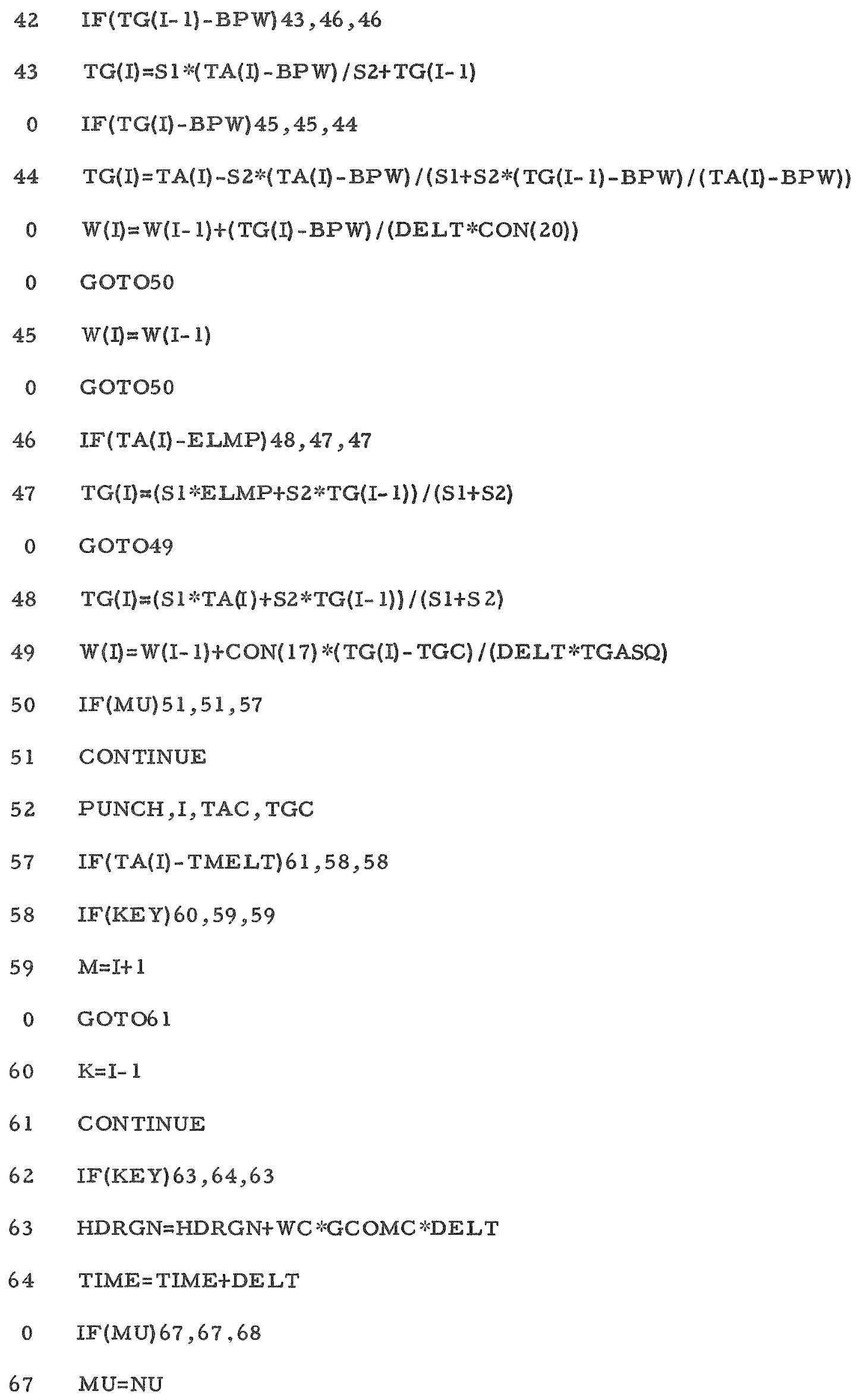




$\begin{array}{cl}0 & \text { GOTO70 } \\ 68 & \text { MU }=\text { MU-1 } \\ 70 & \text { IF(MU) } 65,65,1 \\ 65 & \text { CONTINUE } \\ 66 & \text { PUNCH, TIME, HDRGN } \\ 69 & \text { GOTO1 } \\ 70 & \text { STOP }\end{array}$




\section{APPENDIX D}

RADIATION HEAT TRANSFER EFFECTS 


\section{APPENDIX D}

\section{RADIATION HEAT TRANSFER EFFECTS}

When a double 14-in. break occurs at the top of the reactor (Case I), the watersteam mixture vents from the reactor for a period of $30 \mathrm{sec}$. At this time, all the water has escaped from the reactor and essentially stagnant steam left in the reactor blankets the process tubes. The maximum temperatures of the 12 -rod ring and 6-rod ring elements are approximately $500 \mathrm{~F}$, and the Zircaloy-2 wall and aluminum wall enclosing the 12 and 6 rods are at $220 \mathrm{~F}$. After a $25-\mathrm{sec}$ initial period in Case $\mathrm{I}$, the 12- and 6-rod ring elements are assumed to be completely adiabatic. The temperature rise of these elements was calculated assuming only heat generation because of gamma decay and no heat loss to the stagnant steam layer, which has a negligible heat content. The Zircaloy-2 and aluminum walls remained constant in temperature. The calculations in Case I were done assuming no heat transfer between the $12-r o d$ ring, 6-rod ring, Zircaloy -2 wall, and aluminum wall. Since the gamma decay heat is largest in the 12 -rod ring, the se rods increased in temperature faster thandid those of the 6-rod ring.

However, radiant heat transfer is appreciable at these high temperatures, particularly above $1000 \mathrm{~F}$. Radiation between the se rods and walls will have a moderating effect in reducing the temperatures of the 12- and 6-rod rings and increasing appreciably the temperatures of the Zircaloy- 2 wall and aluminum wall.

There are various paths for these elements to interchange heat by radiation. A graphical representation of axial radiation between rods is shown in Figure D-1. The center (axially) of the 12 -rod ring, which is the hottest portion, can radiate heat axially to parts of the 6-rod ring and axially to other 12-rod rings which are lower in temperature. However, because of the small area that can be "seen" by the center of the 12rod ring, this axial radiation was found to be negligible (less than 2 per cent) when compared with direct-view center-to-center radiation between the 12 -rod ring and a 6 -rod ring. Hence, axial radiation was neglected in the radiation calculations.

The direct view or center-to-center radiation was important and is shown schematically in Figure D-2. Since the 6-rod ring can "see" only the 12-rod ring, it interchanges heat by radiation only with the 12 -rod ring. The 12 -rod ring radiates heat to both the 6-rod ring and the Zircaloy-2 wall. The Zircaloy-2 wall receives heat from the 12-rod ring and radiates heat to the aluminum wall. Hence, only center-tocenter radiation was calculated between the center (hottest spot) of the 12-rod ring to the center of the 6-rod ring, center of the 12-rod ring to the part of the Zircaloy- 2 wall directly opposite, and this same spot in the Zircaloy-2 wall to the aluminum wall. The method of computation for the radiation heat transfer effects and the results are discussed below. 
$\mathrm{D}-2$

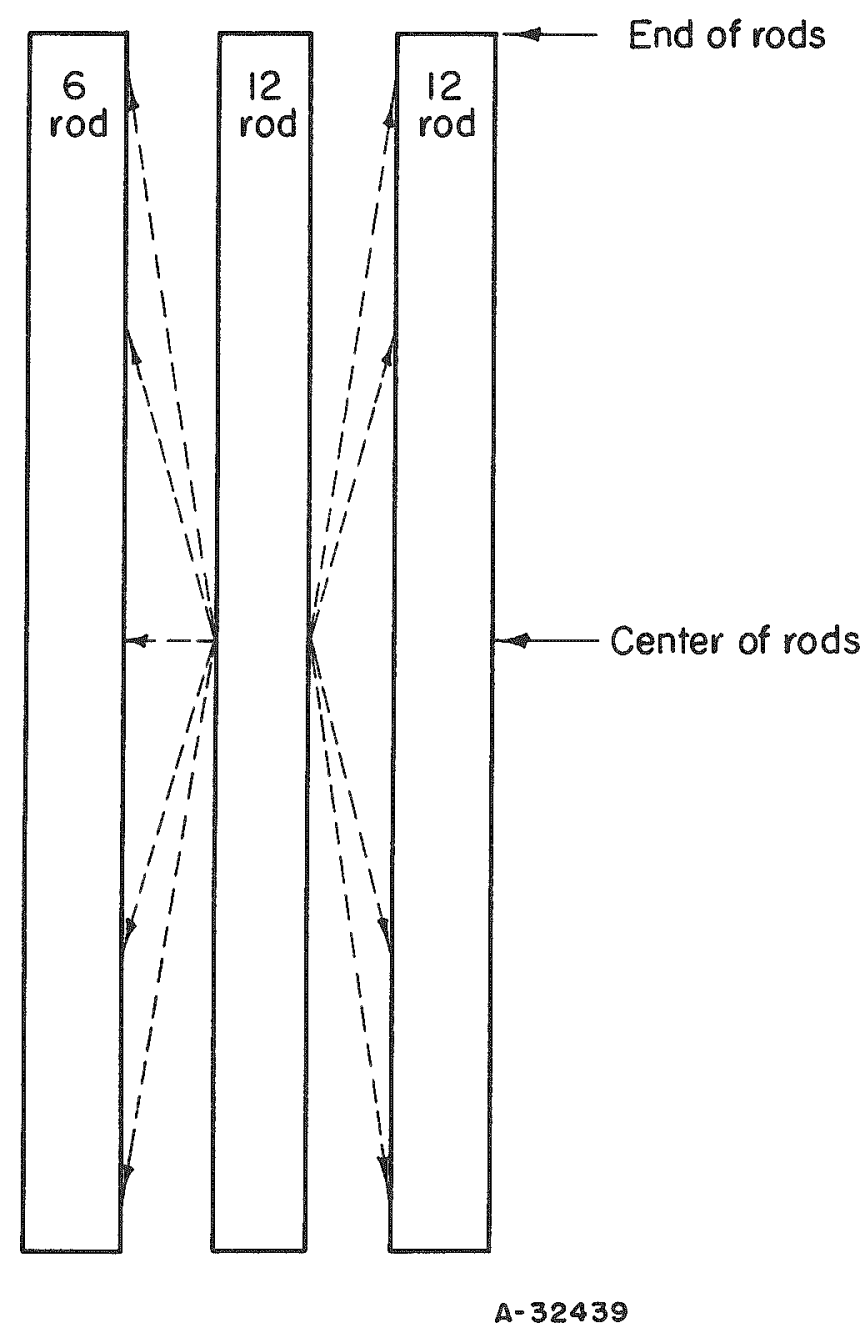

FIGURE D-1. AXIAL RADIATION OF RODS 


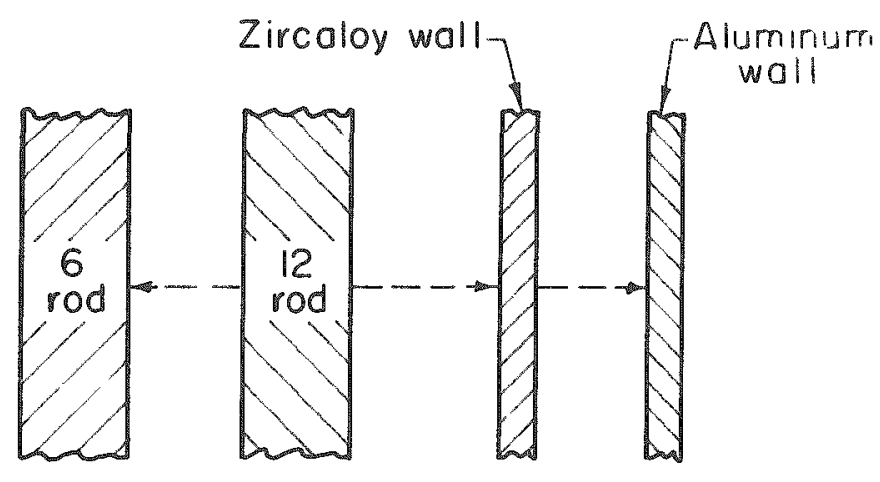

A-32440

FIGURE D-2. DIRECT VIEW (CENTER-CENTER) RADIATION OF RODS AND WALLS

\section{Approximations and Assumptions}

In order to calculate the effect of radiation, various assumptions and approximations were employed.

(1) The effect of absorption of some of the radiant heat by the gaseous steam between the radiating surfaces was calculated and found to be negligible.

(2) Natural convection between the aluminum and Zircaloy-2 walls was found to be negligible because of the narrow enclosed space in this helium gap. Natural convection between the 6- and 12-rod rings and the Zircaloy -2 was also neglected.

(3) Conduction in the helium gas between the Zircaloy-2 and aluminum was neglected in this section but is included in a later section.

(4) The effect of axial heat conduction in the solid elements, 12-rod ring, 6 -rod ring, Zircaloy -2 wall, or aluminum wall was found to be negligible compared with the direct-view radiation (less than 3 per cent).

\section{Calculation Methods}

The basic equation for radiant heat transfer between two surfaces is

$$
q_{1 \rightarrow 2}=F_{12} A_{1}(0.173)\left[\left(\frac{T_{1}}{100}\right)^{4}-\left(\frac{T_{2}}{100}\right)^{4}\right],
$$


where

$$
\begin{aligned}
\mathrm{q}_{1 \rightarrow 2} & =\text { heat transferred from surface } 1 \text { to } 2, \mathrm{Btu} \text { per } \mathrm{hr} \\
\mathrm{F}_{12} & =\text { view factor between } 1 \text { and } 2 \text { (includes emissivities of } 1 \text { and } 2 \text { ) } \\
\mathrm{A}_{1} & =\text { area of } 1, \mathrm{ft}^{2} \\
\mathrm{~T}_{1} & =\text { temperature of } 1, \mathrm{R} \\
\mathrm{T}_{2} & =\text { temperature of } 2, \mathrm{R}
\end{aligned}
$$

The view factors for the surfaces were calculated to be as follows:

$$
\begin{array}{ll}
\multicolumn{1}{c}{\text { Heat Transferred }} & \text { View Factor } \\
\mathrm{q}_{12 \rightarrow 6}(12-\text { to } 6-\text { rod ring) } & \mathcal{F}_{12 \rightarrow 6}=0.145 \\
q_{\mathrm{Zr} \rightarrow 12} \text { (Zircaloy-2 wall to 12-rod ring) } & \mathcal{F}_{\mathrm{Zr} \rightarrow 12}=0.218 \\
\mathrm{q}_{\mathrm{Al} \rightarrow \mathrm{Zr}} \text { (Aluminum wall to Zircaloy-2 wall) } & \mathcal{F}_{\mathrm{Al} \rightarrow \mathrm{Zr}}=0.075
\end{array}
$$

Starting with $30 \mathrm{sec}$ after the break, time increments of about 50 sec were used, and a complete heat balance was made on the four elements which included the adiabatic rise and the radiation effects. The trial-and-error calculations were done by hand. The general heat balance for an element is as follows for a given time increment.

$$
\text { Accumulation = heat in - heat out . }
$$

These general equations for the four elements are as follows:

$$
\begin{gathered}
q_{12 \text { accum. }}=q_{12 \text { decay }}-q_{12 \rightarrow 6}-q_{12 \rightarrow Z_{r}} \\
q_{6 \text { accum. }}=q_{6 \text { decay }}+q_{12 \rightarrow 6} \\
q_{Z r \text { accum. }}=q_{12 \rightarrow Z_{r}}-q_{Z r \rightarrow A 1}-q_{Z r \rightarrow A 1} \text { (gas conduc.) } \\
q_{A 1 \text { accum. }}=q_{Z r \rightarrow A 1}+q_{Z r \rightarrow A 1} \text { (gas conduc.), }
\end{gathered}
$$

where

$$
\begin{aligned}
& \mathrm{q}_{12} \text { accum. }=\text { heat accumulating in the } 12 \text {-rod } x \text { ing in the time increment } \\
& \mathrm{q}_{12 \text { decay }}=\text { decay heat in the } 12 \text {-rod ring } \\
& q_{12 \rightarrow 6}=\text { heat lost by radiation from the } 12 \text {-rod ring to the } 6 \text {-rod ring } \\
& \mathrm{q}_{\mathrm{Z} \rightarrow \mathrm{Al}} \text { (gas conduc.) }=\text { heat transferred from the Zircaloy }-2 \text { wall to the }
\end{aligned}
$$




\section{Discussion and Results}

The calculated results for adiabatic plus radiation are plotted in Figure D-3 and compared with the results for just adiabatic rise. As shown in Figure D-3, the aluminum wall reaches a melting temperature of $1220 \mathrm{~F}$ in $710 \mathrm{sec}$. The aluminum wall does not start to increase appreciably in temperature until after about $400 \mathrm{sec}$, when the Zircaloy -2 wall has risen to about $1050 \mathrm{~F}$.

From 30 to about $250 \mathrm{sec}$ the $12 \mathrm{-rod} \mathrm{ring}$ is at a higher temperature than the 6 rod ring and loses heat to both the 6-rod ring and the Zircaloy-2 wall. After 250 sec the 12-rod ring drops below the 6-rod ring because of its large radiation loss to the Zircaloy - 2 wall.

The effect of the net heat loss of the 12-rod ring and the 6-rod ring to the Zircaloy2 and aluminum walls is to reduce their temperatures considerably below the adiabatic temperatures. At $710 \mathrm{sec}$ the 12 -rod ring has dropped about $750 \mathrm{~F}$ below adiabatic and the 6-rod ring about $240 \mathrm{~F}$.

\section{Effect of Conduction in Helium Gas Phase}

If the heat transfer from the Zircaloy -2 wall to the aluminum wall by conduction in the helium gaseous phase is included in Equations (D-5) and (D-6), an appreciable effect is found. The distance, $x$, between the two walls is only $0.025 \mathrm{ft}$. The $\mathrm{k} / \mathrm{x}$ values or $h$ values for the helium gap range from 4 to $7 \mathrm{Btu} /(\mathrm{hr})(\mathrm{F})\left(\mathrm{ft} \mathrm{t}^{2}\right)$. The heat transferred by conduction can be calculated by

$$
\mathrm{q}_{\mathrm{Z} \rightarrow \mathrm{Al}} \text { (gas conduc.) }=\frac{k}{\mathrm{x}} \mathrm{A}_{\mathrm{Al}}\left(\mathrm{T}_{\mathrm{Z}_{\mathrm{r}}}-\mathrm{T}_{\mathrm{Al}}\right)
$$

Approximate calculations using Equation (D-7) in Equations $(D-3),(D-4),(D-5)$, and $(D-6)$ show a large effect of conduction in the helium phase on the temperature of the aluminum wall. The aluminum wall rises more quickly in temperature than in Figure $D-3$ and follows closely behind the Zircaloy -2 wall; the aluminum would melt at a time of between 450 to 500 sec. The temperature of the 12 -and 6-rod rings will be slightly lower than the adiabatic plus radiation values shown in Figure D-3. 


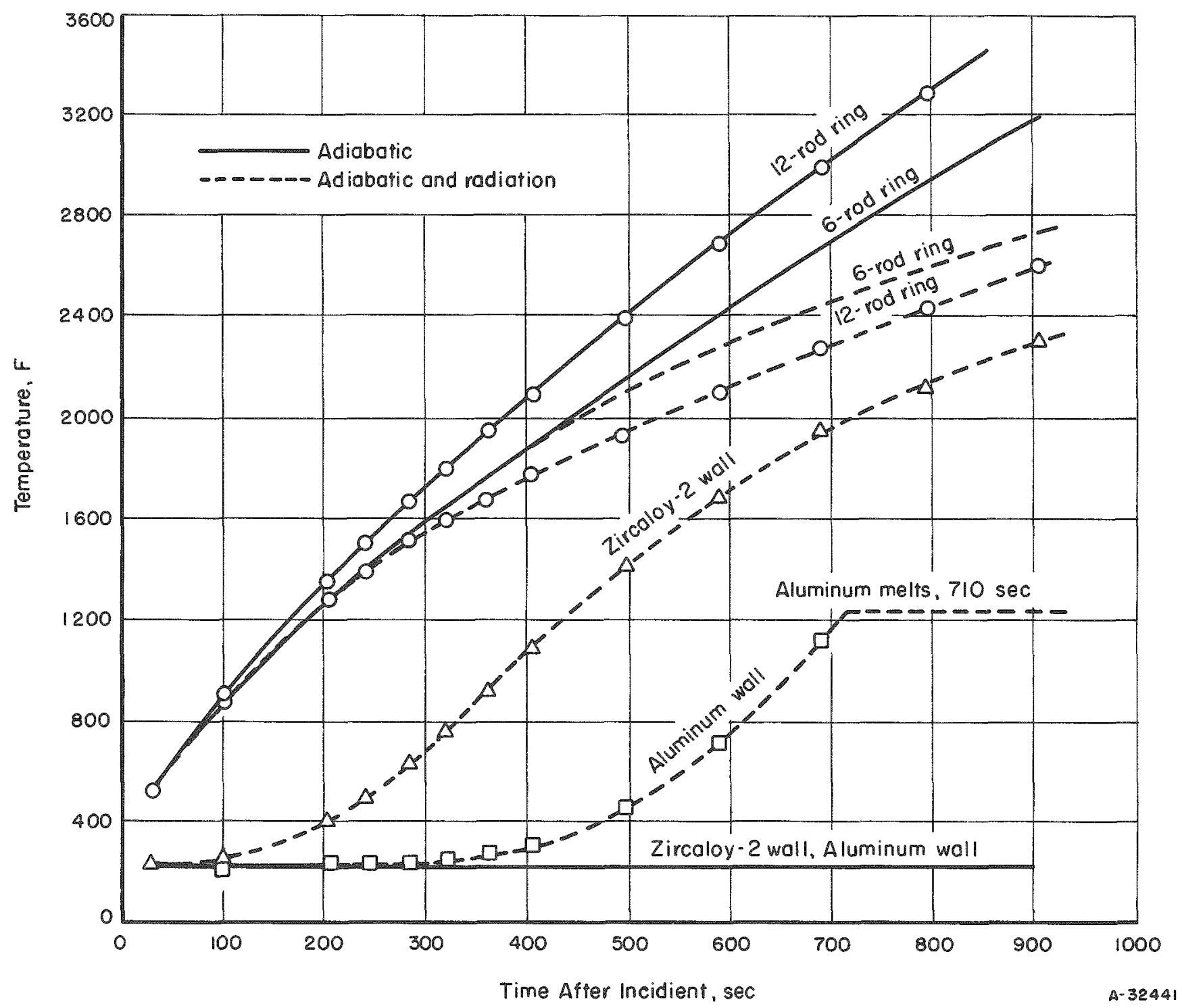

FIGURE D-3. EFFECT OF RADIATION ON PEAK TEMPERATURES OF ADIABATIC PERIOD 